\title{
GASTRIC RESIDUAL VOLUMES IN THE ADULT INTENSIVE CARE PATIENT: A SYSTEMATIC REVIEW
}

\author{
by \\ Rebecca Jane Jarden
}

\begin{abstract}
A thesis submitted to the Victoria University of Wellington in partial fulfilment of the requirements for the degree of Master of Nursing (Clinical)
\end{abstract}

Victoria University of Wellington 2009 


\begin{abstract}
Background: Enteral nutrition is one method of delivering nutrition to intubated patients. There are several issues that prevent optimal delivery of the prescribed enteral nutrition goal rates. The measurement of the patient's gastric residual volume (GRV) may demonstrate tolerability, or intolerability, of enteral nutrition. Identifying a safe GRV, at which to accept and continue enteral nutrition delivery, is essential to ensure the delivery of enteral nutrition adequately achieves the nutritional requirements of patients, and to mitigate the risks associated with the delivery of enteral nutrition.
\end{abstract}

Objectives: This systematic review sought to answer the research question: what is the maximum GRV to accept in order to continue the delivery of enteral nutrition in the Intensive Care Unit (ICU) adult patient? This is specifically related to the primary outcome measures indicative of accepting a specified GRV that is too high or too low. Accepting a GRV that is too high would put the patient at risk of vomiting, regurgitation, aspiration of gastric contents and potentially aspiration pneumonia. Conversely, accepting a GRV that is too low would put the patient at risk of not achieving caloric needs, potentially placing the patient at risk of malnutrition and increased morbidity.

Search methods: Databases searched included: CCTR, CLCMR, CLTA, CLEED, OVID MEDLINE (R) (Ovid SP), EMBASE, CINAHL Plus with Full Text (EBSCO host via helicon), AMED, Ovid Nursing Full Text plus, CDSR, ACP Journal Club, DARE, Proquest via helicon (advanced search), Pubmed via helicon (limits "all adult", "humans", "abstract", "title”), all EBM reviews, and the reference lists of articles.

Selection criteria: The types of studies eligible for inclusion were published randomised controlled trials, case controlled studies, cohort studies and observational studies. Interventions considered were a comparison of two or more GRV measures. The participants eligible were adult ICU or critical care patients receiving enteral nutrition. The primary outcome measures for study 
inclusion were caloric requirement met, and specified potential adverse events including vomiting, regurgitation, or aspiration.

Data collection and analysis: Data was extracted using a data extraction tool created by the researcher. Risk of bias was assessed by the author using two risk of bias assessment tools.

Main results: Three studies met the inclusion criteria for the systematic review (McClave et al., 2005; Metheny, Schallom, Oliver, \& Clouse, 2008; Pinilla, Samphire, Arnold, Liu, \& Thiessen, 2001). Each of these studies contained methodological risks of bias and limitations related to their study designs. McClave et al.'s study was a prospective study $(n=40)$, Metheny et al.'s study was a prospective descriptive study $(\mathrm{n}=206)$, and Pinilla et al.'s study was a randomised controlled trial $(n=80)$. No one study, or a combination of studies, provided conclusive evidence to support the use of one particular GRV over another.

Author's conclusion: No recommendation for a definitive GRV was made in this systematic review due to the lack of strong evidentiary support for one GRV over another. There remain opportunities for enhancing practice through developing a consistent, multidisciplinary approach to managing GRVs. There are future research opportunities related to improving the management of GRVs in the enterally fed ICU patient, and achieving optimal volumes of nutrition delivered.

Key words: nursing practice, enteral nutrition, gastric residual volumes, intensive care, systematic review. 


\section{ACKNOWLEDGEMENTS}

I would like to take this opportunity to both acknowledge and thank several people who have contributed to the success of this research project. Firstly, I would like to thank my friends, family, and colleagues, who have provided encouragement and advice throughout this project. In particular, thank you to my husband Aaron, your words of wisdom and humour kept me motivated and sane. Also, thank you to my friend and colleague Anne, with whom I commenced this quest for knowledge.

I am grateful to the Graduate School of Nursing, Midwifery and Health, Victoria University of Wellington for providing me with several years of excellent learning networks, tutors and, more recently, my supervisor, Sara Quirke who has been a wealth of knowledge, clarity, and a role model - thank you. Capital and Coast District Health Board and CTA funding has been instrumental from the point of conception of this project, through to its completion. I am now charged with using the results of this systematic review to continue this journey and to make a difference to patient health care. 


\section{TABLE OF CONTENTS}

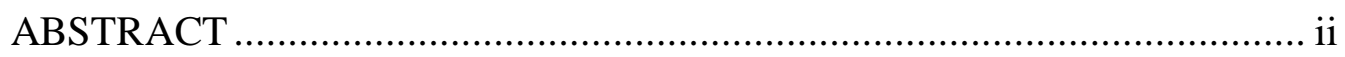

ACKNOWLEDGEMENTS ................................................................ iv

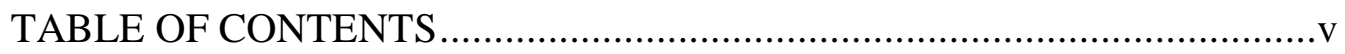

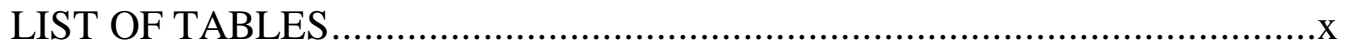

LIST OF FIGURES ..................................................................

LIST OF ABBREVIATIONS .......................................................... xii

GLOSSARY OF TERMS .................................................................. xiii

CHAPTER $1 \quad$ INTRODUCTION ..................................................... 17

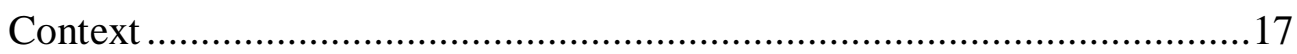

Involving the local stakeholders ....................................................... 18

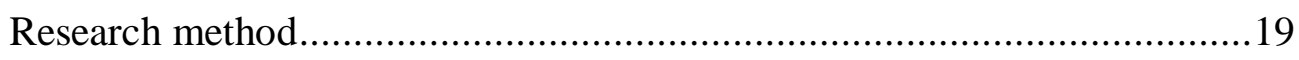

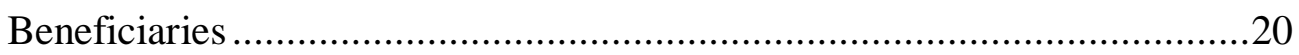

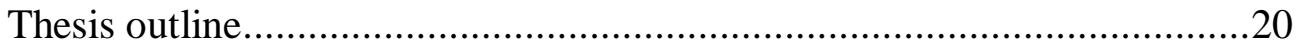

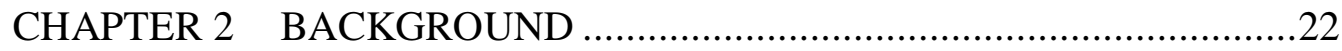

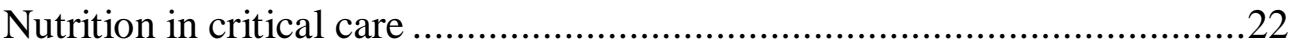

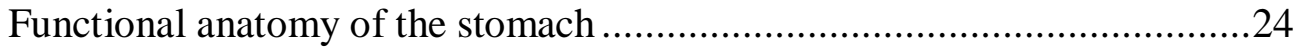

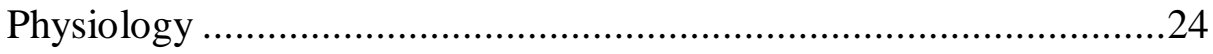

Gastric volumes and gastric emptying ........................................24

The role of enteral nutrition in the stomach .............................................25

Enteral nutrition and maintaining structure and function...................25

Enteral nutrition and defence....................................................26

The impact of critical illness on the gastrointestinal system....................27

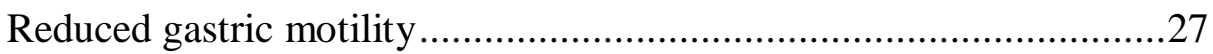

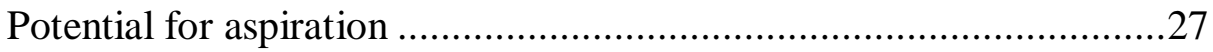

Improving the delivery of enteral nutrition .........................................28

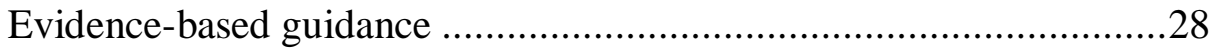


Mitigating risk through the use of an algorithm .....

Use of GRVs as a measure of patient tolerance of enteral nutrition

Assumptions

Inconsistencies in the management of GRVs ...................................32

Debate in the management of GRVs.............................................33

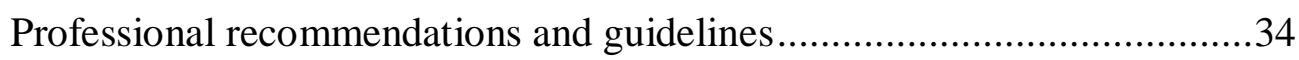

Review and critique of guidelines and recommendations.........................36

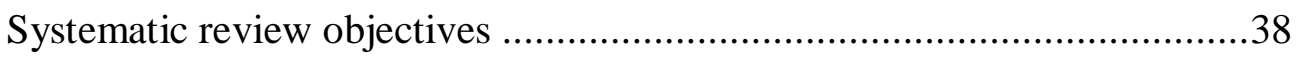

CHAPTER 3 METHODOLOGY ........................................................40

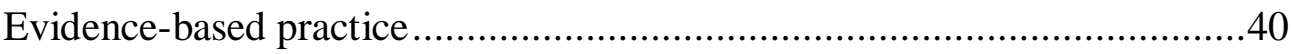

Systematic reviews and meta-analyses .................................................41

The systematic review process ............................................................44

Refining the research question..................................................44

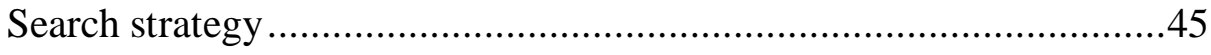

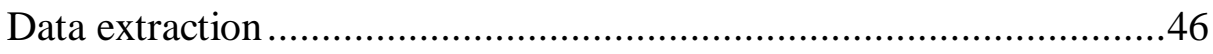

Risk of bias and quality assessment of included studies ...................46

Critical appraisal and levels of evidence .........................................48

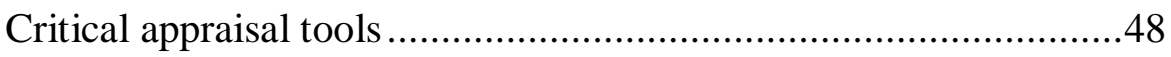

Assigning levels of evidence ..................................................49

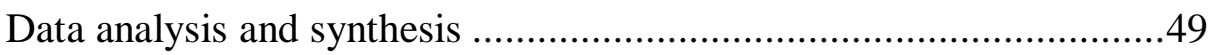

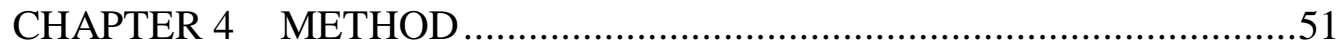

Criteria for considering studies for this review .....................................51

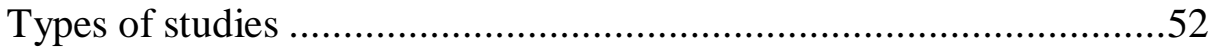

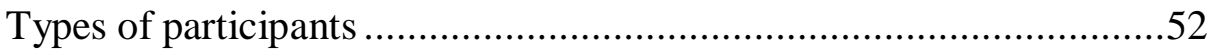

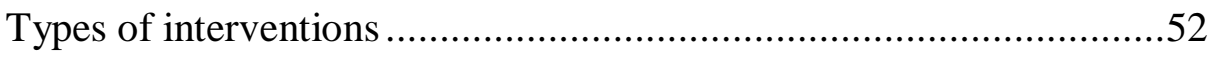

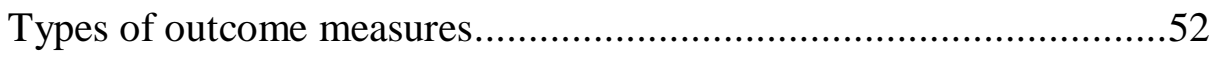

Search methods for identification of studies ........................................52 
Searching other resources

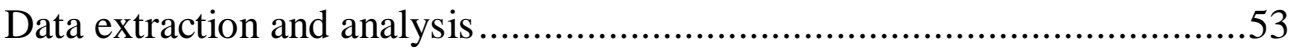

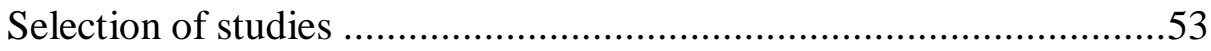

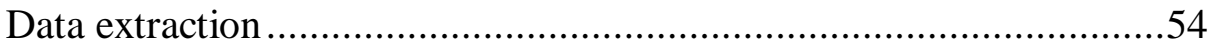

Assessment of methodological quality of included studies .................54

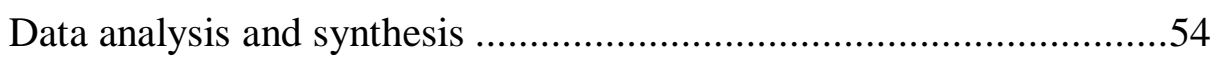

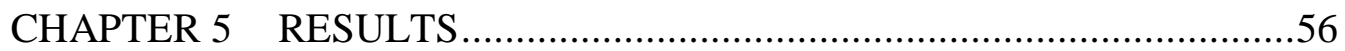

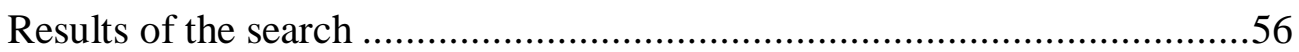

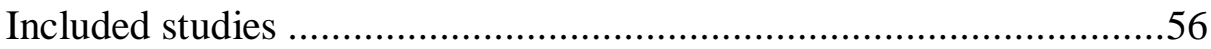

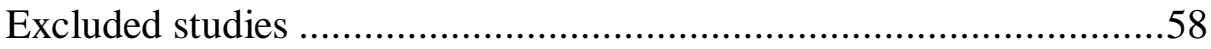

Description of included studies ..........................................................60

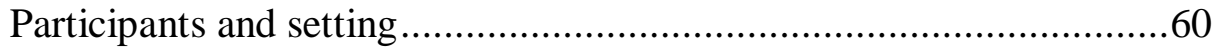

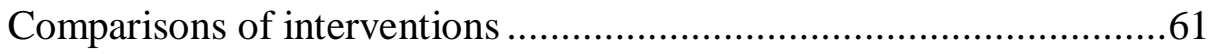

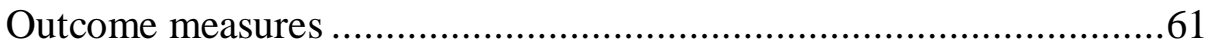

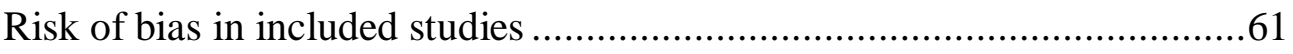

Analysis of the prospective study and the randomised controlled trial.62

Analysis of the prospective observational study.............................62

Effects of comparisons of interventions.............................................63

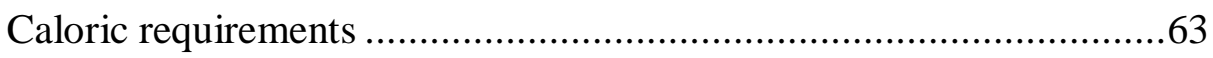

Percentage of goal calories infused .............................................63

Percentage of nutritional requirements received..........................64

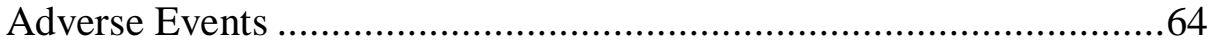

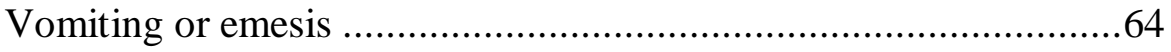

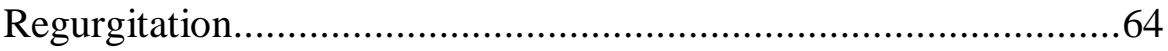

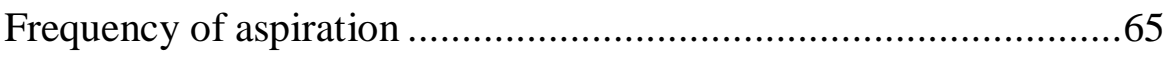

Total intolerance episodes ..................................................66

Meta-analysis feasibility for comparisons ..........................................66 


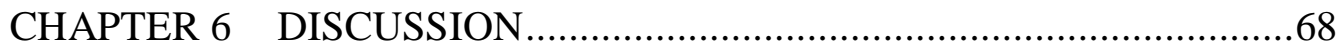

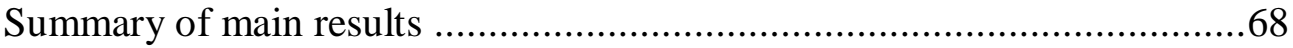

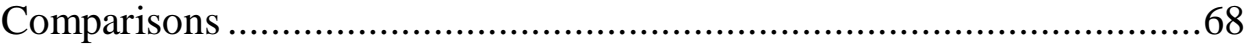

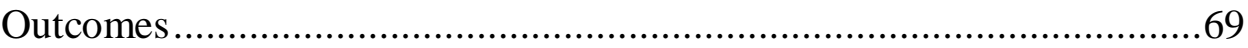

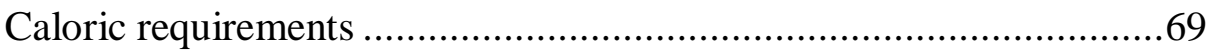

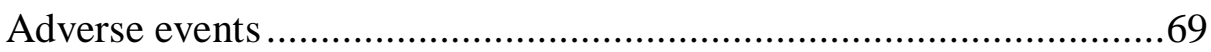

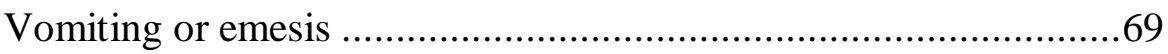

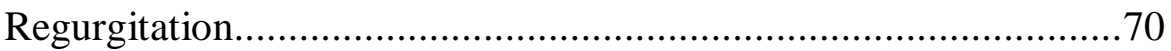

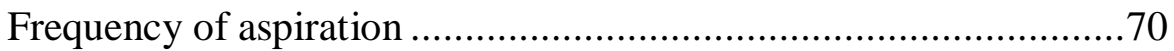

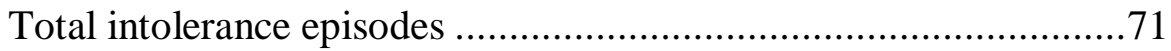

Overall completeness and applicability of evidence.................................71

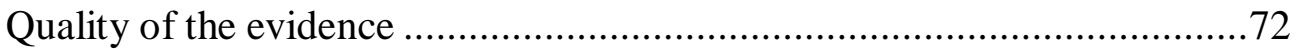

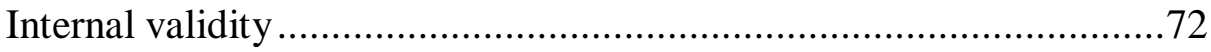

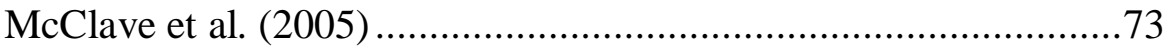

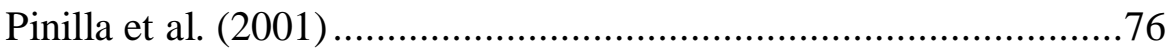

Metheny et al. (2008) ............................................................. 77

Contributions from excluded studies......................................... 78

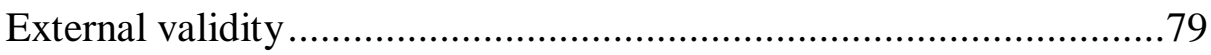

Comparisons with other literature ........................................................ 79

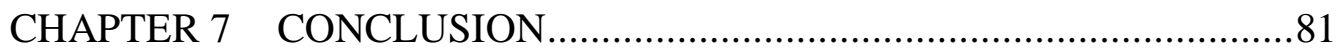

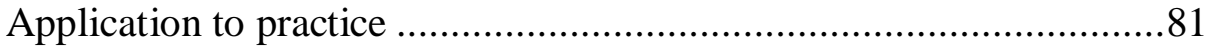

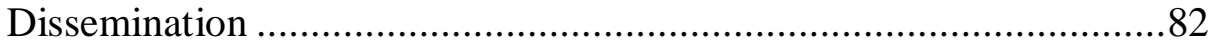

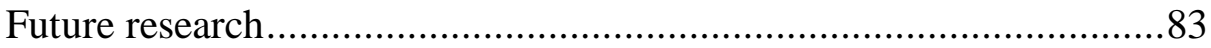

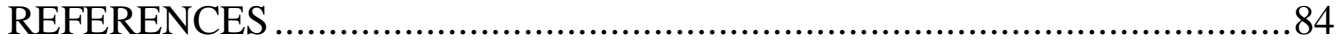

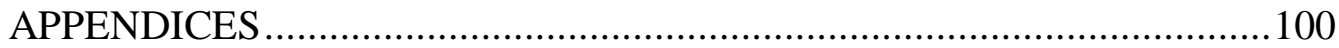

Appendix 1. Systematic review protocol.................................. 100

Appendix 2. Risk of bias assessment tool* .................................114 
Appendix 3. Risk of bias assessment tool for a descriptive observational study* 115

Appendix 4. Cochrane's levels of quality of a body of evidence in the GRADE approach* 116

Appendix 5. Data extraction form.... 117

Appendix 6. Search sources, terms and numbers retrieved 118

Appendix 7. Detailed characteristics of excluded studies 120

Appendix 8. Risk of bias analysis for randomised controlled trials* 135

Appendix 9. Risk of bias analysis for descriptive observational study* 136 


\section{LIST OF TABLES}

Table 1. Reviews, professional guidelines, and recommendations for GRV

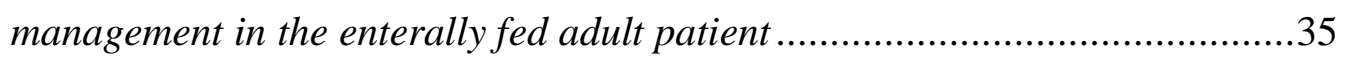

Table 2. Characteristics of included studies .............................................58

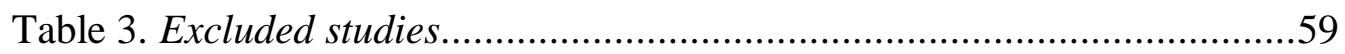

Table 4. Caloric requirements met .......................................................63 


\section{LIST OF FIGURES}

Figure 1. Prisma flow diagram (adapted from Moher et al., 2009) ...............57 


\section{LIST OF ABBREVIATIONS}

\begin{tabular}{|l|l|}
\hline Abbreviation & In full \\
\hline APACHE & $\begin{array}{l}\text { Acute physiology and chronic health evaluation } \\
\text { evaluation }\end{array}$ \\
\hline GRADE & Gastric residual volume \\
\hline GRV & Intensive care unit \\
\hline ICU & Injury severity score \\
\hline ISS & Nasogastric tube \\
\hline NGT & Multiple organ dysfunction syndrome \\
\hline MODS & Percutaneous endoscopic gastrostomy \\
\hline PEG & Simplified acute physiology score \\
\hline SAPS & $\begin{array}{l}\text { Strengthening the reporting of observational studies in } \\
\text { epidemiology }\end{array}$ \\
\hline STROBE & Trauma injury severity score \\
\hline TISS &
\end{tabular}




\section{GLOSSARY OF TERMS}

\begin{tabular}{|c|c|}
\hline Term & Definition \\
\hline Algorithm & $\begin{array}{l}\text { Provides a summary of guideline recommendations } \\
\text { in the form of a flow chart, with linked process steps } \\
\text { and decision points (New Zealand Guidelines Group, } \\
2001 \text { ). }\end{array}$ \\
\hline Enteral nutrition & $\begin{array}{l}\text { The delivery of nutritional support directly into the } \\
\text { gut via a tube (National Institute for Health \& } \\
\text { Clinical Excellence, 2006). Enteral nutrition is a } \\
\text { form of nutrients that can be administered via a tube } \\
\text { directly to the stomach. This tube may extend from } \\
\text { the nose or the mouth, and pass directly to the } \\
\text { stomach (naso-gastric or oro-gastric); or may pass } \\
\text { beyond the stomach (postpyloric) to the jejunum or } \\
\text { duodenum (naso-jejunal or naso-duodenal); or may } \\
\text { be percutaneously placed, using an endoscope, } \\
\text { directly through the abdominal wall to the stomach } \\
\text { or jejunum (percutaneous endoscopic gastrostomy or } \\
\text { percutaneous endoscopic jejunostomy) (Urden, } \\
\text { Stacy, \& Lough, 2006). }\end{array}$ \\
\hline Forest plot & $\begin{array}{l}\text { A geographical plot of each of the studies combined } \\
\text { in a meta-analysis, usually depicted as a square for } \\
\text { each study result, with the confidence interval } \\
\text { illustrated by a line passing through the square. The } \\
\text { combined results of all studies are plotted graphically } \\
\text { at the bottom of the plot by a diamond with the } \\
\text { horizontal corners of the diamond illustrating the } \\
\text { confidence interval. A diamond clear of the line of } \\
\text { no effect shows significance (Lewis \& Clarke, 2001). }\end{array}$ \\
\hline Funnel plot & $\begin{array}{l}\text { A graphical plot of effect estimates against sample } \\
\text { size to assess validity of meta-analyses. Based on the }\end{array}$ \\
\hline
\end{tabular}




\begin{tabular}{|c|c|}
\hline Term & Definition \\
\hline & $\begin{array}{l}\text { assumption that accuracy is directly related to sample } \\
\text { size. Skewed or asymmetrical funnel plots suggest } \\
\text { bias, and symmetry suggests absence of bias (Egger, } \\
\text { Smith, Schneider, \& Minder, 1997). }\end{array}$ \\
\hline $\begin{array}{l}\text { Gastric residual } \\
\text { volume or gastric } \\
\text { aspirate volume }\end{array}$ & $\begin{array}{l}\text { A volume obtained by aspirating (withdrawing) the } \\
\text { stomach contents via the gastric tube. During } \\
\text { intragastric feeding, the gastric volume includes the } \\
\text { amount of nutrition delivered and the endogenous } \\
\text { secretions (Metheny, Schallom, \& Edwards, 2004). }\end{array}$ \\
\hline Malnutrition & $\begin{array}{l}\text { Malnutrition is a pathological state caused by relative } \\
\text { or absolute deficiency of one or more essential } \\
\text { nutrients (Atkinson \& Worthley, 2003). Malnutrition } \\
\text { in the critically ill has been defined as a disorder of } \\
\text { body composition whereby nutrient deficiencies } \\
\text { occur when required nutrition is not met causing } \\
\text { reduced organ function, altered blood chemistry } \\
\text { studies, reduced body mass and sub-optimal clinical } \\
\text { outcomes (Cerra et al., 1997). This may be measured } \\
\text { through history taking, physical examination and } \\
\text { nutritional assessment indices (Atkinson \& } \\
\text { Worthley, 2003). The most common cause of } \\
\text { malnutrition is inadequate nutritional intake as a } \\
\text { result of reduced intake, increased requirements or } \\
\text { impaired ability to absorb or use the nutrients } \\
\text { (Stratton, 2007). }\end{array}$ \\
\hline Nutrition & $\begin{array}{l}\text { Nutrition provides the carbohydrate, lipid, amino } \\
\text { acids, water, vitamins and minerals required for } \\
\text { growth, development and the maintenance of } \\
\text { physiological and bodily functions in the human } \\
\text { body. Nutrition may be provided by diet, which } \\
\text { requires active participation to meet their nutritional } \\
\text { needs, or by nutrition support, which is delivered }\end{array}$ \\
\hline
\end{tabular}




\begin{tabular}{|c|c|}
\hline \multirow[t]{2}{*}{ Term } & Definition \\
\hline & $\begin{array}{l}\text { nutrition that bypasses the patient's active } \\
\text { participatory responses (Case, Cuddy, \& Dooling- } \\
\text { McGurk, 2000). In normal nutrition there is an } \\
\text { alternate state of feeding and fasting (Atkinson \& } \\
\text { Worthley, 2003). Feeding increases glycogen } \\
\text { reserves and protein synthesis; fasting reduces } \\
\text { insulin secretion and increases glucagon secretion. } \\
\text { After hepatic glycogen is depleted, body protein is } \\
\text { used to meet glucose demands. Fasting for longer } \\
\text { than 72hrs induces a state of starvation (Atkinson \& } \\
\text { Worthley, 2003). }\end{array}$ \\
\hline Optimal nutrition & $\begin{array}{l}\text { Sufficient intake of nutrients to support the metabolic } \\
\text { requirements of the body (Jarvis, 2003). }\end{array}$ \\
\hline Overnutrition & $\begin{array}{l}\text { Excessive intake of nutrients, surplus to the } \\
\text { requirements of the body (Jarvis, 2003). The impact } \\
\text { of overfeeding total calories may cause exacerbation } \\
\text { of hyperglycemia, fatty liver, increased } \mathrm{CO}_{2} \\
\text { production, and an increased amount of energy } \\
\text { expenditure to manage excessive caloric loading } \\
\text { (Parrish \& McCray, 1999). }\end{array}$ \\
\hline Parenteral nutrition & $\begin{array}{l}\text { The delivery of nutrition support intravenously } \\
\text { (Leonard, 2009). }\end{array}$ \\
\hline Pulmonary aspiration & $\begin{array}{l}\text { Pulmonary aspiration is the passage of foreign } \\
\text { material into, and distal to, the trachea. One example } \\
\text { of a foreign material may be regurgitated gastric } \\
\text { contents. The gastric acid in these gastric contents } \\
\text { damages the alveolar and capillary endothelial cells, } \\
\text { consequentially protein rich fluid leaks into the } \\
\text { interstitum and alveoli causing atelectasis and } \\
\text { consolidation (Urden et al., 2006). }\end{array}$ \\
\hline Refeeding syndrome & $\begin{array}{l}\text { Commencing a normal volume of nutrition following } \\
\text { a period of starvation may result in refeeding }\end{array}$ \\
\hline
\end{tabular}




\begin{tabular}{|l|l|}
\hline Term & Definition \\
\hline & $\begin{array}{l}\text { syndrome. This is associated with serum electrolyte } \\
\text { disturbances including hypophosphataemia, } \\
\text { hypokalaemia and hypomagnesaemia. Rebound } \\
\text { effects may manifest as cardiac and respiratory } \\
\text { failure, paraesthesia and seizures (Leonard, 2003). }\end{array}$ \\
\hline Regurgitation & $\begin{array}{l}\text { The appearance of digestive fluid into the } \\
\text { oropharynx (Desachy et al., 2008). }\end{array}$ \\
\hline Undernutrition & $\begin{array}{l}\text { Insufficient nutritional intake to maintain adequate } \\
\text { nutritional reserves or to meet the metabolic } \\
\text { requirements of the body (Jarvis, 2003). }\end{array}$ \\
\hline
\end{tabular}




\section{CHAPTER 1 INTRODUCTION}

Engaging in evidence-based and collaborative critical care nursing to achieve optimal outcomes for patients poses a significant challenge in the Intensive Care Unit (ICU). Clinical questions are identified on a daily basis when providing and facilitating high quality nursing care. Some of these are answered easily by expert clinicians and the multidisciplinary team (MDT) and are informed by existing knowledge bases. Other questions are complex, multidisciplinary and not so easily answered. In these cases, research may be required to address these questions. The clinical question at the forefront of this research project is both complex and multidisciplinary. This systematic review sought to answer the research question: what is the maximum GRV to accept and continue the delivery of enteral nutrition in the ICU adult patient?

\section{Context}

I (the researcher) am a registered nurse $(\mathrm{RN})$ employed in an ICU of a New Zealand tertiary hospital. During one shift a colleague was caring for a patient who had a nasogastric tube and was being enterally fed (nutrition delivered via the gastric tube). The current local protocol and policy which informs the ICU nurse's management of enteral nutrition includes aspirating the gastric tube to measure the residual volume in a patient's stomach every four hours. There is also a directive, within this protocol, related to the process to follow depending on the volume of gastric residual obtained. This indicates how much aspirate to return, and how to manage the infusion rate of the enteral nutrition.

My nursing colleague identified a concern when conducting gastric residual aspiration on an enterally fed ICU patient (note: the term 'ICU patient' has been used synonymously with the terms 'critical care patient' and 'critically ill patient'). The concern was that the gastric residual volume (GRV) aspirated was over $300 \mathrm{~mL}$. The volume was considered to be a large amount by this nurse. The nurse was concerned that with such a high GRV, the patient might be at risk of vomiting and aspirating their gastric contents. These concerns 
were informally discussed amongst the nursing and medical staff available during the shift, related to what they would do with that GRV in order to clinically manage this patient. There were various responses, which demonstrated several different interpretations of the existing enteral nutrition protocol and policy. This provoked a review of the 1998 policy related to enteral feeding in the adult intensive care patient, encompassing the 10 year period from 1998 to 2008 .

\section{Involving the local stakeholders}

As part of the review of the enteral nutrition policy, the clinical question regarding the management of GRVs led to the sourcing of literature. This literature search incorporated the nursing management of GRVs and enteral nutrition in the intensive care unit, with a timeframe of 1998 to 2008. It was anticipated by the researcher that since 1998 there would be evidence from research to inform practice and improve the evidence-base to the existing policy. A MDT (dietetics, doctors and nurses) meeting was arranged to discuss the existing policy and the review of this literature. The existing policy encompassed a broad range of management strategies related to the delivery of enteral nutrition including: indications and contraindications, safety considerations, and a procedural guide to the safe delivery of enteral nutrition. One aspect of the policy was an algorithm providing specific guidance on the management of GRVs.

The agenda of the MDT meeting focussed on the components of the algorithm related to the management of GRVs. What was discovered was that the most appropriate management strategy surrounding GRVs was contentious. The MDT identified the GRV as one method of assessing if the patient was tolerating the infusion of nutrients, or was at risk of vomiting or regurgitating and potentially aspirating gastric contents. The MDT agreed that a specific volume would be appropriate to include in an enteral nutrition management algorithm, however identifying the critical numerical GRV to use highlighted the inconsistencies both within and between disciplines. The questions that 
arose were, what critical volume could be used in the algorithm as the volume of gastric aspirate that would lead nurses to either continue delivering, or potentially increase the infusion rate towards a goal rate of enteral nutrition? Alternatively, what critical volume could be used to lead nurses to either cease or reduce the infusion rate of enteral nutrition if it was less than that critical volume? Different MDT professionals, both within and between disciplines, identified different critical volumes, based on their experiences, the available guidelines and recommendations they had seen, current practice management strategies and protocols, and personal opinion.

There were specific patient-related factors that influenced both the practice and the recommendations of members of the MDT. Further discussion related to these factors highlighted that most clinicians feared patients would regurgitate and aspirate gastric contents, potentially causing aspiration pneumonia during enteral nutrition delivery. Or alternatively, that patients receiving enteral nutrition would not receive adequate nutrients. What was clear from these MDT discussions was that further research would be required to complete the policy review.

\section{Research method}

No formal literature review process had been adopted to retrieve the articles on which the MDT meeting discussions were based. For example, there was no documented search strategy, nor was the quality of the studies appraised. Furthermore, outcome measures associated with the individual studies were not considered. The literature sourced for the policy review and algorithm development was not sufficient to generate a practice change, or to enable completion of the policy review related to the management of GRVs. It became apparent that a more robust method of extracting evidence would be required. Planning was then commenced to identify the most appropriate research method to answer the clinical question raised. A systematic review was considered in further detail, and decided upon by the researcher as the optimal way of addressing this clinical question more rigorously and systematically, in 
an effort to enhance the management of GRVs in the enterally fed adult ICU patient.

\section{Beneficiaries}

The cornerstones of this research project, and those that will benefit most from answering this clinical question, are the ICU patients. This thesis seeks to enhance the standard of care in the management of enteral nutrition delivery by identifying the best evidentiary GRV to use. The MDT involved in the delivery of enteral nutrition to the ICU patient will also benefit from clarification of management strategies related to GRVs in the provision of enteral nutrition.

\section{Thesis outline}

This thesis is presented in the form of seven chapters. Chapter one has provided an introduction to the systematic review, highlighting how the clinical question arose and why the research is required. The nurses' role in the assessment of GRVs is outlined. This positions the researcher and the principal beneficiaries in the context of the research project.

Chapter two will identify and discuss the background to GRVs in the enterally fed adult patient in the ICU setting. Gastric residual volumes are introduced in the wider setting of nutrition and enteral nutrition. Existing literature, reviews, and clinical practice guidelines and recommendations that identify specific GRVs are summarised and critiqued. The connection of GRVs to nursing practice is addressed, particularly focusing on the contextual implications, and evaluating the role of systematic reviews in evidence-based nursing practice. The aim of this systematic review is introduced and the key objectives are outlined. The methodology for the systematic review is then discussed in Chapter three.

The methodology of systematic review and a meta-analysis is presented in the context of evidence based practice. The systematic review and meta-analysis approaches and processes are outlined with a discussion of the Cochrane 
methodology of systematic review. Two tools for the assessment of the risk of bias are introduced, and a method of assessing the level of quality of a body of evidence is identified. The data extraction process is included in a discussion related to the promotion of reliability and validity. This is followed by the method for the systematic review in Chapter four.

The method chapter of this systematic review addresses the criteria for considering the studies for this review, including the types of studies, participants, interventions and outcome measures eligible for inclusion. The search method is defined for identification of the studies, and the method of data collection and analysis is described. Chapter five presents the results of the systematic review.

The results provide a description of the studies, which includes both the characteristics of included and excluded studies. The included studies are then reviewed with respect to the study methodologies, participants and settings. The risk of bias is analysed using relevant risk of bias analysis tools. The effects of the comparative GRVs from the studies are described and these results are then discussed in Chapter six.

The discussion provides a summary of the main results of the systematic review in light of the identified outcome measures and related literature. The quality of the evidence and the potential for bias within the systematic review is also considered. This chapter is followed by the conclusion.

Chapter seven presents a concluding statement. This discusses the implications of the findings of this systematic review in relation to clinical practice. A strategy for the dissemination of the research implications is provided. Future research opportunities are presented. 


\section{CHAPTER 2 BACKGROUND}

The previous chapter has provided an introduction to the clinical context of this research thesis and the position of the researcher. Chapter two outlines the background to GRVs in the enterally fed adult patient in the ICU setting. Gastric residual volumes are introduced in the context of nutrition and enteral nutrition. The functional anatomy of the stomach is described and linked with the impact of critical illness. Achieving nutritional requirements is examined in relation to the role of enteral nutrition in maintaining gastric structure, function, and defence mechanisms. The role of GRVs as a measure of tolerance to enteral nutrition is considered, and literature that identifies specific GRVs is summarised and critiqued. The aim of the systematic review is introduced and the key objectives are outlined.

\section{Nutrition in critical care}

Nutrition is a key determinant of health and development (Ministry of Health \& University of Auckland, 2003; World Health Organisation, 2009). The New Zealand Ministry of Health identified improving nutrition as one of their 13 health priorities in the New Zealand Health Strategy (Ministry of Health, 2007). Admission to hospital and into the unique environment of the ICU, requires alternative strategies to achieve optimal nutrition for patients (Kozier, Erb, Berman, \& Burke, 2000). Nutritional support is a fundamental aspect of care in the critically ill (Kozier et al., 2000) and is now accepted standard practice (Leonard, 2009).

Historically, the provision of nutrition has been considered as an adjunct to intervention, supporting the intensive care of a patient; more recently the provision of early nutritional support to the ICU patient has been repositioned as a therapeutic intervention (McClave \& Heyland, 2005). The primary goal of the delivery of nutrition is to ensure adequate nutritional support for body requirements to minimise complications and support recovery, in particular when oral intake is insufficient or unsafe (National Institute for Health \& 
Clinical Excellence, 2006). Malnutrition in the critically ill patient may contribute to prolonged ventilation, and increased risks for infection and mortality (Hermsen et al., 2008; MacIntyre, 2001). The association of critical illness with hypermetabolism potentially exacerbates the likelihood of poor outcomes in inadequately nourished patients (Buckley \& Kudsk, 1998).

Sedation and ventilation of many ICU patients necessitates an alternative method to oral nutritional intake. Enteral nutrition is one option. Three methods for delivering enteral nutrition to the stomach are the administration via an orogastric tube (extends from the mouth to the stomach), a nasogastric tube (extends from the nose to the stomach), or a percutaneous endoscopic gastrostomy tube (passes percutaneously through the abdominal wall to the stomach) (Thomas \& Bishop, 2007). In this systematic review, enteral nutrition is confined to the provision of continuous enteral nutrition to the stomach via one of these three types of gastric tubes.

One method of assessing a patient's tolerance to enteral nutrition, frequently mentioned in the literature, is by intermittently measuring the residual volume of liquid contents in the stomach, known as the GRV (Metheny, 2008; Parrish \& McClave, 2008). Measuring GRVs involves attaching a large syringe to the feeding tube and aspirating (drawing back on the syringe), to evaluate the volume of the remaining contents in the stomach (Arbogast, 2002). The GRV aspirated is then managed according to local practice, guidelines, protocol, or policy, and this may include the return of some, all, or none of the aspirated volume. A discussion of the functional anatomy of the stomach provides the foundations for further discussion of the use of GRVs during the delivery of enteral nutrition. 


\section{Functional anatomy of the stomach}

\section{Physiology}

Anatomically, the hollow stomach can be differentiated into the cardia, fundus, gastric body, antrum and pylorus. Functionally, the proximal area provides a reservoir for a meal and distally there is an ability to generate contractions to mix, grind and empty the stomach of food (Tack, 2006). Circular, peristaltic waves assist this process distally by altering tonicity of the stomach. Duodenal contractions in the full duodenum delay further gastric emptying due to the reduced capacity of the duodenum (Tack). Movement through the small intestine to the colon for storage and elimination is dependent on effective motor function to facilitate mixing and propulsion (Hasler, 2006). The pancreas assists in the neutralising of the gastric secretions for duodenal digestion, alongside providing the enzymes and enzyme precursors required for this process (Gorelick \& Jamieson, 2006). The stimulus for this secretory process is thought to be primarily associated with the ingestion, digestion and absorption of food (Gorelick \& Jamieson).

\section{Gastric volumes and gastric emptying}

Normal gastric emptying for liquids is related to fundic pressure which increases with the infusion of a volume of liquid into the stomach (Parrish \& McClave, 2008). This causes an initial rapid phase of emptying the stomach, this rate then slows to empty the remaining liquid. In a computer simulation model, Lin and Van Citters (1997) reported that 4000-5000mL of normal secretions pass through the stomach per day. The gastrointestinal tract is innervated extrinsically by the parasympathetic and sympathetic nervous systems in response to gastric distension, via mechanoreceptors, and gastric contents, via chemoreceptors (Shulkes, Baldwin, \& Giraud, 2006). Vagal stimulation activates gastric secretion, motility and blood flow, sympathetic stimulation reduces gastric secretion and blood flow (Shulkes et al.). Thus, 
blood flow is generally increased with gastric secretion, in response to histamine, gastrin and acetylcholine, but reduced by catecholamines, atropine and somatostatin. Consequently, maintenance of the structure and function of the stomach is fundamental to effective gastric emptying.

\section{The role of enteral nutrition in the stomach}

\section{Enteral nutrition and maintaining structure and function}

Literature supports the use of enteral nutrition as a first choice in the administration of nutrition in the critical care setting, unless this was unavailable, impractical or unsafe (McClave \& Heyland, 2005). They suggest that use of the gastrointestinal tract was fundamental following critical illness. McClave and Heyland also proposed that the provision of $50 \%$ to $60 \%$ of the caloric goal rate may be required to prevent the loss of both functional and structural integrity alongside modulating the systemic immune response.

The maintenance of gastric function and structural integrity is important as it has been shown to reduce morbidity in ICU patients (Farber, Moses, \& Korn, 2005; MacKenzie, Zygun, Whitmore, Doig, \& Hameed, 2005). Principally, the delivery of enteral nutrition involves the provision of sufficient energy and nutrients to facilitate normal physiological functions, such as body tissue growth, repair, replacement, and protection (Thomas \& Bishop, 2007). Additionally, enteral nutrition has been found to have an essential role in maintaining the structure and function of the gastrointestinal mucosal barrier, promoting gut motility, and avoiding the infectious complications and costs associated with parenteral nutrition, which is an alternative method of nutrient delivery (Jolliet et al., 1998; Kudsk, 2001, 2002). These benefits primarily arise from the role of enteral nutrition in preventing mucosal atrophy through enhancing mucosal blood flow and the secretion of immunoglobulins and hormones (Jolliet et al., 1998; Peng, Yuan, \& Xiao, 2001). Furthermore, maintenance of the structure and function of the stomach are essential for maintaining a system of defence. 


\section{Enteral nutrition and defence}

Research has demonstrated that the provision of enteral nutrition in the critically ill has benefits beyond those associated directly with adequate nutrition (Eckmann, 2006; Grant, 2006; Johansen et al., 2006; Kudsk, 2001, 2002). The gastrointestinal tract's immune system has an innate ability to elicit antimicrobial activity through activation of molecules by enzymes. This ability is highly effective in infection control as a first line of defence (Eckmann). At the mucosal surface, immunoglobulins modulate this system of defence (Johansen et al.). The gastric mucosal surface protects the gastrointestinal tract against this acid and, the protein digesting enzyme, pepsin. Improved critical care management of patients with single organ failure has reduced mortality, but increased the risk of multiple organ dysfunction syndrome (C. Doig, Sutherland, Sandham, Verhoef, \& Meddings, 1998).

Doig et al.'s (1998) prospective, observational cohort study compared intestinal permeability and the development of multiple organ dysfunction syndrome (MODS) in a group of critically ill ICU patients. In the healthy person, the intestinal epithelial barrier selectively enables the movement of molecules through the epithelium; however, Doig et al. found that patients who developed MODS had significantly worse intestinal permeability at admission than the non-MODS cohort. Damaged intestinal mucosa plays a key role in increased permeability (Johnson \& Kudsk, 1999). Without adequate nutrition, the ability to mount an inflammatory response is diminished (Griffiths, 2007). Enteral stimulation enhances immune defences (Kudsk, 2001) and facilitates the hosts protection from bacteria and toxic products (Kudsk, 2002). It has also been suggested that commencing enteral nutrition may also restore intestinal anatomy and function (Grant, 2006). Initiating enteral nutrition early as a means to ameliorate septic complications is purported to be important. For example, a meta-analysis in 1992 highlighted the potential for early enteral nutrition to reduce the development of septic complications (Moore et al., 1992). Furthermore, research on mice has demonstrated a reduced rate of death when subjects are enterally fed as opposed to parenterally fed (Fukatsu et al., 
2001). What this research highlights is that enteral nutrition is essential to the promotion of health in the critically ill patient and thus, ensuring the effective and adequate delivery of this critical component of intensive care is crucial.

\section{The impact of critical illness on the gastrointestinal system}

\section{Reduced gastric motility}

Critical illness has been associated with reduced gastric motility (Dive, Moulart, Jonard, Jamart, \& Mahieu, 1994; Gue, 2006). Stress alters gastrointestinal motor function and gut motility, particularly inhibiting gastric emptying (Gue). The critically ill mechanically ventilated patient has less peristaltic activity, particularly in the stomach, compared to that of healthy individuals (Dive et al.). A literature review addressing aspects of critical illness that impact on gastrointestinal motility discussed the impact of both acute illness and therapeutic interventions such as opioids, $\beta$-adrenergic blockers, and anticholinergic drugs (Fruhwald, Holzer, \& Metzler, 2008). Several factors that reduce the natural defence mechanisms of the gastrointestinal tract were discussed, including abdominal surgery, haemodynamic instability, fluid and electrolyte alterations, vasoactive medication, sedation and analgesia. The provision of enteral nutrition to ameliorate the impact of these has been purported, however patients would require adequate intestinal motility (Fruhwald et al.). One method of promoting intestinal motility is the administration of prokinetics to facilitate gastric emptying (Deane, Fraser, \& Chapman, 2009).

\section{Potential for aspiration}

Critical illness has also been linked with the aspiration of gastric contents (Bullock, Waltrip, Price, \& Galandiuk, 2004; Elpern, 1997; Grant, 2006). This risk for aspiration has been associated with the intubated patient who has a 
naso- or oro-gastric tube, and also with the head-injured patient who has reduced oesophageal sphincter pressure, particularly in those patients with delayed gastric emptying reflected in elevated GRVs. In the intubated patient, the endotracheal tube stents the glottis open, and if a naso- or oro-gastric tube is present this stents the oesophageal sphincter open. This may predispose the intubated and enterally fed patient to aspiration (Bullock et al.). Gastric distension may result in gastroesophageal reflux and ultimately pulmonary aspiration (Grant). Despite the use of cuffed endotracheal tubes, these do not reliably prevent aspiration of substances into the lower airway (Elpern).

\section{Improving the delivery of enteral nutrition}

In an effort to mitigate the potential risks associated with delivering enteral nutrition, standardisation of practice has been proposed as one method to improve the management of enteral nutrition. Many critically ill patients do not meet their nutritional goals, which has been linked to inconsistencies related to enteral nutrition practices both within and between ICUs (Marshall \& West, 2004). The lack of reliable and valid research related to the effective delivery of enteral nutrition, may mean that there is a reliance on largely unchallenged tradition and rituals (Marshall \& West). Marshall and West identified that the strategies for the management of enteral nutrition may result in insufficient delivery of feed. For the ICU patient, one of the most frequently reported reasons for discontinuation or inadequate delivery of enteral nutrition is high GRVs (Bourgault, Ipe, Weaver, Swartz, \& O'Dea, 2007; McClave et al., 1999; Roberts, Kennerly, Keane, \& George, 2003).

\section{Evidence-based guidance}

The effective use of an algorithm has been shown to improve the delivery of prescribed enteral nutrition rates (Adam \& Batson, 1997; Bowman et al., 2005; Mackenzie, Zygun, \& Hameed, 2003; MacKenzie et al., 2005; Martin, Doig, Heyland, \& Sibbald, 2004; McClave \& Snider, 2002). Martin et al. (2004) conducted a multicentre, cluster-randomised clinical trial in Canadian ICUs, 
and concluded that there was improved provision of nutritional support and clinical outcomes with the implementation of evidence-based recommendations. Martin et al.'s findings were consistent with other studies which identified that evidence-based nutritional support protocols improved the delivery of enteral nutrition (Adam \& Batson, 1997; MacKenzie et al., 2005) and increased the frequency of goal rates being achieved whilst decreasing the reports of aspiration pneumonia and ventilator-associated pneumonia (Bowman et al., 2005). What these studies highlight is that having a protocol or algorithm to guide enteral nutrition delivery is of benefit. However, a rigorous evidencebase to the components of the protocol or algorithm, for example the process guiding GRV management, is essential.

\section{Mitigating risk through the use of an algorithm}

Using an evidence-based algorithm in the management of GRVs seeks to mitigate two of the issues of most concern in GRV management. This is related to the practice of accepting a GRV that is either too high or too low. Accepting a GRV that is too high may predispose a patient to gastroesophageal reflux, and potentially aspiration (Metheny et al., 2004). Furthermore, the stomach has previously been identified as a source of bacteria for colonising the trachea in the mechanically ventilated critical care patient (Pingleton, Hinthorn, \& Liu, 1986; Tryba, 1991). The impact of accepting a GRV that is too low may influence whether a patient's nutritional requirements are adequately met. Both of these scenarios, either the delivery of too much nutrition (overfeeding), or too little nutrition (underfeeding), have been demonstrated to occur in the context of the ICU patient.

Underfeeding was found to be common in ICU; in one study of 129 critically ill patients, $43 \%$ were found to be malnourished (Giner, Laviano, Meguid, \& Gleason, 1996). These malnourished patients had a higher incidence of complications and fewer were discharged from the hospital. Underfeeding was associated with malnutrition, and overfeeding was associated with poor glycaemic control and impaired weaning from mechanical ventilation (Reid, 
2006). Comparatively, overfeeding predominantly occurs when patients receive both an oral and enteral diet, and when patients are delivered a nutrient dense enteral formula (Reid, 2006). Nutrients are well matched to requirements of the immune response in the healthy person, but these are confounded by the inpatients variables of immobility and continuous nutrient delivery in the critically ill (Griffiths, 2007). This highlights the importance of facilitating the safe delivery of enteral nutrition, both to achieve caloric requirements and to mitigate a potential risk of aspiration.

\section{Use of GRVs as a measure of patient tolerance of enteral nutrition}

Tolerance and intolerance of enteral nutrition in the critically ill patient has wide variation in definition. Indicators of intolerance to enteral nutrition have been defined as vomiting, abdominal distension, diarrhoea and high GRV (Kozar et al., 2002). The historical premise for measuring a GRV, as highlighted by McClave and Snider (2002), is that large residual volumes have been thought to indicate gastric intolerance to enteral feeding, a potential for vomiting and aspiration, and ultimately a risk for aspiration pneumonia. Conversely, based on these assumptions, low GRVs would suggest enteral nutrition tolerance and a minimal risk of aspiration (McClave \& Snider). However, accepting a GRV too low may subject the patient to underfeeding, and hence their nutritional needs not being met. This potential may be exacerbated by not returning a GRV. One randomised, prospective, clinical trial of 125 critically ill patients supported the reintroduction of a GRV following measurement (Juve-Udina et al., 2009). The authors found that participants who had the GRV reintroduced had a lower incidence and severity of delayed gastric emptying episodes. The practice of measuring a GRV has experienced considerable debate related to the paucity of evidence, and abundance of assumptions, to support the relationship between elevated GRVs and enteral nutrition intolerance. 


\section{Assumptions}

Parrish and McClave (2008) suggest that the practice of assessing GRVs developed from a set of assumptions that reflect a paucity of scientific data. These assumptions include that: the practice of assessing GRVs will identify abnormal gastric emptying, elevated GRVs are a direct result of delayed gastric emptying, the measurement of a GRV may reflect retention of enteral formula, accumulation of enteral nutrition in the stomach leads to aspiration, and aspiration of gastric contents results in pneumonia. According to Parrish and McClave, the ultimate impact of these assumptions is that enteral nutrition is frequently discontinued inappropriately based on the practice of assessing GRVs.

The underlying assumption that the stomach has a fixed volume capacity, and measurement of the volume of stomach contents enables prediction of potential overflow into the oesophagus and increased aspiration risk, has been dismissed as inherently flawed (McClave \& Snider, 2002). This premise for aspiration risk assessment may be further undermined by Metheny et al.'s (2008) descriptive study which found that of their 206 participants, 93\% had at least one tracheal secretion positive for pepsin. This was deemed as a proxy for the aspiration of gastric contents by Metheny et al. Although this percentage of aspiration increased as GRVs increased, even patients who had a GRV between 0-50mL had 34\% positive pepsin assays (Metheny et al.). Furthermore, the assumption that enteral feeding intolerance leads to the development of pneumonia has also been questioned. For example, Umbrello, Elia, Destrebecq, and Iapichino's (2009) study of 78 ICU patients confirmed that the development of pneumonia was not associated with upper digestive intolerance.

Despite these inherent flaws to the argument for using GRVs to inform management of enteral nutrition, GRV management algorithms remain abundant in practice (Bowman et al., 2005; Marshall \& West, 2004). Other methods have been proposed in the literature as a measure to assess gastric 
emptying including scintigraphy, the paracetamol absorption test, breath tests, refractometry, ultrasound, and gastric impedance monitoring (Moreira \& McQuiggan, 2009). Moreira and McQuiggan's narrative review found refractometry to be the most appropriate of these methods. A refractometer measures the degree of light bending between substances of different densities (Chang, McClave, Hsieh, \& Chao, 2007). Using the refractometer and a refractive index to measure gastric contents, Chang, McClave, Lee, and Chao (2004) raised the potential feasibility that refractometry may be a method of bedside monitoring of tolerance and gastric emptying to complement traditional GRV measurement (Chang et al., 2004). These proposed alternative evaluation methods require further validation in clinical practice, and until this validation occurs, GRVs remain the most common method of assessing gastric emptying. Hence, with the ongoing reliance on the aspirated GRVs to inform management of enteral nutrition, despite the lack of supporting research, ensuring the existing practices related to GRVs is evidence-based is crucial.

\section{Inconsistencies in the management of GRVS}

There are inconsistencies between accepted GRVs and management strategies related to the volume of gastric residual identified, both in the literature (Bourgault et al., 2007; Bowman et al., 2005; Cerra et al., 1997; Kattelmann et al., 2006; Keithley \& Swanson, 2004; Marshall, 2005; McClave et al., 2002; McClave \& Snider, 2002; Metheny, 2008; Parrish \& McClave, 2008; Parrish \& McCray, 2003; Pinilla et al., 2001; Zaloga, 2005), and in the recommendations of clinical practice guidelines (American Gastroenterological Association, 1994; American Society for Parenteral and Enteral Nutrition Board of Directors \& The Clinical Guidelines Task Force, 2002; Cerra et al., 1997; Critical Care Nutrition, 2007; Dietitians Association of Australia Nutrition Support Interest Group, 2007; Heyland, Dhaliwal, Day, Jain, \& Drover, 2004; Heyland, Dhaliwal, Drover, Gramlich, \& Dodek, 2003; Jolliet et al., 1998; McClave et al., 2002; National Collaborating Centre for Acute Care, 2006; Stroud, Duncan, \& Nightingale, 2003). The recommended acceptable GRVs vary widely, from $150 \mathrm{~mL}$ to $500 \mathrm{~mL}$, and management strategies range from 
ceasing enteral nutrition infusions for an elevated GRV, to continuing with caution. Furthermore, the use of GRVs as a marker for tolerance remains contentious and is related to the lack of reliability in the measure (Bochicchio et al., 2006; Chang et al., 2007; Kompan, Vidmar, Spindler-Vesel, \& Pecar, 2004; Landzinski, Kiser, Fish, Wischmeyer, \& MacLaren, 2008; Lin \& Van Citters, 1997; MacLaren, Kiser, Fish, \& Wischmeyer, 2008; McClave et al., 2005; McClave \& Snider, 2002; Metheny, 2008).

\section{Debate in the management of GRVs}

It has been suggested that the use of GRVs has never been shown to improve patient outcome or reduce complications and thus there is little point in standardising this practice (Parrish \& McClave, 2008). Poor sensitivity, specificity and accuracy in the GRVs correlation to gastric emptying or predicting outcomes means these GRVs should not be solely relied upon in clinical practice to direct patient care (Parrish \& McClave). Despite this, high gastric residual volumes have been identified as one of the primary reasons for discontinuing enteral nutrition (McClave et al., 1999).

One recent prospective observational study in the United States of America (USA) suggested removing the measurement of GRVs from enteral nutrition protocols to improve delivery (O'Meara et al., 2008). Metheny (2008) critiqued this study, and argued that GRV assessment may identify patients at high risk for aspiration and aspiration-related pneumonia. What is apparent is that there remains inconsistent evidence regarding the role of assessment of GRVs, in conjunction with a clinical assessment of tolerance, in the enterally fed critically ill patient. It may still be appropriate to assess GRVs until more data is available recommending other measures (Parrish \& McClave, 2008). In order to ensure that all possible sources of information pertaining to GRVs were identified, on-line databases and websites related to critical care, ICU, dietetic societies, organisations, and associations internationally were reviewed for current recommendations, guidelines, consensus statements and collaborative reports. 


\section{Professional recommendations and guidelines}

Several professional recommendations and guidelines exist to inform practice surrounding the management of GRVs in the ICU adult enterally fed patient. Literature and systematic reviews were sought through a search of electronic databases. The findings the search were examined for consensus or disagreement of their principle findings related to specified GRVs, and the implications drawn from the primary research reviewed. Principle findings are displayed in Table 1. 
Table 1. Reviews, professional guidelines, and recommendations for GRV management in the enterally fed adult patient

\begin{tabular}{|c|c|}
\hline Professional Groups & GRV and action recommended \\
\hline $\begin{array}{l}\text { American Gastroenterological } \\
\text { Association (1994) }\end{array}$ & $\begin{array}{l}\text { GRV > 200mL: prompt concern about intolerance and } \\
\text { closely monitor although they suggest that a single high } \\
\text { GRV is not cause to cease enteral nutrition. }\end{array}$ \\
\hline $\begin{array}{l}\text { European Society of Intensive } \\
\text { Care Medicine (Jolliet et al., } \\
\text { 1998) }\end{array}$ & $\begin{array}{l}\text { GRV > 300mL: decrease enteral nutrition infusion rate } \\
\text { by } 50 \% \text { for } 4-6 \mathrm{hr} \text {, then resume over } 24-48 \mathrm{hrs} \text { while } \\
\text { monitoring GRV twice daily and administering a } \\
\text { prokinetic. }\end{array}$ \\
\hline $\begin{array}{l}\text { American Society for Parenteral } \\
\text { and Enteral Nutrition Board of } \\
\text { Directors \& The Clinical } \\
\text { Guidelines Task Force (2002) }\end{array}$ & $\begin{array}{l}\text { GRV > 200mL: cease enteral nutrition if this occurs on } \\
\text { two successive assessments. }\end{array}$ \\
\hline $\begin{array}{l}\text { Canadian Critical Care Trials } \\
\text { Group, (Heyland et al., 2003) }\end{array}$ & $\begin{array}{l}\text { GRV }=250 \mathrm{~mL} \text { : tolerate and consider administering a } \\
\text { prokinetic at the initiation of enteral nutrition to } \\
\text { optimise delivery to the critically ill patient }\end{array}$ \\
\hline $\begin{array}{l}\text { British Society of } \\
\text { Gastroenterology (Stroud et al., } \\
\text { 2003) }\end{array}$ & GRV > 200mL: reduce feeding rates. \\
\hline $\begin{array}{l}\text { National Collaborating Centre } \\
\text { for Acute Care (2006) }\end{array}$ & $\begin{array}{l}\text { GRV > 200-300mL: consider as a high aspirate, reduce } \\
\text { continuous feeding rate and/or introduce prokinetics }\end{array}$ \\
\hline $\begin{array}{l}\text { National Institute for Health } \\
\text { and Clinical Excellence (2006) }\end{array}$ & $\begin{array}{l}\text { GRV }=200-300 \mathrm{~mL} \text { : consider as 'large', depending on } \\
\text { local policy, reduce infusion rate or consider prokinetics. }\end{array}$ \\
\hline $\begin{array}{l}\text { Dietitians Association of } \\
\text { Australia Nutrition Support } \\
\text { Interest Group (2007) }\end{array}$ & $\begin{array}{l}\text { GRV > 500mL: consider as 'large' and to replace up to } \\
500 \mathrm{~mL} \text {. } \\
\text { GRV > 200mL: take care to minimise aspiration risk. }\end{array}$ \\
\hline $\begin{array}{l}\text { Society of Critical Care } \\
\text { Medicine and American Society } \\
\text { for Parenteral and Enteral } \\
\text { Nutrition (Martindale et al., } \\
2009)\end{array}$ & $\begin{array}{l}\text { GRV < 500mL: avoid holding enteral nutrition in the } \\
\text { absence of other signs of intolerance }\end{array}$ \\
\hline
\end{tabular}




\begin{tabular}{|l|l|}
\hline Reviews & GRV and action recommended \\
\hline Cerra et al. (1997) & $\begin{array}{l}\text { GRV > 150mL: moderate infusion rate and consider } \\
\text { total parenteral nutrition or small bowel feeding. }\end{array}$ \\
\hline Edwards \& Metheny (2000) & $\begin{array}{l}\text { GRV } \geq 200 \mathrm{~mL} \text { : prompts concern related to enteral } \\
\text { nutrition tolerance. }\end{array}$ \\
\hline McClave \& Snider (2002) & $\begin{array}{l}\text { GRV < 400-500mL: unless there is overt regurgitation } \\
\text { or aspiration, continue delivery of enteral nutrition. } \\
\text { Also, trend in GRV may be more important than a single } \\
\text { elevated GRV. }\end{array}$ \\
\hline McClave et al. (2002) & $\begin{array}{l}\text { GRV < 500mL: enteral nutrition should only be stopped } \\
\text { if there is overt regurgitation or aspiration. } \\
\text { GRV < 500mL be returned to the patient. } \\
\text { GRV }=200-500 \mathrm{~mL}: \text { careful bedside evaluation and risk }\end{array}$ \\
\hline Bourgault et al. (2007) & $\begin{array}{l}\text { GRV }=200 \mathrm{~mL}: \text { assess the patient for indications of } \\
\text { enteral nutrition intolerance. }\end{array}$ \\
\hline Kowman et al. (2005) & $\begin{array}{l}\text { GRV > 250mL: stop feeding. } \\
\text { situation, but if there are two or more consecutive GRV } \\
\text { of 250mL stop the delivery of enteral nutrition. }\end{array}$ \\
\hline
\end{tabular}

\section{Review and critique of guidelines and recommendations}

As part of the literature review to provide a rationale for this SR, professional recommendations and guidelines were reviewed. There was considerable disparity in the recommendations and guidelines of the professional groups and the reviews internationally. The lowest recommended GRV to accept was $150 \mathrm{mLs}$, although this was also the earliest dated review identified in the search (Cerra et al., 1997). Since the year 2000, the minimum GRV to accept was $200 \mathrm{~mL}$, with the highest being $500 \mathrm{~mL}$ (Dietitians Association of Australia Nutrition Support Interest Group, 2007; Martindale et al., 2009; McClave et al., 2002; McClave \& Snider, 2002). However, each of these latter higher recommendations relied heavily on the review of McClave and Snider (2002).

There was similar disparity in recommended actions in response to specified GRVs. The most common recommended action was to reduce the enteral 
nutrition infusion rates (Cerra et al., 1997; Jolliet et al., 1998; National Collaborating Centre for Acute Care, 2006; National Institute for Health \& Clinical Excellence, 2006; Stroud et al., 2003). Other recommendations included to cease the enteral nutrition (American Society for Parenteral and Enteral Nutrition Board of Directors \& The Clinical Guidelines Task Force, 2002; Bowman et al., 2005; Kattelmann et al., 2006), to introduce prokinetics (Heyland et al., 2003; Jolliet et al., 1998; National Collaborating Centre for Acute Care, 2006; National Institute for Health \& Clinical Excellence, 2006), to monitor the patient closely (American Gastroenterological Association, 1994; Edwards \& Metheny, 2000; McClave \& Snider, 2002), or to implement aspiration risk reduction methods (Dietitians Association of Australia Nutrition Support Interest Group, 2007; Martindale et al., 2009; McClave \& Snider, 2002). Some recommendations included the combination of several of the above actions, for example, to introduce prokinetics and implement aspiration risk reduction methods. The quality of evidence for the basis of these recommendations varied considerably.

Of the 15 recommendations, three were clearly based on a reproducible search strategy (Edwards \& Metheny, 2000; Heyland et al., 2003; Kattelmann et al., 2006), five provided clear documentation of identification of the strength of the recommendations or a level of evidence (American Society for Parenteral and Enteral Nutrition Board of Directors \& The Clinical Guidelines Task Force, 2002; Heyland et al., 2003; Kattelmann et al., 2006; Martindale et al., 2009; Stroud et al., 2003), two provided evidence of critical appraisal of the research (Heyland et al., 2003; McClave \& Snider, 2002), four were clearly peer reviewed (American Gastroenterological Association, 1994; Dietitians Association of Australia Nutrition Support Interest Group, 2007; Heyland et al., 2003; Stroud et al., 2003), and only one appeared to have been validated (Heyland et al., 2003).

In summary, there were several existing reviews and clinical practice guidelines with recommendations related to GRVs. A variety of GRVs were highlighted as the maximum value to potentially consider for enteral nutrition intolerance, ranging from $150 \mathrm{~mL}$ to $500 \mathrm{~mL}$. Various interventions were 
recommended related to the specified GRVs, including cessation of enteral nutrition, reducing enteral nutrition, continuing enteral nutrition with careful assessment, implementing alternative strategies to reduce the potential risk of aspiration, and introducing prokinetics. These recommendations were supported from sources ranging from a single expert opinion or a single randomised controlled trial, to a systematic review of several research trials, which reflects the disparity in the rigour of the evidence-base.

\section{Systematic review objectives}

What has been highlighted so far is the potential scope for a systematic review to inform this topic more effectively than the existing literature to date. It is essential to balance important benefits against important harms when administering enteral nutrition and this is demonstrated in the objectives of this systematic review. The objectives seek the potential benefits of the delivery of optimal caloric intake by identifying the best evidentiary GRV. This is balanced against the complications related to accepting a GRV too high or too low, potentially predisposing the adult ICU patient to harm.

The aim of this systematic review was to investigate, from the year 1998 to 2008, GRVs in the gastrically fed adult ICU patient related to the primary outcome measures indicative of: accepting a specified GRV too high, and hence placing the patient at risk of vomiting, regurgitation, aspiration of gastric contents and potentially aspiration pneumonia; or accepting a specified GRV too low, and hence not achieving caloric needs, potentially placing the patient at risk of malnutrition and increased morbidity. This systematic review sought to answer the research question: what is the maximum GRV to accept and continue the delivery of enteral nutrition in the ICU adult patient? The key research objectives included to: develop an appropriate research method to answer the question; conduct the systematic literature search; critically appraise the results of the systematic literature search; discuss the results of the systematic review of the literature considering the position of key reference groups related to this subject; identify limitations of the systematic review; 
draw on implications for current practice to be disseminated; and finally, identify future opportunities for research.

This background chapter contextualised GRVs in relation to nutrition in the adult intensive care setting. The implications of tradition, ritual, and evidence based practice in nursing were considered in association with optimising the delivery of enteral nutrition. This was positioned within the literature that identified recommendations related to specified GRVs in the enterally fed adult ICU patient. The aim of the systematic review was identified and the overarching objectives were outlined. 


\section{CHAPTER 3 METHODOLOGY}

The previous chapter described the background and context to the use of GRVs in the delivery of enteral nutrition. Clinical practice guidelines and review recommendations were identified and critiqued. The objectives and aims for the systematic review were outlined. The methodology will now be addressed in more detail. This chapter initially highlights the use of evidence-based practice in nursing. There is discussion of the rationale for conducting a systematic review and meta-analysis in order to answer the objectives of this research project. The format of the systematic review is addressed, specifically why the Cochrane Collaboration methodology was used for the systematic review, and the structure of the Cochrane systematic review is described. Two tools for the assessment of the risk of bias are introduced, and a method of assessing the level of quality of evidence is identified. This is followed by defining the data extraction process and a discussion related to the promotion of reliability and validity.

\section{Evidence-based practice}

For the practice of managing GRVs to be evidence based, evaluation of the research is required. Using the best possible evidence in the provision of patient care is widely supported both in the literature, and in organisations which support and promote the development and dissemination of research (Fulbrook \& Mooney, 2003; Higgins \& Green, 2008; Houser, 2008; Joanna Briggs Institute, 2008; National Institute for Health \& Clinical Excellence, 2006; Polit \& Beck, 2008; Rycroft-Malone et al., 2004). Engaging in evidencebased nursing practice has become an expectation (Gillis \& Jackson, 2002). Determining what evidence is, and how to use evidence, is thought to be more challenging (Rycroft-Malone et al.).

Research, clinical experience, patient experience, and local information are all proposed as sources of evidence supporting a broader definition of evidencebased patient-centred care (Rycroft-Malone et al., 2004). DiCenso, Cullum, 
and Ciliska (1998) highlight the impact of the availability of resources to achieving evidence-based patient-centred care. A systematic approach both to research, and to the evaluation of research, is deemed as essential when evaluating the effectiveness of an intervention (Gillis \& Jackson, 2002). Nursing accountability, related to quality, safety and cost effectiveness, elicits the need for streamlining care, with the elimination of unnecessary and ineffective practice (Houser, 2008). With this in mind, the most appropriate research approach to answer the aims and objectives of this research project will now be discussed.

\section{Systematic reviews and meta-analyses}

Several possible research methods were considered, prior to electing a systematic review and meta-analysis, to answer the research question: what is the maximum GRV to accept and continue the delivery of enteral nutrition in the ICU adult patient? The search for evidence to answer a research question may be successfully conducted using qualitative and quantitative research methodologies, either individually or a combination of both (Houser, 2008). The most appropriate method to inform a research question has been described as the method that identifies the best evidence, using the type of research most methodologically appropriate, rigorous, and clinically relevant (Polit \& Beck, 2008). Three potential options considered for this research thesis were a narrative literature review, a randomised controlled trial, or a systematic review and meta-analysis. To ascertain which of these research methods to elect, the literature was consulted in order to identify which would provide the best possible evidence to answer the research question.

Stevens (2001) suggests that building the bridge between research and practice is challenging. This is due to the disparate nature of research and clinical practice, particularly with respect to the way knowledge is shared. Specifically, the language used may be a barrier to building the bridge. Scientific knowledge based on accuracy and reported in scientific terms may not meet the needs of those working in the clinical field. Clinicians may require reporting based on 
clinical relevance, usefulness and timeliness (Stevens). Randomised controlled trials, systematic reviews and meta-analyses are assigned the highest level of evidence in clinical research (Melnyk, 2004; Polit \& Beck, 2008; Stevens). These are followed by observational studies, including cohort and case controlled studies (Polit \& Beck). Assigning a level of evidence to a particular piece of research provides the reader with information related to the quality of methodological design and the potential strength of the research findings (Melnyk). Due to its prominent position in the hierarchy of evidence, a systematic review and meta-analysis is considered in further detail as the research methods to use in addressing the research question.

Traditionally, a review of the literature took the form of a narrative which synthesised research findings (Polit \& Beck, 2008). Narrative reviews provide a broad overview of a specified condition, or treatment, combined with the experienced authors practical knowledge (Garg, Hackam, \& Tonelli, 2008). The narrative review provides evidence to support statements. Whether the recommendations are based on the author's experience, reviewed literature, or one particular study over another, is not specifically clarified. Hence it is purported that there is a potential for a narrative review author to selectively cite reports to support their personal view (Garg et al.). A more rigorous and systematic method of reviewing the literature is depicted in the methodology of the systematic review.

The focus of the systematic review and meta-analysis is the application of a definitive methodology to the identification and analysis of research, and the use of statistical data from quantitative studies (Polit \& Beck, 2008). Stevens (2001) highlights the strengths of the systematic review as its ability to increase the power and validity of the relationship between an intervention and an outcome. Furthermore, the systematic review limits bias through the use of rigorous scientific methods.

Potentially the systematic review provides a basis for clinical decision making, future research planning, and the establishment of clinical policy (Cook, Mulrow, \& Haynes, 1997). Systematic reviews seek to identify, appraise, and 
summarise studies relevant to a specific question, and to facilitate appropriate decision making (Clarke, 2007). Also, the systematic review enables accumulation of evidence and learning from many studies, through its methodology, to provide new insights to a particular question (Harden, 2006).

To support the development and dissemination of research, and particularly systematic reviews, several collaborative organisations have become renowned within the healthcare setting. Two of these include the Cochrane Collaboration and the Joanna Briggs Institute (JBI). Each of these organisations supports and delivers evidence elicited through research. The JBI promotes their unique systematic review approach that supports more diverse forms of evidence. Within their conceptual model of evidence-based healthcare, JBI promotes evidence generation through discourse, clinical experience and all forms of research (The Joanna Briggs Institute, 2008). The JBI was established in 1996 in Australia, with an overarching goal of translating evidence research into practice. Their reviews are classified in terms of feasibility, appropriateness, meanfulness, and effectiveness. This research is synthesised and rated accordingly. Their reviewer's manual highlights their close relationship with the Cochrane Collaboration (Joanna Briggs Institute, 2008). The JBI purport their own position as leaders in systematic reviews that encompass qualitative, economic and policy research, and point researchers who conduct systematic reviews of effects towards the Cochrane Review Groups (The Joanna Briggs Institute, 2008).

Comparatively, the Cochrane Collaboration reviews focus on evidence identified in relevant scientific studies (The Cochrane Collaboration, 2008). The Cochrane Collaboration was founded in 1993 and seeks to support, promote, and disseminate the search for evidence from clinical trials and studies of healthcare interventions. Their database of systematic reviews is published quarterly. These reviews aim to establish the consistency or variance of effects of healthcare. With this in mind, and considering this systematic review seeks to evaluate the effect of a healthcare intervention using clinical trials rather than discourse or clinical experience, the chosen methodology to conduct this review is using the Cochrane Collaboration systematic review 
framework. This type of systematic review was selected to promote reliability and rigour in the research methods, and to enhance the validity of the results identified through evidence based on scientific studies.

With the numerous clinical practice guidelines and reviews available with recommendations related to GRVs, it was anticipated that there would be a large number of scientific studies that would inform the research question of this systematic review. Due to this potential, conducting a subsequent metaanalysis of the identified systematic review results was planned. Clarke (2007) defines a meta-analysis as combining the results of similar studies to provide a more reliable and significant result. Statistical meta-analysis may enable pooling of studies to enhance the effect size (Harden, 2006). The potential benefits of a meta-analysis include the provision of information which can be merged with clinical judgement and contextualised (Acton, 2001). As a result, this may enhance clinical decision making and improve health outcomes (Acton).

\section{The systematic review process}

Prior to the commencement of the systematic review, the Cochrane Collaboration requires the development of a research protocol (Green \& Higgins, 2008). This protocol mitigates the risk of bias in the review process. A research protocol was developed by the researcher and is included in Appendix 1.

\section{Refining the research question}

Cochrane reviews require a clearly defined research question incorporating the types of participants, interventions (and comparisons), and outcomes. This question may describe: participants by the disease, condition or diagnosis, the age-group and the setting; interventions by the type of intervention or comparison; and outcomes as a potential benefit and/or harm. Asking a clear and focused question, which may be formulated as a set of objectives, defines 
the eligibility criteria of the systematic review (Bigby \& Williams, 2003; O'Connor, Green, \& Higgins, 2008).

\section{Search strategy}

The search strategy, although specific and reproducible, needs to be extensive enough to ensure all relevant studies are identified (Bigby \& Williams, 2003; Lefebvre, Manheimer, \& Glanville, 2008). Many Cochrane reviews are restricted to including randomised trials only (O'Connor et al., 2008). What is thought to be most important is considering the type of studies that will provide the most reliable data to answer the study objectives (O'Connor et al.). For example, non-randomised trials may be considered if the effect (benefit or harm) of an intervention cannot be adequately studied by a randomised trial. It is essential for this search strategy to identify the appropriate evidence to answer the research question.

The eligibility criteria for the study form the basis of the search strategy. This specifies the types of participants, interventions and outcomes eligible, and also the types of studies to be included in the systematic review. In order to minimise the potential risk of bias associated with the exclusion of relevant studies, it is not common to add limiters to a search. One example would be limiting the timeframe of the search, unless the intervention was only available after a particular date or the timeframe was a requirement in order to answer the research question (Lefebvre et al., 2008). The search strategy used for the identification of eligible studies is provided in the systematic review protocol (see Appendix 1). To enhance rigour and clarity in reporting of the systematic review, the Preferred Reporting Items for Systematic Reviews and MetaAnalyses (PRISMA) flow diagram was adopted (Moher, Liberati, Tetzlaff, Altman, \& and the PRISMA Group, 2009). A data extraction tool, to collect relevant information from the identified studies, was developed based on the recommendations of Higgins and Deeks (2008). 


\section{Data extraction}

Systematic reviews usually require at least two reviewers, who abstract and record data. A data extraction form is developed to assist with this process. It is recommended, when extracting data, to carefully consider the amount of data recorded to ensure enough information is obtained (Higgins \& Deeks, 2008). Higgins and Deeks also suggest that forms are useable and information is applicable to all aspects of the review question and criteria for inclusion. When designing a data extraction form, Higgins and Deeks suggest including study identification, sample sizes, eligibility criteria with a checklist related to criteria met or not met, and outcome data. Furthermore, the inclusion of numbers lost in follow-up, size of effect, and quality criteria have also been suggested (Bigby \& Williams, 2003). Should there be more than one reviewer, any differences in opinion would most commonly be settled by consensus (Bigby \& Williams).

The Cochrane Collaboration clearly outlines methods to minimise the potential bias, both throughout the systematic review and meta-analysis process, and also for the assessment of bias within the systematic review when evaluating included studies for potential bias.

\section{Risk of bias and quality assessment of included studies}

Bias is a form of systematic error that may cause underestimation or overestimation of the effect of an intervention (Higgins \& Altman, 2008). Clarity and transparency in the systematic review process, and specifically the method, is fundamental to the systematic review definition. When assessing included studies in the research process, there are several key sources of bias: sequence generation, allocation concealment, blinding, incomplete outcome data, and selective reporting (Higgins \& Altman).

Sequence generation reduces the chance of selection bias by a random process of allocation of participants to different interventions. This process is 
strengthened by allocation concealment, which prevents those involved in the trial having foreknowledge of the random allocations (Gluud, 2006; Schulz, 1995). Following enrolment, blinding of all personnel involved in the study, including both participants and ancillary study personnel, may ensure that all participants are exposed to similar conditions throughout the study period (Sackett, 2000; Schulz, Chalmers, \& Altman, 2002). This would reduce the potential for knowledge of the intervention, rather than the intervention itself, altering study outcomes (Higgins \& Altman, 2008). Both exclusions and attrition may contribute to a potential for bias related to incomplete outcome data within a study (Gluud, 2006). This may alter estimates related to the size of the effect. Selective reporting of the analyses within a study, particularly the likelihood of reporting statistically significant differences rather than nonsignificant differences, may also result in bias (Higgins \& Altman).

Further potential sources of bias may occur, and some of these are dependent on particular study designs. For example, in both systematic reviews and metaanalyses, there are possible publication biases related to positive findings of studies being more likely to be published than negative findings of studies (Egger \& Smith, 1995; Gluud, 2006). Published trials show an overall greater treatment effect than grey (not formally published) literature (Hopewell, McDonald, Clarke, \& Egger, 2007). The presence of publication bias can be assessed by a funnel plot (Bigby \& Williams, 2003), which graphically plots effect estimates against sample sizes to evaluate meta-analysis validity (Egger et al., 1997). However, this is not considered reliable for a meta-analysis based on a limited number of small trials (Egger et al., 1997). In identifying studies for a review, a combination of hand searching and electronic database searching is the most comprehensive method (Hopewell et al.). However, Hopewell et al. note that where time and resources are limited, electronic searching identifies the majority of published trials.

With the potential for bias within both a systematic review and a meta-analysis, minimising risk is important (Cook et al., 1997). In order to identify the risk of bias within a study, several critical appraisal tools have been highlighted in the literature. 


\section{Critical appraisal and levels of evidence}

\section{Critical appraisal tools}

One critical appraisal tool available to facilitate appraisal of the quality of studies is the Cochrane Collaboration guide (Higgins \& Altman, 2008). This tool recommends the assessment of several areas specifically related to: allocation; blinding; follow-up and exclusions; selective reporting; and other potential sources of bias. This assessment tool outlines the framework for assessing the risk of bias (see Appendix 2). A further framework for critical appraisal is that of the 'Strengthening the Reporting of Observational Studies in Epidemiology' (STROBE) guide (von Elm et al., 2007), which provides a checklist of items that should be addressed in reports of observational studies (see Appendix 3). Using these critical appraisal checklists facilitates a structured approach to the quality assessment of the studies included in a systematic review.

However, Moher et al. (1995) have investigated checklists and scales that assist in the assessing and reporting of randomised controlled trials, and found several shortcomings in aspects related to the design and conduct of trials. Jadad et al. (1996) describe the development of a tool to assess randomised controlled trials for quality, and the impact of rater blinding on the quality assessment. Within the Jadad et al. study blinded assessments of randomised controlled trials were significantly lower and more consistent than open assessments. One implication of this is that a blinded approach to appraisal of the included studies would enhance consistency and minimise potential bias, should this be feasible. 


\section{Assigning levels of evidence}

Following the critical appraisal of a study, it may be possible to assign a level of evidence to the research. One example of an approach to the assignation of a level of evidence is the 'Grades of Recommendation, Assessment, Development and Evaluation' (GRADE), (see Appendix 4). Assigning a level of evidence to a study may facilitate identifying the quality and strength of the research methods used (Melnyk, 2004). The Cochrane Collaboration (Reeves, Deeks, Higgins, \& Wells, 2008) outline the GRADE approach to guide appropriation of a level of quality to a body of evidence (see Appendix 4).

\section{Data analysis and synthesis}

Either a statistical or narrative structure may be used to analyse the study characteristics and findings of a systematic review (Deeks, Higgins, \& Altman, 2008). It is generally recommended that data and analyses within a Cochrane review are reported in the form of outcome data, forest plots and meta-analysis of the results (Schunemann et al., 2008). Should the data not be sufficiently suitable for a meta-analysis, a subjective narrative assessment of the data may be made. This assessment would draw from the data extraction, summarising study characteristics and data related to specified outcomes in the form of a narrative. Within a meta-analysis, it is essential to assess for homogeneity of the studies. Homogeneity is defined as the similarity of studies with respect to study methods, samples, interventions and levels of quality (Acton, 2001). It is likely that there will be some variation between studies, and this is referred to as heterogeneity (Acton). Evaluating and ensuring a high level of clinical, methodological and statistical homogeneity are fundamental to the validity of a meta-analysis (Deeks et al., 2008).

Deeks et al (2008) have outlined criteria to assess sources of potential heterogeneity. They suggest assessing for clinical heterogeneity by considering the specific interventions and patient characteristics. If the studies are clinically 
homogenous, methodological heterogeneity may be determined by considering the use of blinding, allocation concealment, and outcome measures. Should the studies be both clinically and methodologically homogenous, statistical heterogeneity may be determined by assessment of outcome measures with subgroup or sensitivity analyses using the chi-squared test, which would be included in forest plots (Deeks et al.). This test would measure whether identified differences in results could be attributable to chance alone. Inconsistency may be measured using I-squared $\left(\mathrm{I}^{2}\right)$ to identify whether variability in effect may be due to heterogeneity or purely chance (Deeks et al.). Should data from randomised controlled trials be of sufficient quality and generalisability, these may be combined in a meta-analysis to provide a pooled effect estimate. Whether a meta-analysis is possible or not, a systematic, consistent, and ordered approach to presenting the data should be adopted. This may include comparisons and outcomes specified in the protocol, or alternatively a summary of findings table (Schunemann et al., 2008).

This methodology chapter has discussed the rationale for using the systematic review with a meta-analysis in the context of evidence-based practice. The Cochrane Collaboration systematic review methodology has been presented as a way to systematically identify, appraise, and report available evidence in order to answer the research questions. The process of conducting a systematic review has been outlined, from the formulation of the research question and the search strategy, through to the data collection and analysis, and finally to the presentation of the results. A discussion of potential sources of bias, and the critical appraisal tools available to assess for the risk of bias, have been provided. The method chapter will now apply this methodology to the research question, in order to develop a process for this systematic review to identify, appraise and report the evidence that is available to inform the research objectives. 


\section{CHAPTER 4 METHOD}

The methodology chapter has placed the systematic review and a meta-analysis within the context of developing evidence-based practice. The Cochrane Collaboration methodology of a systematic review with a meta-analysis has been described as the framework for this research project. The rigorous methodology of the Cochrane Collaboration systematic review was proposed as a framework to provide structure, rigour, and clarity to this systematic review. This method chapter defines the criteria for considering the studies for this review, including the types of studies, participants, interventions, and outcome measures eligible for inclusion. The search method is described for identification of the studies, and the method of data collection and analysis are outlined. Variation from the methods outlined in the protocol is discussed.

This systematic review was conducted in order to investigate gastric residual volume management in the gastrically fed adult ICU patient. This related specifically to the primary outcome measures indicative of: accepting a specified GRV that is too high, and hence placing the patient at risk of vomiting, regurgitation, aspiration of gastric contents and potentially aspiration pneumonia; or accepting a specified GRV that is too low, and hence not achieving caloric needs, potentially placing the patient at risk of malnutrition and increased morbidity.

\section{Criteria for considering studies for this review}

The criteria for considering studies for this review relate to the types of studies, participants, interventions and outcome measures. 


\section{Types of studies}

Four types of studies were eligible for inclusion: randomised controlled trials with random or quasi-random allocation of subjects to intervention and control groups; case controlled studies; cohort studies; and observational studies.

\section{Types of participants}

Included were studies of participants aged 16 years or over, in the critical care or intensive care unit, and delivered enteral nutrition by a nasogastric, orogastric, or percutaneous endoscopic gastrostomy tube.

\section{Types of interventions}

Studies which compared two or more GRVs were included.

\section{Types of outcome measures}

Primary outcomes eligible for inclusion were caloric requirements met, and/or adverse events including vomiting (or emesis), regurgitation, and/or aspiration.

\section{Search methods for identification of studies}

The databases searched included: The Cochrane Library; CINAHL Plus with Full Text (EBSCO host via helicon); AMED, Ovid Nursing Full Text plus, EMBASE, CDSR, ACP Journal Club, DARE, CCTR, CLCMR, CLTA, CLEED, OVID MEDLINE (R) (Ovid SP); Proquest via helicon (advanced search); Pubmed via helicon (limits "all adult", "humans", "abstract", "title"); and all EBM reviews. The key search terms included: 'gastric residual', 'gastric aspirate', or 'residual volume'; 'enteral nutrition', 'gastric feeding', 'nutrition' or 'tube feeding'; and 'intensive care', 'ICU' or 'critically ill'. In 
alignment with the clinical research question, the search was limited to research published within the time period of 1998-2008.

\section{Searching other resources}

Parenteral and enteral nutrition association websites including: American Society for Parenteral and Enteral Nutrition (ASPEN), Australian Society for Parenteral and Enteral Nutrition (AUSPEN), European Society for Parenteral and Enteral Nutrition (ESPEN), British Association of Parenteral and Enteral Nutrition (BAPEN), Canadian Parenteral and Enteral Nutrition Association, and the South African Society for Parenteral and Enteral Nutrition, were also searched. Critical care websites searched included the Joint Faculty of Intensive Care Medicine (JFICM) and the European Society of Intensive Care Medicine (ESICM). The computer search was supplemented by citation and author review of the articles selected and search of the grey literature. These were searched for further relevant literature.

\section{Data extraction and analysis}

\section{Selection of studies}

In accordance with the defined inclusion criteria in the protocol (see Appendix 1), titles and abstracts were reviewed by the author for relevance to the inclusion criteria. For any uncertainty related to acceptability of the study, the full text of the citation was obtained for further evaluation. Following this title and abstract review by the author, all primary studies identified in the title and abstract review that would potentially meet the inclusion criteria were obtained in full-text or portable document format (PDF). The full-text studies or PDFs were then reviewed against the inclusion criteria. Justification for excluding studies at this stage was documented. The numerical data from this process was entered into the PRISMA flow diagram (Moher et al., 2009). Any doubt related 
to inclusion of a study was discussed with the researcher's principal research supervisor. There were no disagreements in study eligibility.

\section{Data extraction}

A data extraction form was developed by this author for the review which provided a tool to collect data from each of the included studies (see Appendix 5). The data extracted by the author comprised of: study design; types of participants, interventions, and outcome measures; sample size; participant demographics; methods; and reported outcomes.

\section{Assessment of methodological quality of included studies}

Included studies were assessed by the author for methodological quality using the applicable risk of bias assessment tools. The prospective study (McClave et al., 2005) and the randomised controlled trial (Pinilla et al., 2001) were assessed using the risk of bias assessment tool (see Appendix 2), and the observational study (Metheny et al., 2008) was assessed using the risk of bias assessment tool for a descriptive observational study (see Appendix 3). A level of evidence (GRADE) was evaluated and entered onto the data collection form by the author.

\section{Data analysis and synthesis}

Sources of potential heterogeneity were assessed according to the criteria outlined by Deeks et al. (2008). Firstly, clinical heterogeneity was assessed by considering the specific interventions and patient characteristics. No studies were clinically homogenous hence a meta-analysis was not conducted. As there were fewer than ten studies, publication bias was not assessed. No missing data was identified in the three included studies. As the data is not eligible for metaanalysis, and is too disparate for a summary of findings table, the raw data is presented from each included study as a narrative summary. 
This chapter has provided the search strategy for the identification of studies. The process of study selection, related to the criteria for inclusion, has been described. The method of data extraction was presented, followed by a description of the evaluation of risk of bias for the included studies. The data analysis and synthesis related to assessment of heterogeneity and the rationale for a narrative summary is provided. The results of the systematic review will now be presented. 


\section{CHAPTER 5 RESULTS}

The previous chapter outlined the method for this systematic review, clarifying variations from the methodology of a Cochrane systematic review or protocol. This chapter presents the results of the systematic review. The search terms and numbers of studies retrieved are presented. This is followed by a description of the studies, including the characteristics of both the included and excluded studies. The included studies are then reviewed with respect to study methodologies, participants and settings. Risk of bias is analysed using relevant bias risk analysis tools. The effects of comparative GRVs from the studies is described, particularly addressing outcome measures, which included caloric requirements met and the adverse events (vomiting or emesis, regurgitation, and aspiration).

\section{Results of the search}

\section{Included studies}

The total number of search result hits was 1446 (see Appendix 6). Of these, the title and abstract review identified 18 studies as requiring full text review. Of these 18 studies, four were clinical trials, seven were case-controlled studies, and seven were cohort studies. Three of these studies were eligible for inclusion in this review; one prospective study (McClave et al., 2005), one prospective observational study (Metheny et al., 2008), and one randomised controlled trial (Pinilla et al., 2005). Of these three studies, one sought to validate the use of an elevated GRV as a marker for risk of aspiration and consequently regulation of the delivery of enteral tube feeding (McClave et al., 2005). The second study compared gastrointestinal tolerance using two different enteral feeding protocols in critically ill patients (Pinilla et al., 2001). The third study described the association between GRV and aspiration of gastric contents in a group of critically ill patients receiving gastric tube feedings (Metheny et al., 2008). The numerical data from this process of 
inclusion and exclusion is illustrated in the PRISMA flow diagram shown in Figure 1.



1446 records identified through database searching

0 additional records identified through other sources

1446 records after duplicates removed qualitative synthesis

$\frac{0}{0}$

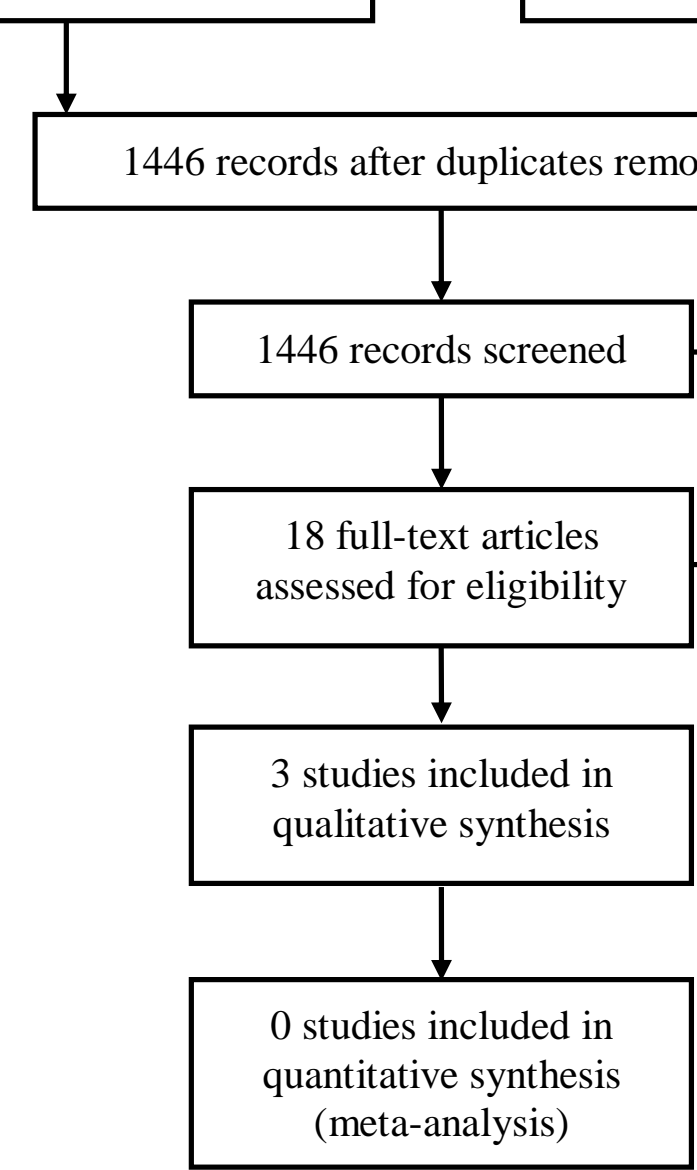

15 full-text articles excluded

Figure 1. Prisma flow diagram (adapted from Moher et al., 2009) 
The characteristics of the three included studies (McClave et al., 2005; Metheny et al., 2008; Pinilla et al., 2001) are summarised and shown in Table 2.

Table 2. Characteristics of included studies

\begin{tabular}{|c|c|c|c|c|}
\hline Study & Methods & Participants & Intervention & Outcome measures \\
\hline $\begin{array}{l}\text { McClave } \\
\text { et al. } \\
(2005)\end{array}$ & $\begin{array}{l}\text { Prospective } \\
\text { study }\end{array}$ & $\begin{array}{l}\mathrm{n}=40 \\
\text { Demographics: } \\
\text { mean age } 45 \mathrm{yrs}, \\
70 \% \text { men. } \\
\text { No sample size } \\
\text { calculations } \\
\text { reported. }\end{array}$ & $\begin{array}{l}\text { Comparison of two } \\
\text { groups: } \\
\text { 1. Study group: } \\
\text { GRV > 400mL. } \\
\text { 2. } \quad \text { Control group: } \\
\text { GRV > 200mL. }\end{array}$ & $\begin{array}{l}\text { 1. Caloric goals met. } \\
\text { 2. Regurgitation or } \\
\text { aspiration. } \\
\text { 3. Development of } \\
\text { new suspected or } \\
\text { definitive } \\
\text { pneumonia. }\end{array}$ \\
\hline $\begin{array}{l}\text { Pinilla et } \\
\text { al. (2001) }\end{array}$ & $\begin{array}{l}\text { Randomised } \\
\text { controlled } \\
\text { trial }\end{array}$ & $\begin{array}{l}\mathrm{n}=80 \\
\text { Demographics: } \\
\text { mean age } 53 \mathrm{yrs} \text {, } \\
55 \% \text { men. } \\
\text { The sample size } \\
\text { was calculated } \\
\text { using a power of } \\
80 \% \text {. }\end{array}$ & $\begin{array}{l}\text { Comparison of two } \\
\text { groups: } \\
\text { 1. Group 1: } \\
\text { GRV 150mL } \\
\text { with an optional } \\
\text { prokinetic. } \\
\text { 2. Group 2: } \\
\text { GRV 250mL } \\
\text { with a mandatory } \\
\text { prokinetic. }\end{array}$ & $\begin{array}{ll}\text { 1. } & \text { High GRV } \\
& (\geq 150 \mathrm{~mL}) . \\
\text { 2. } & \text { Emesis. } \\
\text { 3. } & \text { Days of diarrhoea. } \\
\text { 4. } & \text { Total intolerance } \\
\text { episodes. } \\
\text { 5. Time to reach goal } \\
\text { rate. } \\
\text { 6. Nutritional } \\
\text { requirement met. } \\
\text { 7. Reasons enteral } \\
\text { nutrition stopped } \\
\text { or reduced. }\end{array}$ \\
\hline $\begin{array}{l}\text { Metheny } \\
\text { et al. } \\
\text { (2008) }\end{array}$ & $\begin{array}{l}\text { Prospective } \\
\text { observational } \\
\text { study }\end{array}$ & $\begin{array}{l}\mathrm{n}=206 \\
\text { Demographics: } \\
\text { mean age } 52 \mathrm{yrs}, \\
61 \% \text { men. } \\
\text { No sample size } \\
\text { calculations } \\
\text { reported. }\end{array}$ & Non-interventional. & $\begin{array}{l}\text { 1. Pepsin assay to } \\
\text { assess for } \\
\text { aspiration. } \\
\text { 2. Frequency of high } \\
\text { GRVs. } \\
\text { 3. Frequency of } \\
\text { vomiting. }\end{array}$ \\
\hline
\end{tabular}

\section{Excluded studies}

Fifteen studies did not meet inclusion criteria and were excluded. These studies were a combination of both interventional and non-interventional studies. Exclusion of these studies was due to lack of separate analysis of the impact of 
variable GRVs. An indepth description of the characteristics of the excluded studies was conducted (see Appendix 7), and the reasons for exclusion are shown in Table 3.

Table 3. Excluded studies

\begin{tabular}{|c|c|}
\hline Study & Reason for exclusion \\
\hline Bochicchio et al. (2006) & No analysis of a comparison of two or more GRVs \\
\hline Davies et al. (2002) & No analysis of a comparison of two or more GRVs \\
\hline Desachy et al. (2008) & No analysis of a comparison of two or more GRVs \\
\hline $\begin{array}{l}\text { Elpern, Stutz, Peterson, } \\
\text { Gurka, \& Skipper (2004) }\end{array}$ & No analysis of a comparison of two or more GRVs \\
\hline $\begin{array}{l}\text { Esparza, Boivin, } \\
\text { Hartshorne, \& Levy } \\
(2001)\end{array}$ & No analysis of a comparison of two or more GRVs \\
\hline Fiaccadori et al. (2004) & No analysis of a comparison of two or more GRVs \\
\hline Kearns et al. (2000) & No analysis of a comparison of two or more GRVs \\
\hline Kompan et al. (2004) & No analysis of a comparison of two or more GRVs \\
\hline $\begin{array}{l}\text { Kortbeek, Haigh, \& } \\
\text { Doig (1999) }\end{array}$ & No analysis of a comparison of two or more GRVs \\
\hline McClave et al. (1999) & No analysis of a comparison of two or more GRVs \\
\hline Mentec et al. (2001) & No analysis of a comparison of two or more GRVs \\
\hline Montejo (1999) & No analysis of a comparison of two or more GRVs \\
\hline Montejo et al. (2002) & No analysis of a comparison of two or more GRVs \\
\hline $\begin{array}{l}\text { Neumann \& DeLegge } \\
\text { (2002) }\end{array}$ & No analysis of a comparison of two or more GRVs \\
\hline $\begin{array}{l}\text { Taylor, Fettes, Jewkes, } \\
\text { \& Nelson (1999) }\end{array}$ & No analysis of a comparison of two or more GRVs \\
\hline
\end{tabular}




\section{Description of included studies}

\section{Participants and setting}

Two of the studies were set in the USA (McClave et al., 2005; Metheny et al., 2008) and one in Canada (Pinilla et al., 2001). The total number of participants across all three studies was 326. Sample sizes varied from 40 participants (McClave et al.) to 206 participants (Metheny et al.). Mean age across the three studies was 48 years (range 18-88 years). The participants of McClave et al's study had the highest mean age of all groups (54.4 years, range 18-72 years). Mean percentage of men across the three studies was higher than women (62\%). Admitting diagnoses of participants varied between studies. The predominant diagnoses in each study were: medical (Pinilla et al); trauma and surgery, with a large proportion of participants having head injuries and cranial neurosurgical conditions (Metheny et al); and trauma, with a large proportion of participants having a closed head injury (McClave et al).

Intubation of participants was a requirement for inclusion in both McClave et al.'s (2005) and Metheny et al.'s (2008) studies, but was not specified for Pinilla et al.'s (2001) study. Pinilla et al.'s participants were $\geq 16$ years of age, whereas McClave et al.'s and Metheny et al.'s participants were $\geq 18$ years of age. McClave et al.'s participants had a mean acute physiology and chronic health evaluation (APACHE) III score of 41, and Metheny et al's participants had a mean APACHE score of 23. Pinilla et al's participants had a mean multiple organ dysfunction syndrome (MODS) score of 8 , a simplified acute physiology score (SAPS) II of 42-44, and a mean trauma injury severity score (TISS) of 41. Pinilla et al.'s participants only received gastric enteral nutrition via a nasogastric or orogastric tube, whereas Metheny et al. and McClave et al. included participants receiving either nasogastric or percutaneous endoscopic gastrostomy tube delivered enteral nutrition. 


\section{Comparisons of interventions}

McClave et al.'s (2005) study compared a GRV > 400mL, which involved enteral nutrition being withheld until the GRV was $<400 \mathrm{~mL}$, with a GRV > 200mL which involved enteral nutrition being withheld until the GRV was < 200mL. Pinilla et al.'s (2001) compared a GRV of $150 \mathrm{~mL}$ and an optional prokinetic, with a GRV of $250 \mathrm{~mL}$ and a mandatory prokinetic. Metheny et al's (2008) study was non-interventional, but compared three overlapping groups, a GRV of at least $150 \mathrm{~mL}$, a GRV of at least $200 \mathrm{~mL}$, and a GRV of at least $250 \mathrm{~mL}$.

\section{Outcome measures}

McClave et al.'s (2005) outcome measures included the participant's caloric intake divided by goal calories, the presence of yellow microscopic colorimetric microspheres and/or blue food colouring in the patient's oropharynx (deemed by the authors as reflecting regurgitation) or trachea (deemed by the authors as reflecting aspiration), and the development of newly suspected or definitive pneumonia. Pinilla et al.'s (2001) outcome measures included high GRV, emesis, days of diarrhoea, total intolerance episodes (intolerance was defined by these authors as emesis, high GRV, or diarrhoea), time to reach goal rate, percentage of nutritional requirements received by patients, and other reasons enteral nutrition was decreased or interrupted. Metheny et al's (2008) outcome measures were a pepsin assay to assess for aspiration, the frequency of high GRVs, and the frequency of vomiting. These are depicted in the characteristics of included studies (see Table 2).

\section{Risk of bias in included studies}

The methodological quality of the prospective study, the randomised controlled trial, and the prospective observational study was assessed by two different bias risk analysis tools, appropriate for their differing study methodologies. 


\section{Analysis of the prospective study and the randomised controlled trial}

Both the prospective study and the randomised controlled trial were analysed for their potential risk of bias using Cochrane's handbook for systematic review of interventions (Higgins \& Altman, 2008), (see Appendix 8). In McClave et al.'s (2005) study, the adequacy of sequence generation and allocation concealment was unclear due to the process of randomisation not being described. There was no blinding in the study, no incomplete data identified, no indication of selective reporting, nor any other potential risks of bias identified. The overall level of quality using the GRADE approach (Reeves et al., 2008) was identified, by the systematic review author, as moderate.

Pinilla et al.'s (2001) study clearly described adequate sequence generation and allocation concealment, however there was no blinding of groups. No incomplete data was identified, nor any indication of selective reporting, or any other potential risks of bias identified. The overall level of quality using the GRADE approach (Reeves et al., 2008) was identified, by the systematic review author, as moderate.

\section{Analysis of the prospective observational study}

Metheny et al.'s (2008) study was analysed for the potential risk of bias using the STROBE guideline (von Elm et al., 2007), (see Appendix 9). Metheny et al.'s study identified a clear design with an informative and balanced abstract. The scientific background and rationale for their study was presented clearly and objectives specified. The key elements of their study design were presented early alongside the setting, location, and data collection. Outcome measures were identified, including a description of the methods of measurement. Potential sources of bias were considered, although there was no discussion as to the calculation of the study size. Statistical methods were described, and outcome measures were discussed. The key results were summarised and 
limitations of the study were considered. However, there was no discussion of generalisability of the results of the study by the authors. The overall level of quality using the GRADE approach (Reeves et al., 2008) was identified, by the systematic review author, as low.

\section{Effects of comparisons of interventions}

\section{Caloric requirements}

\section{Percentage of goal calories infused}

The percentage of calories met in McClave et al.'s (2005) study and Pinilla et al.'s (2001) study are provided in Table 4. McClave et al. found no significant difference in the percentage of calories infused between the two groups, however they identified that only $5 \%(\mathrm{n}=1118)$ of GRV were $>200 \mathrm{~mL}$ so it was possible that the small difference in calories may have been attributable to the small difference in GRV. The control group's (200mL GRV) percentage of calories infused was $77 \% \pm 21 \%$, and the study group's $(400 \mathrm{~mL}$ GRV) percentage of calories infused was $78 \% \pm 33 \%$. This difference was not significant $(p=0.927)$.

Table 4. Caloric requirements met

\begin{tabular}{|c|c|c|c|c|}
\hline \multirow{2}{*}{ Author } & \multicolumn{4}{|c|}{ GRV } \\
\hline & $150 \mathrm{~mL}$ & $200 \mathrm{~mL}$ & $250 \mathrm{~mL}$ & $400 \mathrm{~mL}$ \\
\hline $\begin{array}{l}\text { (McClave et } \\
\text { al., 2005) }\end{array}$ & & $77 \% \pm 21 \%$ & & $78 \% \pm 33 \%$ \\
\hline $\begin{array}{l}\text { (Pinilla et al., } \\
\text { 2001) }\end{array}$ & $70 \% \pm 25 \%$ & & $76 \% \pm 18 \%$ & \\
\hline
\end{tabular}




\section{Percentage of nutritional requirements received}

Pinilla et al. (2001) found a significant difference between groups in the percentage of nutritional requirements received, however the use of metoclopramide and other antibiotics was significantly different between groups, so it was possible that the difference in nutritional requirements received may have been attributable to these variables. Group 1's (GRV $150 \mathrm{~mL}$, optional prokinetic) percentage of nutritional requirements received was $70 \% \pm 25 \%$, and Group 2's (GRV 250mL, mandatory prokinetic) percentage of nutritional requirements received was $76 \% \pm 18 \%, p<0.02$.

\section{Adverse Events}

\section{Vomiting or emesis}

In Metheny et al.'s (2008) study, 7\% $(\mathrm{n}=206)$ of all patients vomited during the 3-day study period. The percentage of patients who vomited was not discussed in relation to GRV or aspiration. Pinilla et al. (2001) analysed emesis by both by the number of patients and by the number of events. Pinilla et al. found no significant difference between both groups for either number of events or number of patients. Analysis of vomiting by the number of patients found that: Group 1 (GRV 150mL, optional prokinetic) $=2 / 36$ patients vomited, and Group 2 (GRV 250mL, mandatory prokinetic) = 3/44 (NS) patients vomited. Analysis of vomiting by the number of events found that: Group 1 (GRV 150mL, optional prokinetic) = 2 events of vomiting occurred, and Group $2($ GRV 250mL, mandatory prokinetic $)=4(\mathrm{NS})$ events of vomiting occurred.

\section{Regurgitation}

McClave et al. (2005) identified that the percentage of positive regurgitation between groups was not significant, the control group (200mL GRV) was $35 \%$ 
$\pm 27 \%$ and the study group $(400 \mathrm{~mL}$ GRV) was $28 \% \pm 25 \%, p=0.396$. However a Tukey test (which compares means from a factor in which all levels have equal $n$ in post-hoc analysis, Heiman, 1992), demonstrated there was a significant difference in the percent positive regurgitation between PEG and NG 12-Fr tubes $(p=0.046)$.

\section{Frequency of aspiration}

Metheny et al.'s (2008) study assayed a total of 3203 tracheal secretions for the presence of pepsin. The mean percentage of tracheal secretions positive for pepsin was $36 \% \pm 25 \%$. Of the 206 patients, $93 \%$ had at least one tracheal secretion positive for pepsin. Metheny et al. then categorised the patients according to the frequency of aspiration. They categorised infrequent aspirators $(n=117)$ as patients whose secretions were positive for pepsin in fewer than $40 \%$ of observations (median percentage of pepsin-positive tracheal secretions was $19 \%)$. Frequent aspirators $(n=89)$ were defined as patients whose secretions were positive for pepsin in $40 \%$ or more observations (median percentage of pepsin-positive tracheal secretions was 54\%).

Metheny et al. (2008) then identified what they considered to be high GRVs. A total of $3286 \mathrm{GRVs}$ were measured. The mean of these GRVs was $37 \mathrm{~mL} \pm$ $37 \mathrm{~mL}$. High GRVs were categorised into three groups including: at least $150 \mathrm{~mL}$, and $73 \%(\mathrm{n}=81)$ of these were in large-bore tubes; at least $200 \mathrm{~mL}$, and $75 \%(\mathrm{n}=$ not provided $)$ of these were in large-bore tubes; and at least $250 \mathrm{~mL}$, and $80 \%$ ( $\mathrm{n}=$ not provided) of these were in large-bore tubes. The remainder of the high GRVs were in patients with small-bore tubes. Metheny et al. found that $69 / 81$ patients with one or more GRV of at least $150 \mathrm{~mL}$ had been enrolled in the study within 24 hours of the start of feeding $(P=0.008)$. Metheny et al. assessed the relationship between aspiration and GRV and found that: the percentage of secretions indicating aspiration that occurred when GRVs were between 0 and $50 \mathrm{~mL}$ was $34 \%(\mathrm{n}=3286$ aspirates); and the percentage of aspiration increased as GRVs increased $(F=7.7, P<0.001$, where $F=$ frequency). 
McClave et al. (2005) also identified a percentage of positive aspiration; however this was not significant between groups. The control group $(200 \mathrm{~mL}$ GRV) was $22 \% \pm 26 \%$, and the study group (400mL GRV) was $23 \% \pm 25 \%, p$ $=0.903$. McClave et al. evaluated regurgitation and aspiration events related to an aspiration risk score. The authors based this aspiration risk score on previous studies in the literature to evaluate the risk for aspiration. McClave et al. found no correlation of aspiration risk score with either regurgitation events $(p=0.320)$, or aspiration $(p=0.910)$.

\section{Total intolerance episodes}

Pinilla et al. (2001) evaluated the total number of intolerance episodes, both by patient and by events, and there was no significant difference between groups of intolerance episodes by either patient or events. Pinilla et al. found that when intolerance episodes were evaluated by patient, Group 1 (GRV 150mL, optional prokinetic $)=21$, and Group $2($ GRV $250 \mathrm{~mL}$, mandatory prokinetic $)=$ 20 (NS). When intolerance episodes were evaluated by events, Group 1 (GRV $150 \mathrm{~mL}$, optional prokinetic) $=49$, and Group 2 (GRV 250mL, mandatory prokinetic $)=38(\mathrm{NS})$.

\section{Meta-analysis feasibility for comparisons}

This systematic review intended to include a meta-analysis of the identified results. There was a large void in primary research specifically answering the identified question. None of the three included studies were clinically homogenous; hence a meta-analysis was not feasible. As there were just three included studies, the possibility of publication bias assessment with funnel plots was also eliminated.

The results chapter provided a description of the characteristics of the included studies. This particularly focused on the participants and setting, the interventions and comparisons, and outcome measures. Excluded studies were identified and the reasons for exclusion were provided. The three included 
studies were analysed for their risk of bias. McClave et al. (2005) and Pinilla et al. (2001) were analysed using the framework of Higgins and Altman (2008), and Metheny et al. (2008) was analysed using the STROBE statement as a guide (von Elm et al., 2007). Each of the systematic reviews outcome measures, including caloric requirements met, and the potential adverse events, were addressed when identifying the effects of the interventions, which compared GRVs, in each of the studies. These will be considered further in the discussion. 


\section{CHAPTER 6 DISCUSSION}

The previous chapter presented the results of the systematic review. The main findings were the identification of three studies related to the systematic review objectives, which met the inclusion criteria. The ensuing discussion addresses the main results of this systematic review in light of the identified outcome measures and related literature. The quality of evidence and the potential for bias within the systematic review is discussed. This is followed by a concluding statement related to the overall implications of the results for both nursing practice and future GRV research.

\section{Summary of main results}

The three studies included in the systematic review were McClave et al. (2005), Pinilla et al. (2001), and Metheny et al. (2008). Each of these studies contained methodological risks of bias and limitations related to their unique designs. The three studies included a prospective study (McClave et al.), a prospective descriptive study (Metheny et al.), and a randomised controlled trial (Pinilla et al.). The comparisons and the primary outcome measures of the systematic review are discussed individually.

\section{Comparisons}

Two of the studies compared two different GRVs. McClave et al. (2005) compared the GRV of $200 \mathrm{~mL}$ to the GRV of $400 \mathrm{~mL}$, and Pinilla et al. (2001) compared the GRV of $150 \mathrm{~mL}$ to the GRV of $250 \mathrm{~mL}$. Metheny et al.'s (2008) post hoc analysis compared three overlapping groups; a GRV of at least $150 \mathrm{~mL}$, a GRV of at least $200 \mathrm{~mL}$, and a GRV of at least $250 \mathrm{~mL}$. 


\section{Outcomes}

The outcome measures included caloric requirements met and adverse events. Adverse events included vomiting (or emesis), regurgitation, aspiration, and total intolerance episodes. These will now be discussed individually.

\section{Caloric requirements}

Accepting a higher GRV contributed to more calories received in one study (Pinilla et al., 2001) and no significant difference in calories received in another study (McClave et al., 2005). Pinilla et al. compared a GRV of $150 \mathrm{~mL}$ to $250 \mathrm{~mL}$, found a significant difference between groups in calories received, with the patients randomised to a higher accepted GRV group of $250 \mathrm{~mL}$ receiving more calories. However, the variable of an optional prokinetic in the GRV $150 \mathrm{~mL}$ group versus a mandatory prokinetic in the GRV 250mL group may have confounded these results. Despite more calories being received by patients when a higher GRV was accepted (Pinilla et al.), the methodological limitations to the study related to prokinetic use, reduce the potential significance and implications for clinical practice related to finding. McClave et al. compared a GRV of $200 \mathrm{~mL}$ to $400 \mathrm{~mL}$, and found no significant difference in the calories infused between groups. Of the GRVs, 5\% were > $200 \mathrm{~mL}$ hence, the lack of a significant difference in calories between groups may have been attributable to the small difference in GRVs measured.

\section{Adverse events}

\section{Vomiting or emesis}

Accepting a higher GRV did not significantly impact on the occurrences of vomiting in one study (Pinilla et al., 2001). Pinilla et al.'s study found no significant difference between the $150 \mathrm{~mL}$ GRV group or the $250 \mathrm{~mL}$ GRV 
group, both for the number of occurrences of vomiting and the number of patients who vomited (6\% \& 7\% respectively). Metheny et al.'s (2008) study, which evaluated vomiting among participants, found that $7 \%$ of all 206 patients vomited during the study period, however this was not discussed in relation to GRV. The potential implications for practice, related to there being no significant difference in the occurrence of vomiting when a higher GRV was accepted (Pinilla et al.), are limited by the variation in the use of prokinetics between groups.

\section{Regurgitation}

Accepting a higher GRV was not associated with a difference in the percentage of regurgitation in one study (McClave et al., 2005). McClave et al.'s study found no significant difference in the percentage of positive regurgitation between the two groups (200mL GRV compared to $400 \mathrm{~mL}$ GRV). However, their study did not clearly define group characteristics, with respect to PEG and NG tube, and with respect to group sample sizes. Thus, although their post hoc analysis identified a significant difference between the percentage of positive regurgitation between PEG and 12-Fr NG tubes, the impact of this was unclear with respect to either the $200 \mathrm{~mL}$ GRV or the $400 \mathrm{~mL}$ GRV groups. Thus, although their study found no significant difference in the percentage of positive regurgitation when accepting a higher GRV, the potential implications for clinical practice are limited by these confounding variables.

\section{Frequency of aspiration}

Accepting a higher GRV was associated with an increase in the percentage of aspiration in one study (Metheny et al., 2008), and was not associated with any difference in the percentage of aspiration in another study (McClave et al, 2005). Metheny et al.'s study found that $93 \%$ of the 206 participants had at least one tracheal secretion positive for pepsin. The authors deemed this a proxy for the aspiration of gastric contents. They then categorised participants according to the frequency of aspiration and assessed the relationship between 
GRV and aspiration. The result indicated that the percentage of aspiration increased as GRVs increased. Although one potential implication for clinical practice from this result may point to a higher risk of aspiration for higher GRVs, this study found that even participants in the GRV group between 0$50 \mathrm{~mL}$ had $34 \%$ positive pepsin assays (Metheny et al.). This result may demonstrate the high sensitivity of the pepsin test rather than the potential for an increased risk of complications with higher GRVs. McClave et al. also identified a percentage of positive aspiration, however this was not statistically significant between groups.

\section{Total intolerance episodes}

Accepting a higher GRV did not alter the occurrence of intolerance episodes in one study (Pinilla et al., 2001). Pinilla et al.'s study evaluated the total number of intolerance episodes both by participants experiencing intolerance and by the number of total events, between the group where the acceptable GRV was $150 \mathrm{~mL}$ and the group where the acceptable GRV was $250 \mathrm{~mL}$. This study found no significant difference between groups for either evaluation. The potential implications related to there being no significant difference in intolerance episodes when accepting the higher GRV is limited due to the variation in prokinetic use between groups within the study.

\section{Overall completeness and applicability of evidence}

Of critical relevance to this thesis, no one study, or a combination of studies, provided conclusive evidence to support the use of one particular GRV over another. It is essential to balance important benefits against important harms related to the use of one GRV over another, and this was one of the objectives of this systematic review. This would enable the delivery of optimal caloric intake by identifying the best evidentiary GRV, which would be balanced against the complications related to accepting a GRV either too high or too low. Of the three included studies, each contributed evidence towards one or more of the objectives of the review question. The quality of these studies, and 
the contribution of their evidence to the objectives of the review question, is discussed in the ensuing evaluation of the quality of the evidence. However, there was not sufficient evidence in any one study to address all of the objectives of the review. In the context of current practice, the results of this review may reflect the ongoing inconsistencies in the management of GRVs, as previously highlighted in the background chapter.

\section{Quality of the evidence}

The methodological quality of nutritional support trials in the critically ill patient population has been described as poor (Doig, Simpson, \& Delaney, 2005). Doig et al. identified and assessed 111 articles, regarded as primary nutritional support studies reporting clinically meaningful outcomes. They measured three domains related to quality: randomisation, blinding, and presence of data, and found the methodological quality of the nutritional support trials were significantly worse in all three domains when compared to the sepsis trials. What their study highlighted is closely associated with the findings in this systematic review. The questionable methodological quality of the studies identified in this systematic review limit the ability to formulate strong conclusions based on the results. A further potential methodological limitation to nutritional support studies, highlighted by Kreymann et al. (2006), is the varied use of the heterogeneous terms 'ICU patients' and 'critically ill patients'. As a result, where possible in this systematic review, disease severity scores (APACHE, TISS) have been highlighted in patient characteristics to facilitate identification of homogeneity of population groups.

\section{Internal validity}

Each study included in the systematic review is now assessed with respect to its internal validity. The body of evidence identified in this systematic review does not allow a robust conclusion to be made regarding the objectives of this review. Three studies were included in the systematic review; one prospective study, one prospective descriptive study, and one randomised controlled trial. 
Each study had methodological limitations which increased their risk of bias, and the lack of homogeneity between studies removed the possibility of comparison.

\section{McClave et al. (2005)}

McClave et al.'s (2005) study was dependent on physician and primary care team decision making in the enteral nutrition management. During their study, the decision to stop enteral nutrition was based on concern for aspiration. This decision may have been as a result of observed vomiting/regurgitation, increasing abdominal discomfort, findings of increased abdominal distension, or the development of hypoactive-to-absent bowel sounds on physical examination. The decision was discretional to attending physicians and the primary care team. This dependence on subjective decision making processes of clinicians, rather than a standardised process, reduced the internal validity of the study.

The potential for discord in physicians practice, regarding the management of enteral nutrition, has been highlighted in other research, for example Behara et al. (2008). Behara et al. conducted a survey of attending physician's ratings related to their weighting of the importance of nutrition, their comfort level with nutrition support, and their understanding of nutrition support in critically ill patients. They found considerable differences in both perception and practice of individual physicians related to initiation and management of nutrition in the ICU patient population.

A further limitation to McClave et al.'s (2005) study was the lack of blinding within the study. Although it may not have been possible or appropriate for McClave et al.'s study, there remains the possibility of bias as there was still the potential for MDT members to treat groups differently. Chalmers et al. (1981) suggest ideally quadruple blinding (randomisation, physicians, patients, ongoing results) to enhance randomised controlled trial quality. Furthermore, it is possible that the applicability of the study may be compromised due to the 
large percentage of the participants in McClave et al.'s study having a closed head injury. This group of patients have been previously studied and identified as having a high probability of feeding intolerance (e.g., Bochicchio et al., 2006). This prospective study of 57 consecutively admitted severely traumatic brain-injured patients primarily demonstrated that severely traumatic braininjured patients in an induced barbiturate coma have significantly poor tolerance of enteral nutrition.

A further limitation in McClave et al.'s (2005) study was related to the differing tube feeding properties, such as PEG or NGT, or small bore versus large bore. The variability in GRVs aspirated from small bore compared to large bore NG tubes has been identified in previous research (Metheny et al., 2005). Also, McClave et al.'s participants were more likely to receive an early tracheostomy, which may have required the use of neuromuscular blockade. The use of a neuromuscular blockade may influence the participants ability to tolerate enteral nutrition (Tamion et al., 2003). In McClave et al.'s study, the percentage of positive regurgitation difference between PEG vs NGT was statistically significant, with the percentage of regurgitation in those participants with a NGT being greater. However the number of patients percutaneously fed with positive regurgitation, compared with those nasogastrically fed in each group, was not clearly defined. The lack of clarity in group characteristics limits the interpretation of the results related to GRVs and their relationship to aspiration. It would have been beneficial for McClave et al.'s study to have reported the number and tube type in each group to ascertain if this possible difference would have impacted on the results. More information related to the aspiration risk and bowel function scores, of which allocation was weighted arbitrarily, would have reduced questions related to both the interpretation and validity of McClave et al.'s results.

The tube feeding initiation process, which is described by McClave et al. (2005) as either rapid start-up or stepwise progression (start $25 \mathrm{~mL} / \mathrm{hr}$, increase by $25 \mathrm{~mL} / \mathrm{hr}$ every eight hours until goal rate) was not adequately described or analysed, particularly between group differences related to the process of rapid or stepwise initiation. The addition of this information would have confirmed if 
groups were treated differently. A disadvantage of the assessment of quality processes in reports of studies is that the assessment is largely dependent on the information made available in reports. Jadad et al. (1996) highlighted that in a quality assessment, despite a trial being methodologically sound, it may be deficient due to space constraints in printed journals. The impact of this may result in the authors referring to previous publications for details of trial methods. This aspect was apparent in McClave et al.'s study, where they referred to a description and the validation of the aspiration risk and bowel function scores within previous research, but did not detail this in their report.

Another point to consider regarding McClave et al.'s (2005) study was that their small, apparently uncalculated, sample size resulted in several GRVs being collected on the same patients. Had this been attended to in the method, whereby each participant would have had the same number of GRV collected both within and between groups, these results could have been used in the analysis. However, this was not sufficiently clarified, and thus it remains unclear if the use of several GRVs being collected on the same patients may have skewed the results. In aiding the replicability of their study, a discussion of exactly how, and by whom, the GRVs were measured would have been beneficial. It is likely that different members of the MDT and different clinicians may conduct the aspiration of gastric contents procedure differently.

To summarise, McClave et al.'s (2005) study highlighted that changing the acceptable GRV from $200 \mathrm{~mL}$ to $400 \mathrm{~mL}$ made no difference in the frequency of aspiration. However, because of uncertainties related to sample size and characteristics (i.e., the large proportion of head injured patients and the proportion of PEG delivered enteral nutrition in each group), and the potential impact of early tracheostomy (and possible neuromuscular blockade), it would not be possible to change current practice related to these findings alone. 


\section{Pinilla et al. (2001)}

Pinilla et al.'s (2001) study also contained methodological uncertainties. Pinilla et al. used a mandatory prokinetic in one group, and an optional prokinetic in the other. The different use of a prokinetic may have confounded these results related to: GRVs, nutritional requirements received, and total number of intolerance episodes. Reasons for cessation or reduction of feedings extracted from ICU flow sheets, progress notes, physicians' orders, and radiology reports, means that there is a reliance on staff completing the documentation. Recent research has identified that documentation from these sources may be both inadequate and variable (Saranto \& Kinnunen, 2009). Similar to McClave et al.'s (2005) study, there was no blinding within the study. Blinding of subjects is unlikely to have been possible due to nurses and clinicians being required to carry out the GRV assessment and management. Although blinding is not always possible, there is a potential bias effect; for example, the clinician reviewing the GRV being more vigilant in one particular group compared to another.

Although Pinilla et al. (2001) found patients had improved tolerance to enteral nutrition where a mandatory prokinetic and a higher GRV of $250 \mathrm{~mL}$ was used (compared with $150 \mathrm{~mL}$ and an optional prokinetic), several factors, outlined below, impact on using this information to inform the systematic review question. They sought to compare gastrointestinal tolerance of two enteral feeding protocols in critically ill patients, however added two variables - a change in accepted GRV and also a mandatory versus an optional prokinetic. It is unclear if the statistical analysis enabled adequate comparison of the two groups, minimising the potential for the two variables to confound the study's results. Also, similar to McClave et al.'s (2005) study, there was a reliance on staff documenting the reasons for cessation of enteral nutrition. 


\section{Metheny et al. (2008)}

Metheny et al.'s (2008) study differed significantly from both McClave et al.'s (2005) and Pinilla et al.'s (2001) studies primarily in the methodology. Metheny et al.'s descriptive study's results identified that the percentage of aspiration increased as GRVs increased. For example, aspiration was higher in the 'GRV at least $250 \mathrm{~mL}$ group' than the 'GRV $0-50 \mathrm{~mL}$ group', which implies that in accepting a GRV of at least $250 \mathrm{~mL}$, puts patients at greater risk of aspiration. However, the authors discuss the lack of randomisation, or control for tube types or other treatment conditions, which potentially introduces bias into their study. Like McClave et al.'s study, the lack of clarity around tube types in their groups presents a potential confounding variable related to the implications from the results associated with risk of aspiration. No discussion of the feeding regimen or the volumes infused is provided, making study replication difficult.

One consideration regarding Metheny et al.'s study is that even when the GRV was $0-50 \mathrm{~mL}$, participants still had positive pepsin assays of their tracheal secretions, so regardless of accepted GRV, patients are still potentially at risk of aspiration. This result is based on the assumption that the assay is a proxy to aspiration of gastric contents. The pepsin assay is deemed to be highly sensitive and specific (100\% and 92\% respectively) related to pepsin detection in the proximal oesophagus and has previously been validated (Potluri et al., 2003). Metheny et al.'s results suggested there is an increased risk of aspiration associated with higher GRVs, however the identified inconsistencies in this relationship, the frequency of aspiration to occur even in the 'GRV $0-50 \mathrm{~mL}$ group', and the associated potential for bias related to study methodology reduces the ability for implications to be drawn for this systematic review question. That is, no acceptable GRV was identifiable from this study. 


\section{Contributions from excluded studies}

Despite being excluded from the systematic review due to there being no separate analysis of the impact of variable GRVs, several of the excluded studies do provide insight into an informed discussion related to the identification of a specified acceptable GRV (Davies et al., 2002; Desachy et al., 2008; Kompan et al., 2004; Mentec et al., 2001; Montejo et al., 2002). Potential acceptable GRVs which were identified as causing few or rare complications for patients included 250mL (Davies et al.), 300mL (Desachy et al.), and $\geq 300 \mathrm{~mL}$ (Montejo et al.). These studies did not evaluate variable GRVs, and the outcomes associated with these GRVs were incidental findings. Variable GRVs were not examined independently by the researchers, and any interpretations related to the findings have an associated risk of bias (Parker, 2008).

Mentec et al.'s (2001) prospective study confirmed that, with the earlier commencement of enteral nutrition in critically ill patients, and a thrust to prevent inappropriate cessation of feeding, it becomes even more important to monitor tolerance. Their study found high GRVs were an early indicator of upper digestive intolerance. This intolerance was associated with a higher incidence of nosocomial pneumonia, longer ICU stay, and a higher ICU mortality. The potential risk for the patient was related to either a GRV of 150 $500 \mathrm{~mL}$ twice consecutively, or a GRV $>500 \mathrm{~mL}$. However, the participants in Mentec et al.'s study were predominantly admitted with a medical diagnosis, which would potentially reduce the study's generalisability to the general ICU population. Furthermore, the potential implications for clinical practice related to the association of high GRVs with early indication of upper digestive intolerance identified in this study is incongruent with the study results of Kompan et al. (2004). These authors found that early enteral nutrition reduces upper intestinal intolerance and nosocomial pneumonia in the critically ill. 


\section{External validity}

This systematic review will now be discussed with respect to its external validity. The primary strengths of this systematic review are related to its methodological clarity and potential for repeatability. Limitations included the need for this systematic review to have a single reviewer, appraiser and reporter of the literature identified in the search strategy, aspects which may have compromised the external validity of this systematic review. To enhance validity and reliability, a further reviewer would have been sought if possible. This may have facilitated increased rigour related to the search strategy, inclusion and exclusion criteria, critical appraisal, and the grading of quality level for evidence. It is possible that the lack of a second reviewer may have allowed bias within this systematic review. There is also the possibility that relevant studies may not have been identified during the search strategy, despite the comprehensive search conducted by the author. This potential for bias may have been increased by the exclusion of unpublished research, and the absence of hand journal searching. A further limitation may be the 10 year timeframe applied to the inclusion criteria.

\section{Comparisons with other literature}

The results of this systematic review were not comparable with other reviews (Bourgault et al., 2007; Bowman et al., 2005; Cerra et al., 1997; Edwards \& Metheny, 2000; Kattelmann et al., 2006; McClave et al., 2002; McClave \& Snider, 2002; Parrish \& McCray, 2003). Unlike other reviews, no recommendation for a definitive GRV is made in this systematic review due to the lack of strong evidentiary support for one GRV over another. However like other literature, the inconsistencies in the management of GRVs that contribute to inadequate enteral nutrition delivery were highlighted (Marshall \& West, 2006; McClave \& Snider, 2002; Parrish \& McClave, 2008).

This discussion provided a summary of the main findings of the systematic review related to the outcome measures of caloric requirements met and 
adverse events, including vomiting or emesis, regurgitation, frequency of aspiration and total intolerance episodes. These results have been considered in light of wider research, and their relevance has been applied to the review questions. The quality of evidence has been addressed in a discussion of potential biases in the review process. The next chapter presents the possibility for application to practice, and discusses dissemination of the results of this systematic review. Avenues for future research are proposed. 


\section{CHAPTER 7 CONCLUSION}

Chapter six provided a summary of the results, while discussing wider literature. Applicability of the evidence was addressed, and internal and external validity of this systematic review was considered. Chapter seven provides a discussion of applicability to practice, dissemination of the results of this review, and future opportunities for research.

\section{Application to practice}

The results of this systematic review have implications for practice. There is insufficient evidence to support the use of one particular GRV over another, or to change current practice related to accepting one GRV over another. This paucity of evidence leaves few options. One unsatisfactory, but obvious, option is to judiciously draw from the recommendations of the wider literature, including the professional groups and reviews, until further research provides more evidence. The impact of needing to be informed by recommendations from these professional groups (summarised in the background chapter), highlighted that strong, methodologically sound evidence, sought in this systematic review was not identified, and hence no practice changes are recommended. Despite the lack of firm recommendations, the purpose of this systematic review was to inform practice. In light of the findings, a considerable disparity and inconsistency in management of GRVs remains.

The use of one GRV over another is a practice largely based on ritual and tradition, and is not supported by rigorous evidence. This systematic review benefits from a rigorous methodology used to answer the research question. Using the evidence-base and implementing research into practice requires strong, methodologically sound evidence (Kitson, Ahmed, Harvey, Seers, \& Thompson, 1996). Implementation also requires carefully planned interventions including education, audit and change management strategies. Kitson et al. suggest that, whether an inductive or deductive approach, 
involving staff in the change process and acting on contextual implications is essential to the success of the implementation process.

There is the potential to learn from these findings, and inform practice by working together as a united MDT, and to achieve consistency in the existing management of GRVs. Of benefit would be a consistent team approach, which is regularly reviewed and updated with advances in the evidence-base. The effective dissemination of this knowledge promoting rigorous processes may improve patient care. Furthermore, MDT questions, such as the question that provoked this systematic review, would have had a readily available answer. An added benefit of establishing this shared MDT approach is that advances in knowledge would be more readily disseminated, integrated, and applied to practice.

\section{Dissemination}

Words alone do not provoke action; an incentive to influence attitude, knowledge and behaviour supports dissemination of information (Lomas, 1991). The results of this systematic review have not instigated a practice change related to specific GRVs in the enterally fed adult ICU patient; however the results do inform clinical practice. Methods for dissemination and utilisation of research may include a structured framework, such as that proposed by Dobbins et al. (2002). Their framework includes contextual influences such as the individual, organisation, environment and innovation, and presents a staged process of dissemination incorporating knowledge, persuasion, decision, implementation, and confirmation.

With a structured approach to the dissemination of the findings of this systematic review, publication of the results is just one step in a strategy to enhance patient outcomes through more effective, consistent, and multidisciplinary management of GRVs. Publication would be supplemented with developing the knowledge base of clinicians through one-on-one personal contact with related MDT members, audit, and feedback. This would be 
followed by supporting the initiative into practice, adopting Dobbins et al.'s strategy for research dissemination and utilisation. There is clear potential to enhance strategies surrounding the delivery and management of enteral nutrition and GRVs in the ICU adult patient. Further research would be of significant benefit in addressing the delivery and management of enteral nutrition and GRVs.

\section{Future research}

As demonstrated in this systematic review, there remain opportunities for future research related to the management of GRVs in the enterally fed critically ill patient, and achieving optimal volumes of nutrition delivered. For example, an adequately sized, methodologically sound, randomised controlled trial comparing both the long-term and short-term outcomes associated with accepting a GRV of 500mL (the highest proposed GRV from the guidelines and reviews evaluated) versus $200 \mathrm{~mL}$ (the current average recommendation from the guidelines and reviews evaluated) would be beneficial. Alternatively, there is the potential consideration that GRVs are not an effective marker for enteral nutrition tolerance or intolerance and thus, of benefit would be to begin to explore other areas to enhance the delivery of enteral nutrition and to mitigate risk. One example of an area to investigate further is commencing enteral nutrition at higher infusion rates, or at goal rate. It is clear that there remain opportunities to enhance delivery of nutrition to the critically ill patient, and this research project provides the first step in that journey. 


\section{REFERENCES}

Acton, G. (2001). Meta-analysis: A tool for evidence-based practice. American Association of Critical Care Nurses Clinical Issues, 12(4), 539-545.

Adam, S., \& Batson, S. (1997). A study of problems associated with the delivery of enteral feed in critically ill patients in five ICUs in the UK. Intensive Care Medicine, 23, 261-266.

American Gastroenterological Association. (1994). American Gastroenterology Association technical review: Enteral nutrition: American Gastroenterological Association.

American Society for Parenteral and Enteral Nutrition Board of Directors, \& The Clinical Guidelines Task Force. (2002). Guidelines for the use of parenteral and enteral nutrition in adult and pediatric patients. Journal of Parenteral and Enteral Nutrition, 26(1), 1SA-137SA.

Arbogast, D. (2002). Enteral feedings with comfort and safety. Clinical Journal of Oncology Nursing, 6(5), 275-280.

Atkinson, M., \& Worthley, L. (2003). Nutrition in the critically ill patient: Part 1. Essential physiology and pathophysiology. Critical Care and Resuscitation, 5, 109-120.

Behara, A., Peterson, S., Chen, Y., Butsch, J., Lateef, O., \& Komanduri, S. (2008). Nutrition support in the critically ill: A physician survey. Journal of Parenteral and Enteral Nutrition, 32(2), 113-119.

Bigby, M., \& Williams, H. (2003). Appraising systematic reviews and metaanalyses. Archives of Dermatology, 139, 795-798.

Bochicchio, G., Bochicchio, K., Nehman, S., Casey, C., Andrews, P., \& Scalea, T. (2006). Tolerance and efficacy of enteral nutrition in traumatic brain-injured patients induced into barbiturate coma. Journal of Parenteral and Enteral Nutrition, 30(6), 503-506.

Bourgault, A., Ipe, L., Weaver, J., Swartz, S., \& O'Dea, P. (2007). Development of evidence-based guidelines and critical care nurses' knowledge of enteral feeding. Critical Care Nurse, 27(4), 17-29. 
Bowman, A., Greiner, J., Doerschug, K., Little, S., Bombei, C., \& Comried, L. (2005). Implementation of an evidence-based feeding protocol and aspiration risk reduction algorithm. Critical Care Nursing Quarterly, 28(4), 324-333.

Buckley, S., \& Kudsk, K. (1998). Metabolic response to critical illness and injury. American Association of Critical Care Nurses Clinical Issues, 5(4), 443-449.

Bullock, T., Waltrip, T., Price, S., \& Galandiuk, S. (2004). A retrospective study of nosocomial pneumonia in postoperative patients shows a higher mortality rate in patients receiving nasogastric tube feeding. The American Surgeon, 70(9), 822-826.

Case, K., Cuddy, P., \& Dooling-McGurk, E. (2000). Nutrition support in the critically ill patient. Critical Care Nursing Quarterly, 22(4), 75-89.

Cerra, F., Benitez, M., Blackburn, G., Irwin, R., Jeejeebhoy, K., Katz, D., et al. (1997). Applied nutrition in ICU patients: A consensus statement of the American College of Chest Physicians. Chest, 111, 769-778.

Chalmers, T., Smith, H., Blackburn, B., Silverman, B., Schroeder, B., Reitman, D., et al. (1981). A method for assessing the quality of a randomized controlled trial. Controlled Clinical Trials, 2, 31-49.

Chang, W., McClave, S., Hsieh, C., \& Chao, Y. (2007). Gastric residual volume (GRV) and gastric contents measurement by refractometry. Journal of Parenteral and Enteral Nutrition, 31(1), 63-68.

Chang, W., McClave, S., Lee, M., \& Chao, Y. (2004). Monitoring bolus nasogastric tube feeding by the Brix value determination and residual volume measurement of gastric contents. Journal of Parenteral and Enteral Nutrition, 28(2), 105-112.

Clarke, M. (2007). Overview of methods. In C. Webb \& B. Roe (Eds.), Reviewing Research Evidence for Nursing Practice. Oxford: Blackwell.

Cook, D., Mulrow, C., \& Haynes, R. (1997). Systematic reviews: Synthesis of best evidence for clinical decisions. Annals of Internal Medicine, 126(5), 376-380. 
Critical Care Nutrition. (2007). Updated recommendations from the Canadian clinical practice guidelines for nutrition support. Retrieved 10 November 2008, from www.criticalcarenutrition.com

Davies, A., Froomes, P., French, C., Bellomo, R., Gutteridge, G., Nyulasi, I., et al. (2002). Randomized comparison of nasojejunal and nasogastric feeding in critically ill patients. Critical Care Medicine, 30(3), 714-716.

Deane, A., Fraser, R., \& Chapman, M. (2009). Prokinetic drugs for feed intolerance in critical illness: Current and potential therapies. Critical Care and Resuscitation, 11(2), 132-143.

Deeks, J., Higgins, J., \& Altman, D. (2008). Chapter 9: Analysing data and undertaking meta-analyses [Electronic Version]. Cochrane Handbook for Systematic Reviews of Interventions Version 5.0.1 (updated September 2008). Retrieved 10 May 2009 from www.cochranehandbook.org.

Desachy, A., Clavel, M., Vuagnat, A., Normand, S., Gissot, V., \& Francois, B. (2008). Initial efficacy and tolerability of early enteral nutrition with immediate or gradual introduction in intubated patients. Intensive Care Medicine, 34(6), 1054-1060.

DiCenso, A., Cullum, N., \& Ciliska, D. (1998). Implementing evidence-based nursing: Some misconceptions. Evidence-Based Nursing, 1(2), 38-40.

Dietitians Association of Australia Nutrition Support Interest Group. (2007). Enteral feeding manual for adults in health care facilities: Dietitians Association of Australia.

Dive, A., Moulart, M., Jonard, P., Jamart, J., \& Mahieu, P. (1994).

Gastroduodenal motility in mechanically ventilated critically ill patients: A manometric study. Critical Care Medicine, 22(3), 441-447.

Dobbins, M., Ciliska, D., Cockerill, R., Barnsley, J., \& DiCenso, A. (2002). A framework for the dissemination and utilization of research for healthcare policy and practice [Electronic Version]. The Online Journal of Knowledge Synthesis for Nursing, 9. Retrieved 10 May 2009 from http://www.healthevidence.ca/downloads/A_framework_for_dissemination_(2002).pdf.

Doig, C., Sutherland, L., Sandham, J., Fick, G, Verhoef, M., \& Meddings, J. (1998). Increased intestinal permeability is associated with the development of multiple organ dysfunction syndrome in critically ill 
ICU patients. American Journal of Respiratory and Critical Care Medicine, 158, 444-451.

Doig, G., Simpson, F., \& Delaney, A. (2005). A review of the true methodological quality of nutritional support trials conducted in the critically ill: Time for improvement. Anesthesia Analgesia, 100, 527533.

Eckmann, L. (2006). Innate immunity. In L. Johnson, K. Barrett, F. Ghishan, J. Merchant, H. Said \& J. Wood (Eds.), Physiology of the gastrointestinal tract (Vol. 2, pp. 1033-1066). Burlington: Elsevier.

Edwards, S., \& Metheny, N. (2000). Measurement of gastric residual volume: State of the science. Medsurg Nursing, 9(3), 125-128.

Egger, M., \& Smith, G. (1995). Misleading meta-analysis. British Medical Journal, 310(6982), 752-754.

Egger, M., Smith, G., Schneider, M., \& Minder, C. (1997). Bias in metaanalysis detected by a simple, graphical test. British Medical Journal, 315(7109), 629-634.

Elpern, E. (1997). Pulmonary aspiration in hospitalized adults. Nutrition in Clinical Practice, 12(1), 5-13.

Elpern, E., Stutz, L., Peterson, S., Gurka, D., \& Skipper, A. (2004). Outcomes associated with enteral tube feedings in a medical intensive care unit. American Journal of Critical Care, 13(3), 221-227.

Esparza, J., Boivin, M., Hartshorne, M., \& Levy, H. (2001). Equal aspiration rates in gastrically and transpylorically fed critically ill patients. Intensive Care Medicine, 27, 660-664.

Farber, M., Moses, J., \& Korn, M. (2005). Reducing costs and patient morbidity in the enterally fed intensive care unit patient. Journal of Parenteral and Enteral Nutrition, 29(1), S62-S68.

Fiaccadori, E., Maggiore, U., Giacosa, R., Rotelli, C., Picetti, e., Sagripanti, S., et al. (2004). Enteral nutrition in patients with acute renal failure.

Kidney International, 65(3), 999-1008. 
Fruhwald, S., Holzer, P., \& Metzler, H. (2008). Gastrointestinal motility in acute illness. Wiener Klinische Wochenschrift, 120(1), 6-17.

Fukatsu, K., Zarzaur, B., Johnson, C., Lundberg, A., Wilcox, H., \& Kudsk, K. (2001). Enteral nutrition prevents remote organ injury and death after a gut ischemic insult. Annals of Surgery, 233(5), 660-668.

Fulbrook, P., \& Mooney, S. (2003). Care bundles in critical care: A practical approach to evidence-based practice. Nursing in Critical Care, 8(6), 249-255.

Garg, A., Hackam, D., \& Tonelli, M. (2008). Systematic review and metaanalysis: When one study is just not enough. Clinical Journal of the American Society of Nephrology, 3, 253-260.

Gillis, A., \& Jackson, W. (2002). Research for nurses: Methods and interpretation. Philadelphia: F.A. Davis Company.

Giner, M., Laviano, A., Meguid, M., \& Gleason, J. (1996). In 1995 a correlation between malnutrition and poor outcome in critically ill patients still exists. Nutrition, 12(1), 56-57.

Gluud, L. (2006). Bias in clinical intervention research. American Journal of Epidemiology, 163(6), 493-501.

Gorelick, F., \& Jamieson, J. (2006). Structure-function relations in the pancreatic acinar cell. In L. Johnson, K. Barrett, F. Ghishan, J. Merchant, H. Said \& J. Wood (Eds.), Physiology of the gastrointestinal tract (4th ed., Vol. 2, pp. 1313-1336). Burlington: Elsevier.

Grant, J. (2006). Anatomy and physiology of the luminal gut: Enteral access implications. Journal of Parenteral and Enteral Nutrition, 30(1), S41S46.

Green, S., \& Higgins, J. (2008). Chapter 2: Preparing a Cochrane review [Electronic Version]. Cochrane Handbook for Systematic Reviews of Interventions Version $5 . .1$ (updated September 2008). Retrieved 10 May 2009 from www.cochrane-handbook.org.

Griffiths, R. (2007). Too much of a good thing: The curse of overfeeding. Critical Care, 11(6), 176-177. 
Gue, M. (2006). Effect of stress on gastrointestinal motility. In L. Johnson, K. Barrett, F. Ghishan, J. Merchant, H. Said \& J. Wood (Eds.), Physiology of the gastrointestinal tract (4th ed., Vol. 1, pp. 781-790). Burlington: Elsevier.

Harden, A. (2006). Extending the boundaries of systematic reviews to integrate different types of study: Examples of methods developed within reviews on young people's health. Retrieved 20 March 2009, from www.nice.org.uk.

Hasler, W. (2006). Small intestinal motility. In L. Johnson, K. Barrett, F. Ghishan, J. Merchant, H. Said \& J. Wood (Eds.), Physiology of the gastrointestinal tract (4th ed., Vol. 1, pp. 935-964). Burlington: Elsevier.

Heiman, G. (1992). Basic statistics for the behavioural sciences. Boston: Houghton Mifflin Company.

Hermsen, J., Gomez, F., Maeshima, Y., Sano, Y., Kang, W., \& Kudsk, K. (2008). Decreased enteral stimulation alters mucosal immune chemokines. Journal of Parenteral and Enteral Nutrition, 32(1), 36-44.

Heyland, D., Dhaliwal, R., Day, A., Jain, M., \& Drover, J. (2004). Validation of the Canadian clinical practice guidelines for nutrition support in mechanically ventilated, critically ill adult patients: Results of a prospective observational study. Critical Care Medicine, 32(11), 22602266.

Heyland, D., Dhaliwal, R., Drover, J., Gramlich, L., \& Dodek, P. (2003). Canadian clinical practice guidelines for nutrition support in mechanically ventilated, critically ill adult patients. Journal of Parenteral and Enteral Nutrition, 27(5), 355-373.

Higgins, J., \& Altman, D. (2008). Chapter 8: Assessing risk of bias in included studies [Electronic Version]. Cochrane Handbook for Systematic Reviews of Interventions Version 5.0.1 (updated September 2008). Retrieved 10 May 2009 from www.cochrane-handbook.org.

Higgins, J., \& Deeks, J. (2008). Chapter 7: Selecting studies and collecting data [Electronic Version]. Cochrane Handbook for Systematic Reviews of Interventions Version 5.0.1 (updated September 2008). The Cochrane Collaboration. Retrieved 6 May 2009 from www.cochranehandbook.org. 
Higgins, J., \& Green, S. (2008). Cochrane handbook for systematic reviews of interventions 5.0.1 [updated September 2008]. [Electronic Version]. The Cochrane Collaboration. Retrieved 20 January 2009 from http://www.cochrane.org/resources/handbook/hbook.htm.

Hopewell, S., McDonald, S., Clarke, M., \& Egger, M. (2007). Grey literature in meta-analyses of randomized trials of health care interventions [Electronic Version]. Cochrane Database of Systematic Reviews. Retrieved 20 January 2009 from www.cochrane-handbook.org.

Houser, J. (2008). Nursing research: Reading, using, and creating evidence. London: Jones \& Bartlett Publishers International.

Jadad, A., Moore, A., Carroll, D., Jenkinson, C., Reynolds, J., Gavaghan, D., et al. (1996). Assessing the quality of reports of randomized clinical trials: Is blinding necessary? Controlled Clinical Trials, 17, 1-12.

Jarvis, C. (2003). Physical examination and health assessment (4th ed.). Illinois: Saunders.

Joanna Briggs Institute. (2008). Joanna Briggs Institute Reviewers' Manual [Electronic Version]. Retrieved 5 June 2009 from http://www.joannabriggs.edu.au/about/system_review.php.

Johansen, F., Yen, E., Dickinson, B., Yoshida, M., Claypool, S., Blumberg, R., et al. (2006). Biology of gut immunoglobulins. In L. Johnson, K. Barrett, F. Ghishan, J. Merchant, H. Said \& J. Wood (Eds.), Physiology of the gastrointestinal tract (4th ed., Vol. 2, pp. 1067-1090). Burlington: Elsevier.

Johnson, C., \& Kudsk, K. (1999). Nutrition and intestinal mucosal immunity. Clinical Nutrition, 18(6), 337-344.

Jolliet, P., Pichard, C., Biolo, G., Chiolero, R., Grimble, G., Leverve, X., et al. (1998). Enteral nutrition in intensive care patients: A practical approach. Intensive Care Medicine, 24, 848-859.

Juve-Udina, M., Valls-Miro, C., Carreno-Granero, A., Martinez-Estalella, G., Monterde-Prat, D., Domingo-Felici, C., et al. (2009). To return or to discard? Randomised trial on gastric residual volume management (in press) [Electronic Version]. Intensive and Critical Care Nursing. Retrieved 21 August 2009 from doi:10.1016/j.iccn.2009.06.004. 
Kattelmann, K., Hise, M., Russell, M., Charney, P., Stokes, M., \& Compher, C. (2006). Preliminary evidence for a medical nutrition therapy protocol: Enteral feedings for critically ill patients. Journal of the American Dietetic Association, 106, 1226-1241.

Kearns, P., Chin, D., Mueller, L., Wallace, K., Jensen, W., \& Kirsch, C. (2000). The incidence of ventilator-associated pneumonia and success in nutrient delivery with gastric versus small intestinal feeding: A randomized clinical trial. Critical Care Medicine, 28(6), 1742-1746.

Keithley, J., \& Swanson, B. (2004). Enteral nutrition: An update on practice recommendations. Medsurg Nursing, 13(2), 131-134.

Kitson, A., Ahmed, L., Harvey, G., Seers, K., \& Thompson, D. (1996). From research to practice: One organizational model for promoting researchbased practice. Journal of Advanced Nursing, 23(3), 430-440.

Kompan, L., Vidmar, G., Spindler-Vesel, A., \& Pecar, J. (2004). Is early enteral nutrition a risk factor for gastric intolerance and pneumonia. Clinical Nutrition, 23, 527-532.

Kortbeek, J., Haigh, P., \& Doig, C. (1999). Injury, infection, and critical care duodenal versus gastric feeding in ventilated blunt trauma patients: A randomized controlled trial. Journal of Trauma, 46(6), 992-998.

Kozar, R., McQuiggan, M., Moore, E., Kudsk, K., Jurkovich, G., \& Moore, F. (2002). Postinjury enteral tolerance is reliably achieved by a standardized protocol. Journal of Surgical Research, 104, 70-75.

Kozier, B., Erb, G., Berman, A., \& Burke, K. (2000). Fundamentals of nursing (6th ed.). New Jersey: Prentice-Hall.

Kreymann, K., Berger, M., Deutz, N., Hiesmayr, M., Jolliet, P., Kazandjiev, G., et al. (2006). ESPEN guidelines on enteral nutrition: Intensive care. Clinical Nutrition, 25, 210-223.

Kudsk, K. (2001). Importance of enteral feeding in maintaining gut integrity. Techniques in Gastrointestinal Endoscopy, 3(1), 2-8.

Kudsk, K. (2002). Current aspects of mucosal immunology and its influence by nutrition. The American Journal of Surgery, 183, 390-398. 
Landzinski, J., Kiser, T., Fish, D., Wischmeyer, P., \& MacLaren, R. (2008). Gastric motility function in critically ill patients tolerant vs intolerant to gastric nutrition. Journal of Parenteral and Enteral Nutrition, 32(1), 45-50.

Lefebvre, C., Manheimer, E., \& Glanville, J. (2008). Chapter 6: Searching for studies [Electronic Version]. Cochrane Handbook for Systematic Reviews of Interventions Version 5.0.1 (updated September 2008). Retrieved 10 May 2009 from www.cochrane-handbook.org.

Leonard, R. (2003). Enteral and parenteral nutrition. In A. Bersten, N. Soni \& T. Oh (Eds.), Oh's Intensive Care Manual (5th ed., pp. 903-912). London: Butterworth-Heinemann.

Leonard, R. (2009). Enteral and parenteral nutrition. In A. Bersten \& N. Soni (Eds.), Oh's Intensive Care Manual (6th ed., pp. 981-991). Philadelphia: Butterworth Heinemann.

Lewis, S., \& Clarke, M. (2001). Forest plots: Trying to see the wood and the trees. British Medical Journal, 322(7300), 1479-1480.

Lin, H., \& Van Citters, G. (1997). Stopping enteral feeding for arbitrary gastric residual volume may not be physiologically sound: Results of a computer simulation model. Journal of Parenteral and Enteral Nutrition, 21(5), 286-289.

Lomas, J. (1991). Words without action? The production, dissemination, and impact of consensus recommendations. Annual Review of Public Health, 12, 41-65.

MacIntyre, N. (2001). Evidence-based guidelines for weaning and discontinuing ventilatory support. Chest, 120, 375S-396S.

MacKenzie, S., Zygun, D., \& Hameed, S. (2003). A nutrition support protocol improves the proportion of patients reaching enteral nutrition targets in the adult intensive care unit. Canadian Journal of Dietetic Practice and Research, 64(2), S107.

MacKenzie, S., Zygun, D., Whitmore, B., Doig, C., \& Hameed, S. (2005). Implementation of a nutrition support protocol increases the proportion of mechanically ventilated patients reaching enteral nutrition targets in the adult intensive care unit. Journal of Parenteral and Enteral Nutrition, 29(2), 74-80. 
MacLaren, R., Kiser, T., Fish, D., \& Wischmeyer, P. (2008). Erythromycin vs metoclopramide for facilitating gastric emptying and tolerance to intragastric nutrition in critically ill patients. Journal of Parenteral and Enteral Nutrition, 32(4), 412-419.

Marshall, A. (2005). Research review: Poor validity of residual volumes as markers for risk of aspiration in critically ill patients (McClave, Lukan, Stefater et al, 2005). Critical Care Medicine, 18(3), 130-131.

Marshall, A., \& West, S. (2004). Nutritional intake in the critically ill: Improving practice through research. Australian Critical Care, 17(1), 6-15.

Marshall, A., \& West, S. (2006). Enteral feeding in the critically ill: Are nursing practices contributing to hypocaloric feeding? Intensive and Critical Care Nursing, 22(2), 95-105.

Martin, C., Doig, G., Heyland, D., \& Sibbald, W. (2004). Multicentre, clusterrandomised clinical trial of algorithms for critical-care enteral and parenteral therapy (ACCEPT). Canadian Medical Association Journal, 170(2), 197-204.

Martindale, R., McClave, S., Vanek, V., McCarthy, M., Roberts, P., Taylor, B., et al. (2009). Guidelines for the provision and assessment of nutrition support therapy in the adult critically ill patient: Society of Critical Care Medicine \& American Society for Parenteral and Enteral Nutrition: Executive summary. Critical Care Medicine, 37(5), 1757-1761.

McClave, S., DeMeo, M., DeLegge, M., DiSario, J., Heyland, D., Maloney, J., et al. (2002). Consensus statement. North American summit on aspiration in the critically ill patient: Consensus statement. Journal of Parenteral and Enteral Nutrition, 26(6), S80-85.

McClave, S., \& Heyland, D. (2005). Critical care nutrition. In M. Fink, E. Abraham, J. Vincent \& P. Kochanek (Eds.), Textbook of Critical Care (5th ed., pp. 939-950). Philadelphia: Elseiver Saunders.

McClave, S., Lukan, J., Stefater, J., Lowen, C., Looney, C., Matheson, P., et al. (2005). Poor validity of residual volumes as a marker for risk of aspiration in critically ill patients. Critical Care Medicine, 33(2), 324330. 
McClave, S., Sexton, L., Spain, D., Adams, J., Owens, N., Sullins, M., et al. (1999). Enteral tube feeding in the intensive care unit: Factors impeding adequate delivery. Critical Care Medicine, 27(7), 1252-1256.

McClave, S., \& Snider, H. (2002). Clinical use of gastric residual volumes as a monitor for patients on enteral tube feeding. Journal of Parenteral and Enteral Nutrition, 26(6), S43-50.

Melnyk, B. (2004). Integrating levels of evidence into clinical decision making. Pediatric Nursing, 30(4), 323-325.

Mentec, H., Dupont, H., Bocchetti, M., Cani, P., Ponche, F., \& Bleichner, G. (2001). Upper digestive intolerance during enteral nutrition in critically ill patients: Frequency, risk factors, and complications. Critical Care Medicine, 29(10), 1955-1961.

Metheny, N. (2008). Residual volume measurement should be retained in enteral feeding protocols. American Journal of Critical Care, 17(1), 6264.

Metheny, N., Schallom, L., Oliver, D., \& Clouse, R. (2008). Gastric residual volume and aspiration in critically ill patients receiving gastric feedings. American Journal of Critical Care, 17(6), 512-519.

Metheny, N., Schallom, M., \& Edwards, S. (2004). Effect of gastrointestinal motility and feeding tube site on aspiration risk in critically ill patients: A review. Heart and Lung, 33(3), 131-145.

Ministry of Health. (2007). Statement of Intent: 2007-2010 [Electronic Version]. Retrieved 24 February 2009 from http://www.moh.govt.nz/soi.

Ministry of Health, \& University of Auckland. (2003). Nutrition and the burden of disease: New Zealand 1997-2011 [Electronic Version]. Retrieved 24 February 2009 from http://www.moh.govt.nz.

Moher, D., Jadad, A., Nichol, G., Penman, M., Tugwell, P., \& Walsh, S. (1995). Assessing the quality of randomized controlled trials: An annotated bibliography of scales and checklists. Controlled Clinical Trials, 16, 62-73.

Moher, D., Liberati, A., Tetzlaff, J., Altman, D., \& and the PRISMA Group. (2009). Preferred reporting items for systematic reviews and meta- 
analyses: The PRISMA statement. Annals of Internal Medicine, 151(4), 264-269.

Montejo, J. (1999). Enteral nutrition-related gastrointestinal complications in critically ill patients: A multicentre study. Critical Care Medicine, 27(8), 1447-1453.

Montejo, J., Grau, T., Acosta, J., Ruiz-Santana, S., Planas, M., García-DeLorenzo, A., et al. (2002). Multicenter, prospective, randomized, singleblind study comparing the efficacy and gastrointestinal complications of early jejunal feeding with early gastric feeding in critically ill patients [Electronic Version]. Critical Care Medicine, 796-800 from http://www.mrw.interscience.wiley.com/cochrane/clcentral/articles/410 /CN-00379410/frame.html

Moore, F., Feliciano, D., Andrassy, R., McArdle, A., Booth, F., MorgensteinWagner, T., et al. (1992). Early enteral feeding, compared with parenteral, reduces postoperative septic complications: The results of a meta-analysis. Annals of Surgery, 216, 172-183.

Moreira, T., \& McQuiggan, M. (2009). Methods for the assessment of gastric emptying in critically ill, enterally fed adults. Nutrition in Clinical Practice, 24(2), 261-273.

National Collaborating Centre for Acute Care. (2006). Nutrition support in adults oral nutrition support, enteral tube feeding and parenteral nutrition. Retrieved 02 November 2008, from www.rcseng.ac.uk.

National Institute for Health \& Clinical Excellence. (2006). Nutrition support in adults. Clinical guideline 32. London: NICE.

Neumann, D., \& DeLegge, M. (2002). Gastric versus small-bowel tube feeding in the intensive care unit: A prospective comparison of efficacy. Critical Care Medicine, 30(7), 1436-1438.

New Zealand Guidelines Group. (2001). Handbook for the preparation of explicit evidence-based clinical practice guidelines [Electronic Version]. Retrieved 02 March 2009 from www.nzgg.org.nz.

O'Connor, D., Green, S., \& Higgins, J. (2008). Chapter 5: Defining the review question and developing criteria for including studies [Electronic Version]. Cochrane Handbook of Systematic Reviews of Intervention. Version 5.0.1 (updated September 2008). Retrieved 10 May 2009 from www.cochrane-handbook.org. 
O'Meara, D., Mireles-Cabodevila, E., Frame, F., Hummell, C., Hammel, J., Dweik, R., et al. (2008). Evaluation of delivery of enteral nutrition in critically ill patients receiving mechanical ventilation. American Journal of Critical Care, 17(1), 53-61.

Parker, L. (2008). The future of incidental findings: Should they be viewed as benefits. Journal of Law, Medicine and Ethics, 36(2), 341-213.

Parrish, C., \& McClave, S. (2008). Checking gastric residual volumes: A practice in search of science? Practical Gastroenterology, 32(10), 3347.

Parrish, C., \& McCray, S. (1999). Nutrition support for the mechanically ventilated patient. Critical Care Nurse, 19(1), 91-94.

Parrish, C., \& McCray, S. (2003). Enteral feeding: Dispelling myths. Practical Gastroenterology, 27(9), 33-50.

Peng, Y., Yuan, Z., \& Xiao, G. (2001). Effects of early enteral feeding on the prevention of enterogenic infection in severely burned patients. Burns, $27,145-149$.

Pingleton, S., Hinthorn, D., \& Liu, C. (1986). Enteral nutrition in patients receiving mechanical ventilation. American Journal of Medicine, 80, 827-832.

Pinilla, J., Samphire, J., Arnold, C., Liu, L., \& Thiessen, B. (2001). Comparison of gastrointestinal tolerance to two enteral feeding protocols in critically ill patients: A prospective, randomized controlled trial. Journal of Parenteral and Enteral Nutrition, 25(2), 81-86.

Polit, D., \& Beck, C. (2008). Nursing research: Generating and assessing evidence for nursing practice (8th ed.). Philadelphia: Lippincott Williams \& Wilkins.

Potluri, S., Friedenberg, R., Parkman, H., Chang, A., MacNeal, R., Manus, C., et al. (2003). Comparison of a salivary/sputum pepsin assay with 24hour esophageal $\mathrm{pH}$ monitoring for detection of gastric reflux into the proximal esophagus, oropharynx, and lung. Digestive Diseases and Sciences, 28(9), 1813-1817.

Reeves, B., Deeks, J., Higgins, J., \& Wells, G. (2008). Including nonrandomized studies [Electronic Version]. Cochrane Handbook for 
Systematic Reviews of Interventions Version 5.0.1 (updated September 2008). Retrieved 20 January 2009 from www.cochrane-handbook.org.

Reid, C. (2006). Frequency of under- and overfeeding in mechanically ventilated ICU patients: causes and possible consequences. Journal of Human Nutrition and Dietetics, 19, 13-22.

Roberts, S., Kennerly, D., Keane, D., \& George, C. (2003). Nutrition support in the intensive care unit: Adequacy, timeliness, and outcomes. Critical Care Nurse, 23(6), 49-57.

Roe, B. (2007). Key stages and considerations when undertaking a systematic review: Bladder training for the management of urinary incontinence. In C. Webb \& B. Roe (Eds.), Reviewing research evidence for nursing practice (pp. 9-23). Oxford: Blackwell.

Rycroft-Malone, J., Seers, K., Titchen, A., Harvey, G., Kitson, A., \& McCormack, B. (2004). What counts as evidence in evidence-based practice? Journal of Advanced Nursing, 47(1), 81-90.

Sackett, D. (2000). Why randomized controlled trials fail but needn't: 1. Failure to gain "coal-face" commitment and to use the uncertainty principle. Canadian Medical Association Journal, 162(9), 1311-1314.

Sander, L., \& Kitcher, H. (2006). Systematic and other reviews: Terms and definitions used by UK organisations and selected databases. Systematic review and Delphi survey [Electronic Version]. Retrieved 01 November 2009 from www.nice.org.uk.

Saranto, K., \& Kinnunen, U. (2009). Evaluating nursing documentation research designs and methods: Systematic review. Journal of Advanced Nursing, 65(3), 464-476.

Schulz, K. (1995). Subverting randomization in controlled trials. Journal of the American Medical Association, 274(18), 1456-1458.

Schulz, K., Chalmers, I., \& Altman, D. (2002). The landscape and lexicon of blinding in randomized trials. Annals of Internal Medicine, 136(3), 254259 .

Schunemann, H., Oxman, A., Higgins, J., Vist, G., Glasziou, P., \& Guyatt, G. (2008). Chapter 11: Presenting results and 'Summary of findings' tables [Electronic Version]. Cochrane Handbook for Systematic Reviews of 
Interventions Version 5.0.1 (updated September 2008). Retrieved 10 May 2009 from www.cochrane-handbook.org.

Shulkes, A., Baldwin, G., \& Giraud, A. (2006). Regulation of gastric acid secretion. In L. Johnson, K. Barrett, F. Ghishan, J. Merchant, H. Said \& J. Wood (Eds.), Physiology of the gastrointestinal tract (4th ed., Vol. 2, pp. 1223-1258). Burlington: Elsevier.

Stevens, K. (2001). Systematic reviews: The heart of evidence-based practice. American Association of Critical Care Nurses Clinical Issues, 12(4), 529-538.

Stratton, R. (2007). Malnutrition. In B. Thomas \& J. Bishop (Eds.), Manual Of Dietetic Practice (4th ed., pp. 80-90). Oxford: Blackwell.

Stroud, M., Duncan, H., \& Nightingale, J. (2003). Guidelines for enteral feeding in adult hospital patients. Gut, 52(Suppl VII), VII1-VII12.

Tack, J. (2006). Neurophysiologic mechanisms of gastric reservoir function. In L. Johnson, K. Barrett, F. Ghishan, J. Merchant, H. Said \& J. Wood (Eds.), Physiology of the gastrointestinal tract (4th ed., Vol. 1, pp. 927934). Burlington: Elsevier.

Tamion, F., Hamelin, K., Duflo, A., Girault, C., Richard, J., \& Bonmarchand, G. (2003). Gastric emptying in mechanically ventilated critically ill patients: Effect of neuromuscular blocking agent [Electronic Version]. Intensive Care Medicine, 1717-1722 from http://www.mrw.interscience.wiley.com/cochrane/clcentral/articles/263 /CN-00470263/frame.html

Taylor, S., Fettes, S., Jewkes, C., \& Nelson, R. (1999). Prospective, randomized, controlled trial to determine the effect of early enhanced enteral nutrition on clinical outcome in mechanically ventilated patients suffering head injury. Critical Care Medicine, 27(11), 2525-2531.

The Cochrane Collaboration. (2008). The Cochrane Library. Retrieved 10 May, 2009, from http://www3.interscience.wiley.com/cgibin/mrwhome/106568753/ProductDescriptions.html\#creviews

The Joanna Briggs Institute. (2008). Joanna Briggs Institute Reviewers' Manual [Electronic Version]. Retrieved 5 June 2009 from http://www.joannabriggs.edu.au/about/system_review.php. 
Thomas, B., \& Bishop, J. (Eds.). (2007). Manual of dietetic practice (4th ed.). Oxford: Blackwell.

Tryba, M. (1991). The gastropulmonary route of infection: Fact or fiction. American Journal of Medicine, 91, 135S-146S.

Umbrello, M., Elia, G., Destrebecq, A., \& Iapichino, G. (2009). Tolerance of enteral feeding: From quantity to quality of gastric residual volume? Intensive Care Medicine, 35, 1651-1652.

Urden, L., Stacy, K., \& Lough, M. (2006). Thelan's critical care nursing: Diagnosis and management (5th ed.). St Louis: Mosby.

von Elm, E., Altman, D., Egger, M., Pocock, S., Gotzsche, P., \& Vandenbroucke, J. (2007). The strengthening the reporting of observational studies in epidemiology (STROBE) statement: Guidelines for reporting observational studies. Lancet, 370, 1453-1457.

World Health Organisation. (2009). Nutrition [Electronic Version]. Retrieved 01 February 2009 from http://www.who.int/nutrition/en/.

Zaloga, G. (2005). The myth of the gastric residual volume. Critical Care Medicine, 33(2), 449-450. 


\section{APPENDICES}

\section{Appendix 1. Systematic review protocol}

GASTRIC RESIDUAL VOLUMES IN THE ADULT INTENSIVE CARE

PATIENT: A SYSTEMATIC REVIEW (Protocol)

by

Rebecca Jane Jarden 


\section{BACKGROUND}

There are inconsistencies between accepted gastric residual volumes (GRVs) in the enterally fed adult ICU patient identified both in the literature (Bourgault et al., 2007; Bowman et al., 2005; Cerra et al., 1997; Kattelmann et al., 2006; Keithley \& Swanson, 2004; Marshall, 2005; McClave et al., 2002; McClave \& Snider, 2002; Metheny, 2008; Parrish \& McClave, 2008; Parrish \& McCray, 2003; Pinilla et al., 2001; Zaloga, 2005), and in the recommendations of clinical practice guidelines (American Gastroenterological Association, 1994; American Society for Parenteral and Enteral Nutrition Board of Directors \& The Clinical Guidelines Task Force, 2002; Cerra et al., 1997; Critical Care Nutrition, 2007; Dietitians Association of Australia Nutrition Support Interest Group, 2007; Heyland et al., 2004; Heyland et al., 2003; Jolliet et al., 1998; McClave et al., 2002; National Collaborating Centre for Acute Care, 2006; Stroud et al., 2003). The recommended acceptable GRVs vary widely, from $150 \mathrm{~mL}$ to $500 \mathrm{~mL}$. Furthermore, the use of GRVs as a marker for tolerance remains contentious and is related to the lack of reliability in the measure (Bochicchio et al., 2006; Chang et al., 2007; Kompan et al., 2004; Landzinski et al., 2008; Lin \& Van Citters, 1997; MacLaren et al., 2008; McClave et al., 2005; McClave \& Snider, 2002; Metheny, 2008). Various interventions are recommended within this literature related to the specified GRVs, including cessation of enteral nutrition, reducing enteral nutrition, continuing enteral nutrition with careful assessment, implementing alternative strategies to reduce potential risk of aspiration, and introducing prokinetics. These recommendations were supported from sources ranging from a single expert opinion or a single randomised controlled trial, to a systematic review of several research trials. What is highlighted by this literature review is the potential scope for a systematic review to inform this topic more effectively than the existing literature. 


\section{Description of the intervention}

Marshall and West's (2004) literature review identified that existing management of enteral feeding resulted in insufficient delivery of nutrition. They concluded that enteral feeding protocols had improved nutritional intake, but there was wide scope for further research, particularly in the areas of nursing assessment and management of feeding intolerance. One feature of an enteral nutrition protocol was recommendations related to timeliness of GRV measurements, and specified management strategies for GRVs greater or less than a stated volume. These recommendations were to increase, decrease, or cease the enteral nutrition infusion rate in response to the volume measured, which was thought to reflect patient tolerance or intolerance of the enteral nutrition (Bowman et al., 2005).

Tolerance and intolerance of enteral nutrition in the critically ill patient has wide variation in definition. Indicators of intolerance to enteral nutrition were defined as vomiting, abdominal distension, diarrhoea and high GRV (Kozar et al., 2002). For the purpose of this systematic review, GRVs will be addressed further. Measuring GRVs involves using a large syringe fitted to the feeding tube and aspirating to check the remaining gastric contents of the stomach (Arbogast, 2002). The historical premise for measuring a GRV, as highlighted by McClave and Snider (2002), was that large residual volumes have been thought to indicate gastric intolerance to enteral feeding, a potential for vomiting and aspiration, and ultimately a risk for aspiration pneumonia. Conversely, based on these assumptions, low GRVs would suggest enteral nutrition tolerance and a minimal risk of aspiration (McClave \& Snider). However, accepting a GRV too low may subject the patient to underfeeding, and hence their nutritional needs not being met.

The underlying assumption that the stomach has a fixed volume capacity, and measurement of the volume of stomach contents enables prediction of potential overflow into the oesophagus and increased aspiration risk, has been dismissed as inherently flawed (McClave \& Snider, 2002). This premise for aspiration 
risk assessment may be further undermined by Metheny et al.'s (2008) descriptive study which found that of their 206 participants, $92.7 \%$ had at least one tracheal secretion positive for pepsin. This was deemed as a proxy for the aspiration of gastric contents by Metheny et al. Although this percentage of aspiration increased as GRVs increased, even patients who had a GRV between 0-50mL had $33.7 \%$ positive pepsin assays (Metheny et al.).

Parrish and McClave (2008) suggest that the practice of assessing GRVs developed from a set of assumptions that reflect a paucity of scientific data. These assumptions include that: the practice of assessing GRVs will identify abnormal gastric emptying, elevated GRVs are a direct result of delayed gastric emptying, the GRV evaluates retention of enteral formula, accumulation of enteral nutrition in the stomach leads to aspiration, and aspiration of gastric contents results in pneumonia. According to Parrish and McClave, the ultimate impact of these assumptions was that enteral nutrition was frequently discontinued inappropriately based on the practice of assessing GRVs. Furthermore, they suggest that the use of GRVs has never been shown to improve patient outcome or reduce complications and thus there is little point in standardising this practice. They have highlighted the poor sensitivity, specificity and accuracy in the GRVs correlation to gastric emptying or predicting outcomes. Despite this, high gastric residual volumes were identified as one of the primary reasons for discontinuing enteral nutrition (McClave et al., 1999), and required significant nursing time (Mentec et al., 2001). One recent prospective observational study in the United States of America (USA) suggested removing the measurement of GRV from enteral nutrition protocols to improve delivery (O'Meara et al., 2008). This was contested by Metheny (2008) who, critiques O'Meara et al.'s study.

Metheny (2008) suggested that O’Meara et al.'s (2008) data may not be reliable due to the possibility of the participants 'small-bowel tubes' to have been dislocated upward into the stomach, purporting that this may have accounted for the unusually high residual volumes found in the study. Metheny strongly disagreed with O'Meara et al.'s recommendation to abandon GRV measurements and argued, citing two studies (Mentec et al., 2001; Metheny et 
al., 2008), that GRV assessment may identify patients at high risk for aspiration and aspiration-related pneumonia. Hence, the assessment of GRVs in conjunction with a clinical assessment of tolerance, in the enterally fed critically ill patient, may still be appropriate until more data is available recommending other measures (Parrish \& McClave, 2008).

\section{How the intervention might work}

It is essential to balance important benefits against important harms when administering enteral nutrition and this is demonstrated in the objectives of this systematic review. The objectives seek the potential benefits of the delivery of optimal caloric intake by identifying the best evidentiary GRV. This is balanced against the complications related to accepting a GRV too high or too low, potentially predisposing the adult ICU patient to harm.

\section{OBJECTIVES}

The aim of this systematic review is to investigate gastric residual volumes in the gastrically fed adult ICU patient related to the primary outcome measures indicative of: accepting a specified GRV too high, and hence placing the patient at risk of vomiting, regurgitation, aspiration of gastric contents and potentially aspiration pneumonia; or accepting a specified GRV too low, and hence not achieving caloric needs, potentially placing the patient at risk of malnutrition and increased morbidity. This systematic review sought to answer the research question: what is the maximum GRV to accept and continue the delivery of enteral nutrition in the ICU adult patient?

\section{METHODS}

The review will follow the following protocol. 


\section{Criteria for considering studies for this review}

\section{Types of Studies}

Four types of studies will be eligible for inclusion: randomised controlled trials with random or quasi-random allocation of subjects to intervention and control groups; case controlled studies; cohort studies; and observational studies.

\section{Types of Participants}

Studies of participants aged 16 years or over, in the critical care or intensive care unit, and delivered enteral nutrition by a nasogastric or orogastric tube, will be included.

\section{Types of Interventions}

Studies that compared two or more GRVs will be included.

\section{Types of Outcome Measures}

Eligible studies will have outcome measures including caloric requirements met, or adverse events including: vomiting (or emesis), regurgitation, or aspiration.

\section{Search Methods for Identification of studies}

The databases to be used in the search include: The Cochrane Library; CINAHL Plus with Full Text (EBSCO host via helicon); AMED, Ovid Nursing Full Text plus, EMBASE, CDSR, ACP Journal Club, DARE, CCTR, CLCMR, CLTA, CLEED, OVID MEDLINE (R) (Ovid SP); Proquest via helicon (advanced search); Pubmed via helicon (limits "all adult", "humans", "abstract", "title"); and all EBM reviews. The key search terms will include: 
gastric residual', 'gastric aspirate', or 'residual volume'; 'enteral nutrition', 'gastric feeding', 'nutrition' or 'tube feeding'; and 'intensive care', 'ICU' or 'critically ill'. The search will be limited to research published within the time period of 1998-2008 (a 10 year period), to obtain the most recent evidence available at the date of this review.

\section{Searching Other Resources}

Parenteral and enteral nutrition association websites including: American Society for Parenteral and Enteral Nutrition (ASPEN), Australian Society for Parenteral and Enteral Nutrition (AUSPEN), European Society for Parenteral and Enteral Nutrition (ESPEN), British Association of Parenteral and Enteral Nutrition (BAPEN), Canadian Parenteral and Enteral Nutrition Association, South African Society for Parenteral and Enteral Nutrition, will also be searched. Critical care websites to be searched will include the Joint Faculty of Intensive Care Medicine (JFICM) and European Society of Intensive Care Medicine (ESICM). The computer search will be supplemented by citation and author review of the articles selected and search of the grey literature including unpublished thesis and government documents. These will be searched for further relevant literature.

\section{Data Collection and Analysis}

\section{Selection of Studies}

In accordance with the defined inclusion criteria, titles and abstracts will be reviewed for obviously irrelevant reports, taking care to be over-inclusive at this stage. Included in the title and abstract review will be primary studies from the past 10 years (1998 to 2008) that addressed: specifically gastric residual volumes; factors impeding delivery of enteral nutrition; tolerance or intolerance of enteral nutrition; and risk factors related to provision or delivery of enteral nutrition. 
All primary studies identified in the abstract review that would potentially compare two or more GRVs in the enterally fed ICU adult patient will be obtained in full-text or portable document format (PDF). The full-text studies or PDFs will then be examined for compliance with the eligibility criteria. These final included studies will then be critically appraised.

For any uncertainty related to acceptability of the study, the full text of the citation will be obtained for further evaluation. Following review, the full texts of eligible abstracts will then be re-reviewed by the author and justification for excluding studies at this stage will be documented.

\section{Data Extraction}

A data extraction form was developed by the author for the review which demarked characteristics of the included studies. This is displayed in Table 1. 
Table 1. Data extraction form

\begin{tabular}{|c|c|c|c|}
\hline \multicolumn{4}{|c|}{ DATA EXTRACTION FORM } \\
\hline \multicolumn{4}{|l|}{\begin{tabular}{l|l} 
STUDY ID & \\
\end{tabular}} \\
\hline \multicolumn{4}{|l|}{ REVISION DATE } \\
\hline \multicolumn{4}{|l|}{ REVIEWER ID } \\
\hline \multicolumn{4}{|l|}{ NOTES } \\
\hline & \multicolumn{3}{|c|}{$\begin{array}{l}\text { ELIGIBLE FOR INCLUSION (tick } \\
\text { appropriate box) }\end{array}$} \\
\hline & YES & NO & UNCLEAR \\
\hline $\begin{array}{l}\text { TYPE OF STUDY } \\
\text { Randomised controlled trial/Case } \\
\text { controlled study/Cohort } \\
\text { study/Observational study }\end{array}$ & & & \\
\hline $\begin{array}{l}\text { TYPE OF PARTICIPANTS } \\
\text { Adult ICU patients }\end{array}$ & & & \\
\hline $\begin{array}{l}\text { TYPE OF INTERVENTION } \\
\text { Comparison of } 2 \text { or more GRVs }\end{array}$ & & & \\
\hline $\begin{array}{l}\text { TYPE OF OUTCOME } \\
\text { MEASURE (one or more) } \\
\text { 1. Caloric requirements achieved } \\
\text { 2. Adverse events (one or more) } \\
\text { a) vomiting (or emesis) } \\
\text { b) regurgitation } \\
\text { c) aspiration }\end{array}$ & & & \\
\hline \multicolumn{4}{|l|}{ Sample size } \\
\hline \multicolumn{4}{|l|}{ Participant demographics } \\
\hline \multicolumn{4}{|l|}{ Methods } \\
\hline \multicolumn{4}{|l|}{ Reported outcomes } \\
\hline \multicolumn{4}{|l|}{ Comments } \\
\hline Level of Evidence (GRADE) & & & \\
\hline
\end{tabular}

*Guided by the recommendations of: Higgins JPT, Deeks JJ (editors). Chapter 7: Selecting studies and collecting data. In: Higgins JPT, Green S (editors), Cochrane Handbook for Systematic Reviews of Interventions Version 5.0.1 (updated September 2008). The Cochrane Collaboration, 2008. Available from www.cochrane-handbook.org. 


\section{Quality Assessment of Included Studies}

To facilitate quality assessment of the included studies the author plans to independently assess the quality of randomisation of included studies using the Cochrane Collaboration guideline (Higgins \& Altman, 2008). Recommendations related to: allocation; blinding; follow-up and exclusions; selective reporting; and other potential sources of blinding. This assessment tool is depicted in Table 2, which summarises the framework for assessing the risk of bias.

Table 2. Risk of bias assessment tool*

\begin{tabular}{|l|l|l|}
\hline Domain & $\begin{array}{l}\text { Reviewers } \\
\text { judgement }\end{array}$ \\
\hline Sequence generation & & \\
\hline Allocation concealment & \\
\hline $\begin{array}{l}\text { Blinding of participants, } \\
\text { personnel and outcome } \\
\text { assessors }\end{array}$ & & \\
\hline $\begin{array}{l}\text { Incomplete outcome } \\
\text { data }\end{array}$ & & \\
\hline Selective outcome reporting & & \\
\hline Other sources of bias & & \\
\hline
\end{tabular}

*Adapted from Reeves, B., Deeks, J., Higgins, J., \& Wells, G. (2008). Including non-randomized studies. In J. Higgins \& S. Green (Eds.), Cochrane Handbook for Systematic Reviews of Interventions Version 5.0.1 (updated September 2008): The Cochrane Collaboration.

This framework would not be appropriate for non-randomised controlled trials, so the "Strengthening the Reporting of Observational Studies in Epidemiology" (STROBE) guide (von Elm et al., 2007), which provides a checklist of items that should be addressed in reports of observational studies, was adapted to appraise the quality of non-randomised controlled trials and is summarised in Table 3. 
Table 3. Risk of bias assessment tool for a descriptive observational study*

\begin{tabular}{|l|l|l|}
\hline \multicolumn{2}{|c|}{ Evidence } & $\begin{array}{l}\text { Reviewers decision } \\
\text { (criteria met / not } \\
\text { met) }\end{array}$ \\
\hline Title and abstract & & \\
\hline Introduction & & \\
\hline Background/rationale & & \\
\hline Objectives & & \\
\hline Methods & & \\
\hline Study design & & \\
\hline Setting & & \\
\hline Participants & & \\
\hline Variables & & \\
\hline $\begin{array}{l}\text { Data sources/ } \\
\text { Measurement }\end{array}$ & & \\
\hline Bias & & \\
\hline Study size & & \\
\hline Quantitative variables & & \\
\hline Statistical methods & & \\
\hline Results & & \\
\hline Participants & & \\
\hline Descriptive data & & \\
\hline Outcome data & & \\
\hline Main results & & \\
\hline Other analyses & & \\
\hline Discussion & & \\
\hline Key results & & \\
\hline Limitations & & \\
\hline Interpretation & & \\
\hline Generalisability & & \\
\hline Other information & & \\
\hline Funding & & \\
\hline & & \\
\hline
\end{tabular}

*Adapted from von Elm, E., Altman, D., Egger, M., Pocock, S., Gotzsche, P., \& Vandenbroucke, J. (2007). The strengthening the reporting of observational studies in epidemiology (STROBE) statement: Guidelines for reporting observational studies. Lancet, 370, 1453-1457.

\section{Levels of Evidence, Error and Bias}

Assigning a level of evidence, for the purpose of this systematic review, will be to facilitate identifying the quality and strength of the research methods used in the studies reviewed (Melnyk, 2004). The Cochrane Collaboration (Reeves et 
al., 2008) outline the Grades of Recommendation, Assessment, Development and Evaluation (GRADE) approach to guide appropriation of a level of quality to a body of evidence. The GRADE approach is summarised in Table 4.

Table 4. Cochrane's levels of quality of a body of evidence in the GRADE approach* $^{*}$

\begin{tabular}{|l|l|}
\hline Underlying methodology & Quality rating \\
\hline $\begin{array}{l}\text { Randomised trials; or double-upgraded observational } \\
\text { studies. }\end{array}$ & High \\
\hline $\begin{array}{l}\text { Downgraded randomised trials; or upgraded } \\
\text { observational studies. }\end{array}$ & Moderate \\
\hline $\begin{array}{l}\text { Double-downgraded randomised trials; or } \\
\text { observational studies. }\end{array}$ & Low \\
\hline $\begin{array}{l}\text { Triple-downgraded randomised trials; or downgraded } \\
\text { observational studies; or case series/case reports. }\end{array}$ & Very low \\
\hline
\end{tabular}

*Adapted from Reeves, B., Deeks, J., Higgins, J., \& Wells, G. (2008). Including non-randomized studies. In J. Higgins \& S. Green (Eds.), Cochrane Handbook for Systematic Reviews of Interventions Version 5.0.1 (updated September 2008): The Cochrane Collaboration.

\section{Ethical Considerations}

For this systematic review, it is likely conventional ethics approval will not be required as there are no human subjects. However, there is still the ethical responsibility to identify and critically appraise results accurately. This responsibility required an accurate process related to both the inclusion and exclusion criteria for studies, and also to the critical appraisal of the studies. Ideally, in a systematic review, more than one reviewer would participate in the process of research study inclusion and exclusion, quality assessment, and data extraction to facilitate reliability and validity by avoiding individual bias (Higgins \& Altman, 2008; Roe, 2007). The nature of this research project, as an independent research thesis, meant the review will be conducted by a single author and reviewer. The implication of the author as the sole reviewer 
increases the risk of bias in this systematic review and is identified as one of the limitations.

To address this potential limitation and promote reliability and validity, the research process will be documented in detail in this thesis. All studies reviewed and critically appraised, both included and excluded, will be provided. A rationale for those studies excluded will be provided. Specific criteria have been identified for systematic reviews, and has been published on the National Institute for Health and Clinical Excellence website (Sander \& Kitcher, 2006). These criteria, deemed of priority in the production of a systematic review of quality, included: search strategy; data synthesis; focussed question; study inclusion and exclusion criteria; study quality; data extraction; and study selection assessment. The Cochrane Collaboration and Cochrane systematic reviews have been exemplified throughout systematic review literature (Roe, 2007; Stevens, 2001). The critical appraisal process for this systematic review was adapted from the Cochrane systematic review framework (Higgins \& Altman, 2008) and the STROBE guideline (von Elm et al., 2007). This provided both clarity and validated tools to ensure accuracy in the critical appraisals. Moher et al. (1995) have investigated checklists and scales that assist in the assessing and reporting of randomised controlled trials.

Several shortcomings in checklists and scales for the assessment and reporting of randomised controlled trials have been identified by Moher et al. (1995). Jadad et al. (1996) described the development of a tool to assess randomised controlled trials for quality, and the impact of rater blinding on the quality assessment. Authors found that blinded assessments of randomised controlled trial were significantly lower and more consistent than open assessments. A blinded approach to appraisal of the included studies would have been optimal for this systematic review to enhance consistency and minimise potential bias. The nature of this research project, as previously identified, requires it to be conducted by a single author and reviewer. In effect, it would not possible to blind the reviewer in the appraisal process which further potentiates the risk of bias in this systematic review. 


\section{Data Analysis}

Dichotomous data will be presented as relative risk, and to be calculated as an overall relative risk with a $95 \%$ confidence interval. Sources of potential heterogeneity will be assessed according to the criteria outlined by Deeks et al. (2008). Firstly, clinical heterogeneity will be determined by considering the specific interventions and patient characteristics. If the studies are clinically homogenous, methodological heterogeneity will be determined by considering the use of blinding, allocation concealment, and outcome measures. Should the studies be both clinically and methodologically homogenous, statistical heterogeneity will be determined by assessment of outcome measures with subgroup or sensitivity analyses using the chi-squared test, which will be included in forest plots (Deeks et al.). This test will measure whether identified differences in results could be attributable to chance alone. Inconsistency will be measured using I-squared $\left(\mathrm{I}^{2}\right)$ to identify whether variability in effect may be due to heterogeneity or purely chance (Deeks et al.).

If the data from the randomised controlled trials are of sufficient quality and generalisability, they will be combined in a meta-analysis to provide a pooled effect estimate. Sensitivity will be maximised by excluding unpublished studies and by the critical appraisal of all included studies. Assessment for publication bias will be through the use of funnel plots if sufficient randomised controlled trials are identified.

\section{ACKNOWLEDGEMENTS}

This research project will be supervised by Sara Quirke, Lecturer, Victoria University of Wellington. 


\section{Appendix 2. Risk of bias assessment tool*}

\begin{tabular}{|l|l|l|}
\hline Domain & Description & Reviewers' judgement \\
\hline Sequence generation & & \\
\hline Allocation concealment & & \\
\hline $\begin{array}{l}\text { Blinding of participants, } \\
\text { personnel and outcome assessors }\end{array}$ & & \\
\hline $\begin{array}{l}\text { Incomplete outcome } \\
\text { data }\end{array}$ & & \\
\hline Selective outcome reporting & & \\
\hline Other sources of bias & & \\
\hline
\end{tabular}

*Adapted from Reeves, B., Deeks, J., Higgins, J., \& Wells, G. (2008). Including non-randomized studies. In J. Higgins \& S. Green (Eds.), Cochrane Handbook for Systematic Reviews of Interventions Version 5.0.1 (updated September 2008): The Cochrane Collaboration. 


\section{Appendix 3. Risk of bias assessment tool for a descriptive observational study*}

\begin{tabular}{|l|l|l|}
\hline & Evidence & $\begin{array}{l}\text { Reviewers decision } \\
\text { (criteria met / not } \\
\text { met) }\end{array}$ \\
\hline Title and abstract & & \\
\hline Introduction & & \\
\hline Background/rationale & & \\
\hline Objectives & & \\
\hline Methods & & \\
\hline Study design & & \\
\hline Setting & & \\
\hline Participants & & \\
\hline Variables & & \\
\hline Data sources/Measures & & \\
\hline Bias & & \\
\hline Study size & & \\
\hline Quantitative variables & & \\
\hline Statistical methods & & \\
\hline Results & & \\
\hline Participants & & \\
\hline Descriptive data & & \\
\hline Outcome data & & \\
\hline Main results & & \\
\hline Other analyses & & \\
\hline Discussion & & \\
\hline Key results & & \\
\hline Limitations & & \\
\hline Interpretation & & \\
\hline Generalisability & & \\
\hline Other information & & \\
\hline Funding & & \\
\hline
\end{tabular}

*Adapted from von Elm, E., Altman, D., Egger, M., Pocock, S., Gotzsche, P., \& Vandenbroucke, J. (2007). The strengthening the reporting of observational studies in epidemiology (STROBE) statement: Guidelines for reporting observational studies. Lancet, 370, 1453-1457. 


\section{Appendix 4. Cochrane's levels of quality of a body of evidence in the GRADE approach*}

\begin{tabular}{|l|l|}
\hline Underlying methodology & Quality rating \\
\hline $\begin{array}{l}\text { Randomised trials; or double-upgraded } \\
\text { observational studies. }\end{array}$ & High \\
\hline $\begin{array}{l}\text { Downgraded randomised trials; or } \\
\text { upgraded observational studies. }\end{array}$ & Moderate \\
\hline $\begin{array}{l}\text { Double-downgraded randomised trials; } \\
\text { or observational studies. }\end{array}$ & Low \\
\hline $\begin{array}{l}\text { Triple-downgraded randomised trials; } \\
\text { or downgraded observational studies; } \\
\text { or case series/case reports. }\end{array}$ & Very low \\
\hline
\end{tabular}

*Adapted from Reeves, B., Deeks, J., Higgins, J., \& Wells, G. (2008). Including non-randomized studies. In J. Higgins \& S. Green (Eds.), Cochrane Handbook for Systematic Reviews of Interventions Version 5.0.1 (updated September 2008): The Cochrane Collaboration. 


\section{Appendix 5. Data extraction form}

\begin{tabular}{|c|c|c|c|}
\hline \multicolumn{4}{|c|}{ DATA EXTRACTION FORM } \\
\hline \multirow{2}{*}{\multicolumn{4}{|c|}{\begin{tabular}{l|l} 
STUDY ID/REVIEWER ID & \\
REVISION DATE & \\
\end{tabular}}} \\
\hline & & & \\
\hline & \multicolumn{3}{|c|}{ ELIGIBLE FOR INCLUSION } \\
\hline & YES & $\mathrm{NO}$ & UNCLEAR \\
\hline $\begin{array}{l}\text { TYPE OF STUDY } \\
\text { Randomised controlled trial/Case } \\
\text { controlled trial/Cohort } \\
\text { study/Observational study }\end{array}$ & & & \\
\hline $\begin{array}{l}\text { TYPE OF PARTICIPANTS } \\
\text { Adult ICU patients }\end{array}$ & & & \\
\hline $\begin{array}{l}\text { TYPE OF INTERVENTION } \\
\text { Comparison of } 2 \text { or more GRVs }\end{array}$ & & & \\
\hline $\begin{array}{l}\text { TYPE OF OUTCOME } \\
\text { MEASURE (one or more) } \\
\text { 1. Caloric requirements achieved } \\
\text { 2. Adverse events (one or more) } \\
\text { a) vomiting (or emesis) } \\
\text { b) regurgitation } \\
\text { c) aspiration }\end{array}$ & & & \\
\hline Sample size & & & \\
\hline Participant demographics & & & \\
\hline Methods & & & \\
\hline Reported outcomes & & & \\
\hline Comments & & & \\
\hline Level of Evidence (GRADE) & & & \\
\hline
\end{tabular}

*Guided by the recommendations of: Higgins JPT, Deeks JJ (editors). Chapter 7: Selecting studies and collecting data. In: Higgins JPT, Green S (editors), Cochrane Handbook for Systematic Reviews of Interventions Version 5.0.1 (updated September 2008). The Cochrane Collaboration, 2008. Available from www.cochrane-handbook.org. 


\section{Appendix 6. Search sources, terms and numbers retrieved}

\begin{tabular}{|c|c|c|}
\hline Source searched & Search strategy & Hits retrieved \\
\hline $\begin{array}{l}\text { Cinahl Plus with Full } \\
\text { Text (EBSCOhost via } \\
\text { helicon) }(4 / 08 / 2008) .\end{array}$ & $\begin{array}{l}\text { 1. Enteral nutrition } \\
\text { AND critical care. } \\
\text { 2. Gastric residual. } \\
\text { No limiters used. }\end{array}$ & $\begin{array}{ll}\text { 1. } & 274 \\
\text { 2. } & 47\end{array}$ \\
\hline $\begin{array}{l}\text { AMED, Ovid Nursing } \\
\text { Full Text plus, } \\
\text { EMBASE, CDSR, ACP } \\
\text { Journal Club, DARE, } \\
\text { CCTR, CLCMR, CLTA, } \\
\text { CLEED, OVID } \\
\text { MEDLINE (R) (Ovid } \\
\text { SP) (20/09/2008). }\end{array}$ & $\begin{array}{l}\text { 1. Gastric residual.mp. } \\
{[\mathrm{mp}=\mathrm{ab}, \mathrm{hw}, \mathrm{kw}, \mathrm{ti} \text {, }} \\
\text { ot, sh, tn, dm, mf, tx, } \\
\text { ct, nm]. } \\
\text { No limiters used. }\end{array}$ & 1. 272 \\
\hline $\begin{array}{l}\text { Proquest (advanced } \\
\text { search) (via helicon) }\end{array}$ & $\begin{array}{l}\text { 1. Gastric residual. } \\
(21 / 09 / 2008) . \\
\text { 2. Prevention of } \\
\text { aspiration } \\
\text { pneumonia. } \\
(21 / 09 / 2009) \text {. } \\
\text { 3. Gastric aspirate. } \\
\text { Limiters: 'citation and } \\
\text { abstract'. }\end{array}$ & $\begin{array}{ll}\text { 1. } & 134 \\
\text { 2. } & 48 \\
\text { 3. } & 87\end{array}$ \\
\hline $\begin{array}{l}\text { Pubmed (limits "all } \\
\text { adult", "humans", } \\
\text { "abstract", "title") } \\
\text { (4/08/2008) (Pubmed via } \\
\text { helicon). }\end{array}$ & $\begin{array}{l}\text { 1. Gastric residual. } \\
\text { Limiters: 'all adult, } \\
\text { humans, abstract, title'. }\end{array}$ & 1. 49 \\
\hline Proquest $(02 / 03 / 2009)$ & $\begin{array}{l}\text { 1. Gastric residual } \\
\text { No limiters }\end{array}$ & 1. 53 \\
\hline Pubmed (02/03/2009) & $\begin{array}{l}\text { 1. Gastric residual } \\
\text { No limiters used }\end{array}$ & 1. 112 \\
\hline Cinahl Plus with full text & 1. Gastric residual & 1. 49 \\
\hline The Cochrane Library & 1. Gastric residual & 1. 178 \\
\hline $\begin{array}{l}\text { Amed, all EBM reviews, } \\
\text { EMBASE all years, } \\
\text { Medline 1996-current) } \\
\text { (Ovid SP) }\end{array}$ & $\begin{array}{l}\text { 1. Gastric residual } \\
\text { Removed duplicates }\end{array}$ & 1. 143 \\
\hline
\end{tabular}

Allied and Complementary Medicine (Amed) 1985 - September 2008, EBM Reviews - ACP Journal Club 1991 - August 2008, EBM Reviews - Cochrane 
Central Register of Controlled Trials $3^{\text {rd }}$ Quarter 2008, EMB Reviews Cochrane Database of Systematic Reviews $3^{\text {rd }}$ Quarter 2008, EBM Reviews Cochrane Methodology Register $3^{\text {rd }}$ Quarter 2008, EMB Reviews - Database of Abstracts of Reviews of Effects $3^{\text {rd }}$ Quarter 2008, EBM Reviews - NHS Economic Evaluation Database $3^{\text {rd }}$ Quarter 2008, EMB Reviews - Health Technology Assessment $3^{\text {rd }}$ Quarter 2008, Ovid MEDLINE(R) 1996 to Present with Daily Update, Ovid Nursing Full Text Plus 1950 to September Week 1 2008. 


\section{Appendix 7. Detailed characteristics of excluded studies}

\begin{tabular}{|c|c|c|c|}
\hline $\begin{array}{l}\text { Study \& } \\
\text { Method }\end{array}$ & Participants & Intervention & $\begin{array}{l}\text { Outcome } \\
\text { measures }\end{array}$ \\
\hline $\begin{array}{l}\text { Bochicchio } \\
\text { et al. (2006) } \\
\text { Prospective } \\
\text { study }\end{array}$ & $\begin{array}{l}\text { Setting: USA } \\
\mathrm{n}=57 \text { patients were } \\
\text { enrolled. } \\
\text { No exclusion criteria } \\
\text { reported. } \\
\text { Demographics: } 42 \\
\text { men, a mean age of } \\
37+/-12 \text { years. The } \\
\text { mean injury severity } \\
\text { score was } 24+/-10, \\
38 \text { patients had an } \\
\text { isolated traumatic } \\
\text { brain injury induced } \\
\text { into barbiturate } \\
\text { coma due to } \\
\text { refractory } \\
\text { intracranial } \\
\text { hypertension. } \\
\text { No sample size } \\
\text { calculations } \\
\text { reported. }\end{array}$ & $\begin{array}{l}\text { Non- } \\
\text { interventional }\end{array}$ & $\begin{array}{l}\text { 1. Tolerance to } \\
\text { enteral nutrition }\end{array}$ \\
\hline $\begin{array}{l}\text { Davies et al. } \\
(2002) \\
\text { Randomised } \\
\text { prospective } \\
\text { study }\end{array}$ & $\begin{array}{l}\text { Setting: Australia } \\
\text { n = } 73 \text { ICU patients. } \\
\text { Included: any patient } \\
\text { expected to require } \\
\text { nutritional and } \\
\text { critical care support } \\
\text { for at least } 3 \text { days. } \\
\text { Excluded: unsuitable } \\
\text { for passage of } \\
\text { nasoenteral tube, } \\
\text { already receiving } \\
\text { nutritional support, } \\
\text { expected to die } \\
\text { within } 48 \text { hrs. } \\
\text { Demographics: } \\
\text { Group } 1 \text { ( } \mathrm{n}=39 \text {, } \\
\text { gastric): mean age }\end{array}$ & $\begin{array}{l}\text { Two groups: } \\
\text { 1. Nasojejunal } \\
\text { tube fed. } \\
\text { 2. Nasogastric } \\
\text { tube fed. }\end{array}$ & $\begin{array}{l}\text { 1. Demographics } \\
\text { and admission } \\
\text { diagnosis and } \\
\text { APACHE II } \\
\text { score } \\
\text { 2. Volume of } \\
\text { enteral nutrition } \\
\text { delivered, RV } \\
\text { 6hrly, time and } \\
\text { reason for } \\
\text { cessation of } \\
\text { enteral } \\
\text { nutrition, } \\
\text { intolerance of } \\
\text { enteral } \\
\text { nutrition, ICU } \\
\text { mortality rate, } \\
\text { duration of } \\
\text { enteral } \\
\text { nutrition, time } \\
\text { to reach target } \\
\end{array}$ \\
\hline
\end{tabular}




\begin{tabular}{|c|c|c|c|}
\hline $\begin{array}{l}\text { Study \& } \\
\text { Method }\end{array}$ & Participants & Intervention & $\begin{array}{l}\text { Outcome } \\
\text { measures }\end{array}$ \\
\hline & $\begin{array}{l}53.5 \pm 2.9 y \text { ys, } 24 \text { men } \\
\text { and } 15 \text { women, } \\
\text { APACHE II score at } \\
\text { admission } 20.7 \pm 1.3 \\
\text { and at randomisation } \\
18.6 \pm 1.1 \text {, } \\
\text { mechanically } \\
\text { ventilated } 35 . \\
\text { Group } 2 \text { (n = } 34, \\
\text { jejunal): mean age } \\
55.7 \pm 3.63,26 \text { men } \\
\text { and } 8 \text { women, } \\
\text { APACHE II score at } \\
\text { admission } 20.4 \pm 1.5 \\
\text { and at randomisation } \\
17.6 \pm 1.3 \text {, } \\
\text { mechanically } \\
\text { ventilated } 31 . \\
\text { Primary diagnoses } \\
\text { for both groups were } \\
\text { cardiogenic shock, } \\
\text { septic shock/multiple } \\
\text { organ failure, } \\
\text { pneumonia/acute } \\
\text { respiratory failure, } \\
\text { liver } \\
\text { disease/gastrointesti } \\
\text { nal tract illness, } \\
\text { spinal cord injury, } \\
\text { neurologic illness } \\
\text { and multiple trauma. } \\
\text { Sample size } \\
\text { calculations } \\
\text { conducted by the } \\
\text { authors and were: } 35 \\
\text { participants with } \\
80 \% \text { power and } 5 \% \\
\text { significance. }\end{array}$ & & $\begin{array}{l}\text { enteral nutrition } \\
\text { rate } \\
\text { 3. Development } \\
\text { of pneumonia, } \\
\text { systemic } \\
\text { inflammatory } \\
\text { response } \\
\text { syndrome, } \\
\text { severe sepsis, } \\
\text { septic shock, } \\
\text { renal failure, } \\
\text { gastrointestinal } \\
\text { bleeding, } \\
\text { diarrhoea, } \\
\text { inadvertent } \\
\text { removal of then } \\
\text { NGT, NGT } \\
\text { blockage, and } \\
\text { any other } \\
\text { adverse effects. }\end{array}$ \\
\hline $\begin{array}{l}\text { Desachy et } \\
\text { al. (2008) } \\
\text { Open } \\
\text { prospective } \\
\text { randomised } \\
\text { study }\end{array}$ & $\begin{array}{l}\text { Setting: USA } \\
\mathrm{n}=100 \text { consecutive } \\
\text { intubated and } \\
\text { mechanically } \\
\text { ventilated patients in } \\
\text { medical/surgical }\end{array}$ & $\begin{array}{l}\text { Two groups: } \\
\text { 1. Commence } \\
\text { early enteral } \\
\text { nutrition } \\
\text { gradually } \\
\text { (gradual } \\
\text { early enteral }\end{array}$ & 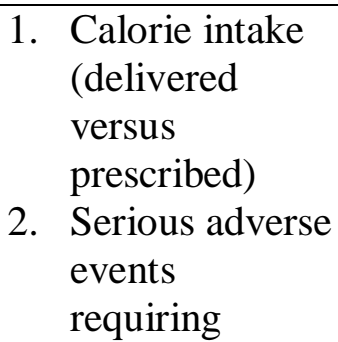 \\
\hline
\end{tabular}




\begin{tabular}{|c|c|c|c|}
\hline $\begin{array}{l}\text { Study \&z } \\
\text { Method }\end{array}$ & Participants & Intervention & $\begin{array}{l}\text { Outcome } \\
\text { measures }\end{array}$ \\
\hline & $\begin{array}{l}\text { ICUs. } \\
\text { Demographics: } \\
\text { Group } 1 \text { ( } \mathrm{n}=50 \text {, } \\
\text { gradual early enteral } \\
\text { nutrition). } \\
\text { Group } 2 \text { ( } \mathrm{n}=50, \\
\text { immediate early } \\
\text { enteral nutrition). } \\
69 \text { men and } 31 \\
\text { women were } \\
\text { enrolled; mean age } \\
\text { was } 61 \pm 16 \text { yrs } \\
\text { (range, } 18-90 \text { years). } \\
\text { Admissions were } 68 \\
\text { medical, } 11 \text { surgical } \\
\text { and } 21 \text { traumas. } \\
\text { Mean SAPS II score } \\
\text { was } 41 \pm 14 \text { (range } 9- \\
83 \text { ). Randomisation } \\
\text { bias led to } \\
\text { significantly more } \\
\text { patients being } \\
\text { admitted post- } \\
\text { surgery in the } \\
\text { gradual group and } \\
\text { more patients being } \\
\text { admitted for trauma } \\
\text { in the immediate } \\
\text { optimal flow group. }\end{array}$ & $\begin{array}{l}\text { nutrition), or } \\
\text { 2. Commence } \\
\text { enteral } \\
\text { nutrition at } \\
\text { optimal flow } \\
\text { rate } \\
\text { (immediate } \\
\text { early enteral } \\
\text { nutrition). }\end{array}$ & $\begin{array}{l}\text { enteral nutrition } \\
\text { withdrawal } \\
\text { (colectasia, } \\
\text { suspected } \\
\text { aspiration, } \\
\text { regurgitation, } \\
\text { vomiting) } \\
\text { 3. Tolerability of } \\
\text { enteral nutrition } \\
\text { (GRVs } \\
\text { measured and } \\
\text { diarrhoea). }\end{array}$ \\
\hline $\begin{array}{l}\text { Elpern, } \\
\text { Stutz, } \\
\text { Peterson, } \\
\text { Gurka, \& } \\
\text { Skipper } \\
\text { (2004) } \\
\text { Prospective } \\
\text { descriptive } \\
\text { study }\end{array}$ & $\begin{array}{l}\text { Setting: USA } \\
\mathrm{n}=39 \text { medical ICU } \\
\text { patients. } \\
\text { Included: } 18 \text { years or } \\
\text { older admitted } \\
\text { during } 3 \text {-month } \\
\text { period of data } \\
\text { collection and } \\
\text { ordered to receive } \\
\text { enteral nutrition. } \\
\text { Excluded: those } \\
\text { patients unlikely to } \\
\text { stay in the ICU for a } \\
\text { minimum of } 48 \text { hrs }\end{array}$ & $\begin{array}{l}\text { Non- } \\
\text { interventional }\end{array}$ & $\begin{array}{l}\text { 1. Feeding } \\
\text { protocol } \\
\text { described, GRV } \\
<150 \mathrm{~mL} \text { was } \\
\text { considered } \\
\text { acceptable to } \\
\text { continue } \\
\text { feeding in this } \\
\text { study. } \\
\text { 2. Compare actual } \\
\text { intake delivered } \\
\text { with ordered } \\
\text { energy intake to } \\
\text { be delivered. } \\
\text { 3. Ascertain } \\
\text { frequency, }\end{array}$ \\
\hline
\end{tabular}




\begin{tabular}{|c|c|c|c|}
\hline $\begin{array}{l}\text { Study \& } \\
\text { Method }\end{array}$ & Participants & Intervention & $\begin{array}{l}\text { Outcome } \\
\text { measures }\end{array}$ \\
\hline & $\begin{array}{l}\text { or if they received } \\
\text { any oral or } \\
\text { parenteral feedings. } \\
\text { Demographics: } 54 \% \\
\text { of patients were } \\
\text { men, the mean age } \\
\text { was } 60.6 \text { years } \\
\text { (range, } 27-93 \text { years), } \\
\text { The mean APACHE } \\
\text { II was } 19.97 \text { (range, } \\
\text { 9-33). Large-bore } \\
\text { NGT were in place } \\
\text { for } 79 \% \text { of feeding } \\
\text { days, PEG tubes in } \\
14 \% \text { and small-bore } \\
\text { feeding tubes for } \\
7 \% \text {. } \\
\text { No sample size } \\
\text { calculations } \\
\text { reported. }\end{array}$ & & $\begin{array}{l}\text { duration, and } \\
\text { reasons for } \\
\text { interruptions of } \\
\text { feedings. } \\
\text { 4. Determine } \\
\text { instances of } \\
\text { feeding } \\
\text { intolerance and } \\
\text { complications } \\
\text { related to } \\
\text { feeding. }\end{array}$ \\
\hline $\begin{array}{l}\text { Esparza et al. } \\
(2001) \\
\text { Prospective } \\
\text { controlled } \\
\text { trial }\end{array}$ & $\begin{array}{l}\text { Setting: USA } \\
\mathrm{n}=54 \text { critically ill } \\
\text { patients. } \\
\text { Inclusion/exclusion } \\
\text { criteria were not } \\
\text { discussed. } \\
\text { Demographics: } \\
\text { Group } 1 \text { ( } \mathrm{n}=27, \\
\text { gastric): mean age } \\
50 \pm 17 \mathrm{yrs}, 17 \text { men } \\
\text { and } 10 \text { women, } \\
\text { APACHE II score } \\
\text { 17.1 }+5.9, \\
\text { mechanically } \\
\text { ventilated } 25, \text { SAPS } \\
10.1 \pm 3.7, \text { and } \\
\text { Glasgow Coma } \\
\text { Score (GCS) } 10 \pm 4 . \\
\text { Group } 2 \text { (n = } 27, \\
\text { transpyloric): mean } \\
\text { age } 45 \pm 14 y r s, 20 \\
\text { men and } 7 \text { women, } \\
\text { APACHE II score } \\
15.8 \pm 4,\end{array}$ & $\begin{array}{l}\text { Two groups: } \\
\text { 1. Gastrically } \\
\text { fed patients. } \\
\text { 2. Transpyloric } \\
\text { ally fed } \\
\text { patients. }\end{array}$ & $\begin{array}{l}\text { 1. Study days, } \\
\text { feed days, } \\
\text { isotopic } \\
\text { aspiration, } \\
\text { average daily \% } \\
\text { of goal feed, } \\
\text { death. } \\
\text { 2. Use of a } \\
\text { motility agent, } \\
\text { volume of feed, } \\
\text { tube position, } \\
\text { evidence of } \\
\text { clinical or } \\
\text { isotopic } \\
\text { aspiration. }\end{array}$ \\
\hline
\end{tabular}




\begin{tabular}{|c|c|c|c|}
\hline $\begin{array}{l}\text { Study \& } \\
\text { Method }\end{array}$ & Participants & Intervention & $\begin{array}{l}\text { Outcome } \\
\text { measures }\end{array}$ \\
\hline & $\begin{array}{l}\text { mechanically } \\
\text { ventilated } 26, \text { SAPS } \\
9.4 \pm 2.8 \text {, and GCS } \\
10 \pm 4 . \\
\text { Primary diagnoses } \\
\text { for both groups were } \\
\text { pneumonia, sepsis, } \\
\text { neurological, } \\
\text { gastrointestinal } \\
\text { bleeding, and liver } \\
\text { disease. } \\
\text { Sample size } \\
\text { calculations } \\
\text { conducted by the } \\
\text { authors and were: } 54 \\
\text { participants with } \\
80 \% \text { power and } 5 \% \\
\text { significance. }\end{array}$ & & \\
\hline $\begin{array}{l}\text { Fiaccadori et } \\
\text { al. (2004) } \\
\text { Prospective } \\
\text { observational } \\
\text { study }\end{array}$ & $\begin{array}{l}\text { Setting: Italy } \\
\mathrm{n}=247 \text { patients ( } 182 \\
\text { with acute renal } \\
\text { failure). } \\
\text { Included: patients } \\
\text { receiving enteral } \\
\text { nutrition before } \\
\text { transferral to the } \\
\text { ICU or patients who } \\
\text { were started on } \\
\text { enteral nutrition in } \\
\text { the ICU. } \\
\text { Excluded: attending } \\
\text { physicians } \\
\text { established } \\
\text { indications for } \\
\text { enteral nutrition, } \\
\text { choice of enteral } \\
\text { nutrition route, and } \\
\text { exclusion criteria. } \\
\text { Demographics: } \\
\text { Group } 1 \text { ( } N=65 \text {, } \\
\text { normal renal } \\
\text { function): mean age }\end{array}$ & $\begin{array}{l}\text { Non- } \\
\text { interventional }\end{array}$ & $\begin{array}{l}\text { 1. Measurements } \\
\text { included: } \\
\text { demographics, } \\
\text { nutritional } \\
\text { support, enteral } \\
\text { nutrition- } \\
\text { related } \\
\text { complications } \\
\text { (gastrointestinal } \\
\text {, mechanical } \\
\text { and metabolic), } \\
\text { and compliance } \\
\text { with enteral } \\
\text { nutrition orders. }\end{array}$ \\
\hline
\end{tabular}




\begin{tabular}{|c|c|c|c|}
\hline $\begin{array}{l}\text { Study \& } \\
\text { Method }\end{array}$ & Participants & Intervention & $\begin{array}{l}\text { Outcome } \\
\text { measures }\end{array}$ \\
\hline & $\begin{array}{l}66.9 y r s, 39 \text { men and } \\
26 \text { women, } \\
\text { APACHE II score } \\
14.6, \text { mechanical } \\
\text { ventilation } 23 . \\
\text { Group } 2 \text { (N = 68, } \\
\text { ARF not on renal } \\
\text { replacement } \\
\text { therapy): mean age } \\
70.9 \text { yrs, } 42 \text { men and } \\
26 \text { women, } \\
\text { APACHE II score } \\
21.1, \text { mechanical } \\
\text { ventilation } 27 . \\
\text { Group } 3 \text { (N = } 114, \\
\text { acute renal failure on } \\
\text { renal replacement } \\
\text { therapy): mean age } \\
71.1 \text { yrs, } 81 \text { men and } \\
\text { 33 women, } \\
\text { APACHE II score } \\
24.0, \text { mechanical } \\
\text { ventilation } 47 . \\
\text { No sample size } \\
\text { calculations } \\
\text { reported. }\end{array}$ & & \\
\hline $\begin{array}{l}\text { Kearns et al. } \\
(2000) \\
\text { Prospective } \\
\text { randomised } \\
\text { controlled } \\
\text { trial }\end{array}$ & $\begin{array}{l}\text { Setting: USA } \\
\mathrm{n}=44 \text { intubated and } \\
\text { ventilated patients } \\
\text { requiring enteral } \\
\text { nutrition in a } \\
\text { medical ICU. } \\
\text { Excluded: } \\
\text { hypotension, } \\
\text { abdominal surgery, } \\
\text { pancreatitis, } \\
\text { gastrointestinal } \\
\text { bleeding, or ileus. } \\
\text { Demographics: } \\
\text { Group } 1 \text { (n = 21, SI): } \\
14 \text { men and } 7 \\
\text { women, mean age }\end{array}$ & $\begin{array}{l}\text { Two groups: } \\
\text { 1. Gastric tube } \\
\text { fed. } \\
\text { 2. Small } \\
\text { intestine } \\
\text { tube fed. }\end{array}$ & $\begin{array}{l}\text { 1. The primary } \\
\text { outcome } \\
\text { measures were } \\
\text { achievement of } \\
\text { caloric goals } \\
\text { and the } \\
\text { incidence of } \\
\text { VAP (process } \\
\text { described). } \\
\text { 2. Secondary } \\
\text { outcome } \\
\text { measures } \\
\text { included } \\
\text { survival, } \\
\text { duration of tube } \\
\text { feeding, } \\
\text { duration of the } \\
\text { ICU and } \\
\text { hospital stay, }\end{array}$ \\
\hline
\end{tabular}




\begin{tabular}{|c|c|c|c|}
\hline $\begin{array}{l}\text { Study \& } \\
\text { Method }\end{array}$ & Participants & Intervention & $\begin{array}{l}\text { Outcome } \\
\text { measures }\end{array}$ \\
\hline & $\begin{array}{l}54 \pm 3 y r s, \text { APACHE } \\
\text { score } 22 \pm 2 . \\
\text { Group } 2(\mathrm{n}=23, \mathrm{G}) \text { : } \\
16 \text { men and } 7 \\
\text { women, mean age } \\
49 \pm 4 \mathrm{yrs}, \text { APACHE } \\
\text { score } 20 \pm 1 . \\
\text { Primary diagnoses } \\
\text { for both groups } \\
\text { were: septic shock } \\
\text { (6), pneumonia (6), } \\
\text { cerebral vascular } \\
\text { accident (4), and } \\
\text { respiratory failure } \\
\text { (4). } \\
\text { Sample size } \\
\text { calculations } \\
\text { conducted by the } \\
\text { authors and were: } 20 \\
\text { participants per } \\
\text { group with } 80 \% \\
\text { power and } 5 \% \\
\text { significance. }\end{array}$ & & $\begin{array}{l}\text { the number of } \\
\text { feeding tubes } \\
\text { placed, the } \\
\text { incidence of } \\
\text { gastrointestinal } \\
\text { bleeding, } \\
\text { feeding } \\
\text { intolerance } \\
\text { (defined as a } \\
\text { GRV > 150mL, } \\
\text { ileus or } \\
\text { abdominal } \\
\text { distension), the } \\
\text { number of } \\
\text { blood cultures, } \\
\text { and days of } \\
\text { diarrhoea } \\
\text { (defined). }\end{array}$ \\
\hline $\begin{array}{l}\text { Kompan, } \\
\text { Vidmar, } \\
\text { Spindler- } \\
\text { Vesel, \& } \\
\text { Pecar (2004) } \\
\text { Prospective } \\
\text { study }\end{array}$ & $\begin{array}{l}\text { Setting: Slovenia } \\
\text { n= 52 patients } \\
\text { Demographics: } \\
\text { Group } 1 \text { ( } \mathrm{n}=27, \\
\text { early enteral } \\
\text { nutrition) } \\
\text { Group } 2 \text { ( } \mathrm{n}=25 \text {, } \\
\text { delayed enteral } \\
\text { nutrition) } \\
\text { Multiply injured } \\
\text { patients with an } \\
\text { injury severity score } \\
\text { of }>20 . \text { Only those } \\
\text { patients who } \\
\text { recovered from } \\
\text { shock within 6hrs of } \\
\text { admission to ICU } \\
\text { were included. } \\
\text { Admission }\end{array}$ & $\begin{array}{l}\text { Two groups: } \\
\text { 1. Intragastric } \\
\text { tube feeding } \\
\text { started } \\
\text { immediately } \\
\text { upon } \\
\text { admission } \\
\text { (early } \\
\text { enteral } \\
\text { nutrition } \\
\text { group). } \\
\text { 2. Delayed } \\
\text { feeding } \\
\text { initiated } \\
\text { more than } 24 \\
\text { hours after } \\
\text { admission } \\
\text { (delayed } \\
\text { enteral } \\
\text { nutrition } \\
\text { group). }\end{array}$ & 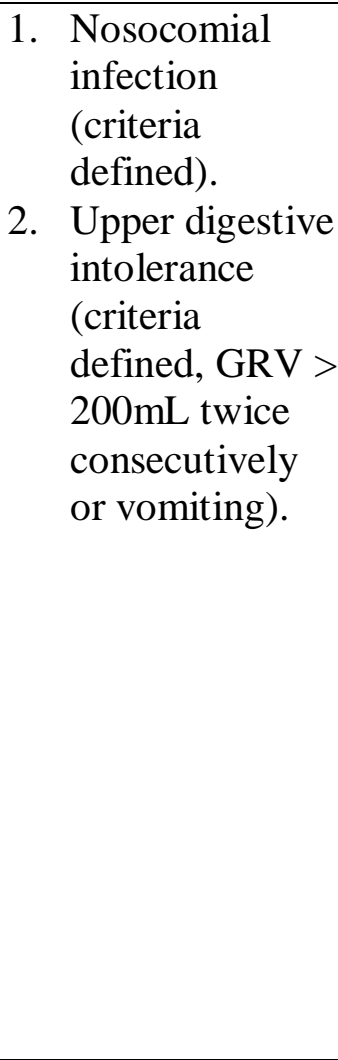 \\
\hline
\end{tabular}




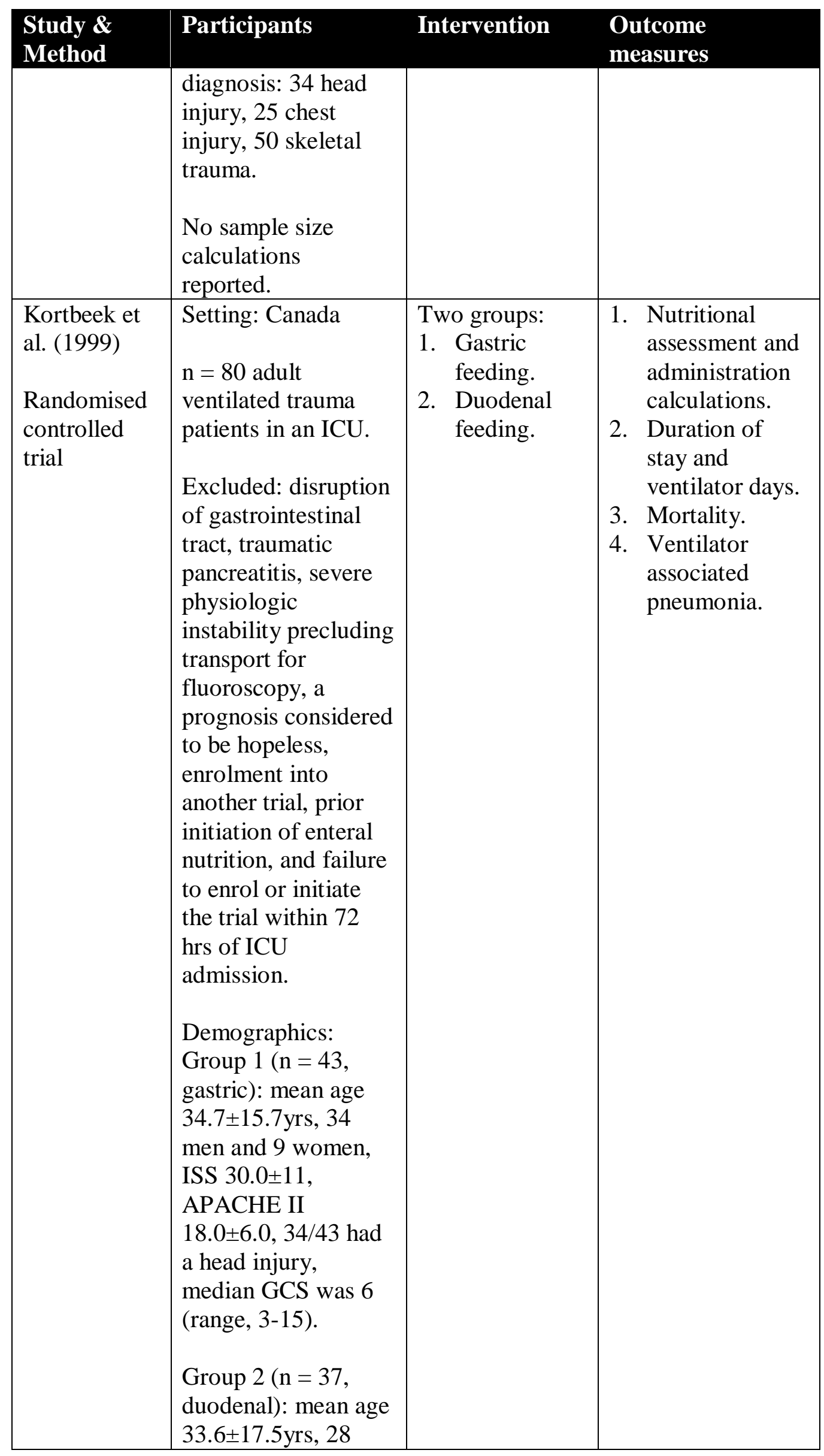




\begin{tabular}{|c|c|c|c|}
\hline $\begin{array}{l}\text { Study \& } \\
\text { Method }\end{array}$ & Participants & Intervention & $\begin{array}{l}\text { Outcome } \\
\text { measures }\end{array}$ \\
\hline & $\begin{array}{l}\text { men and } 9 \text { women, } \\
\text { ISS } 33 \pm 9.7 \text {, } \\
\text { APACHE II } \\
\text { 18.0 } \pm 7.4,28 / 37 \text { had } \\
\text { a head injury, } \\
\text { median GCS was } 5 \\
\text { (range, } 3-15 \text { ). } \\
\text { A sample size } \\
\text { calculation was } \\
\text { reported but this } \\
\text { sample size was not } \\
\text { obtained. }\end{array}$ & & \\
\hline $\begin{array}{l}\text { McClave et } \\
\text { al. (1999) } \\
\text { Prospective } \\
\text { study }\end{array}$ & $\begin{array}{l}\text { Setting: USA } \\
\mathrm{n}=44 \text { medical } \\
\text { ICU/CCU enterally } \\
\text { fed patients. } \\
\text { Demographics: } 44 \\
\text { patients (mean age } \\
57.8 \mathrm{yrs} \text {; } 70 \% \text { male); } \\
26 \text { admitted to } \\
\text { medicine/medical, } \\
12 \text { surgery/trauma, } 6 \\
\text { neurosurgery. Two } \\
\text { patients not } \\
\text { mechanically } \\
\text { ventilated. } \\
\text { Underlying disease } \\
\text { processes: chronic } \\
\text { obstructive } \\
\text { pulmonary disease } \\
\text { (11\%), diabetes } \\
\text { mellitus (23\%), } \\
\text { malignancy (14\%), } \\
\text { Acute disease } \\
\text { processes: trauma } \\
\text { (27\%), acute cardiac } \\
\text { event (16\%), } \\
\text { neurological injury } \\
\text { (45\%). } \\
\text { Excluded: patients } \\
\text { who received any } \\
\text { nutritional support } \\
\text { by oral diet or by } \\
\text { total parenteral }\end{array}$ & $\begin{array}{l}\text { Non- } \\
\text { interventional }\end{array}$ & $\begin{array}{l}\text { 1. } \begin{array}{l}\text { Volume of } \\
\text { formula } \\
\text { delivered }\end{array} \\
\text { /prescribed. } \\
\text { 2. Patient } \\
\text { position. } \\
\text { 3. Presence } \\
\text { /absence of } \\
\text { blue dye in } \\
\text { oropharynx. } \\
\text { 4. Frequency, } \\
\text { duration and } \\
\text { reasons for } \\
\text { cessation of } \\
\text { enteral } \\
\text { nutrition. } \\
\text { Avoidable } \\
\text { cessations were } \\
\text { defined. }\end{array}$ \\
\hline
\end{tabular}




\begin{tabular}{|c|c|c|c|}
\hline $\begin{array}{l}\text { Study \& } \\
\text { Method }\end{array}$ & Participants & Intervention & $\begin{array}{l}\text { Outcome } \\
\text { measures }\end{array}$ \\
\hline & $\begin{array}{l}\text { nutrition or did not } \\
\text { have a feeding tube } \\
\text { placed initially after } \\
\text { admission to the } \\
\text { medical ICU/CCU. } \\
\text { No sample size } \\
\text { calculations were } \\
\text { discussed by the } \\
\text { authors. }\end{array}$ & & \\
\hline $\begin{array}{l}\text { Mentec et al. } \\
(2001) \\
\text { Prospective } \\
\text { observational } \\
\text { study }\end{array}$ & $\begin{array}{l}\text { Setting: France } \\
\mathrm{n}=153 \text { ICU patients } \\
\text { with nasogastric tube } \\
\text { feeding } \\
\text { Demographics: } 142 \\
\text { patients were } \\
\text { admitted with a } \\
\text { medical diagnosis, } 5 \\
\text { surgical, } 6 \text { multi- } \\
\text { trauma. } 47 \text { had } \\
\text { undergone recent } \\
\text { surgery (18 had } \\
\text { laparotomy, } 7 \\
\text { surgery for multiple } \\
\text { trauma, } 22 \\
\text { miscellaneous). } 86 \\
\text { were men and } 67 \\
\text { were women with a } \\
\text { mean age of } 65 \pm 15 \\
\text { and a mean SAPS II } \\
\text { on admission of } \\
52 \pm 17.830 \text { days of } \\
\text { enteral nutrition } \\
\text { were monitored; } \\
\text { median length of } \\
\text { survey per patient } \\
\text { was } 4 \text { days (range, } 1- \\
20 \text { days). } \\
\text { No sample size } \\
\text { calculations } \\
\text { reported. }\end{array}$ & $\begin{array}{l}\text { Non- } \\
\text { interventional }\end{array}$ & $\begin{array}{l}\text { 1. Complications } \\
\text { of enteral } \\
\text { nutrition } \\
\text { 2. Monitoring of } \\
\text { patients for } \\
\text { development of } \\
\text { vomiting and } \\
\text { nosocomial } \\
\text { pneumonia } \\
\text { until ICU } \\
\text { discharge } \\
\text { 3. Patients status } \\
\text { on ICU and } \\
\text { hospital } \\
\text { discharge }\end{array}$ \\
\hline $\begin{array}{l}\text { Montejo } \\
\text { (1999) } \\
\text { Multicentre }\end{array}$ & $\begin{array}{l}\text { Setting: Spain } \\
\mathrm{n}=400 \text { consecutive } \\
\text { patients admitted to }\end{array}$ & $\begin{array}{l}\text { Non- } \\
\text { interventional }\end{array}$ & $\begin{array}{l}\text { 1. Mean time of } \\
\text { enteral nutrition } \\
\text { 2. Mean elapsed } \\
\text { time from ICU }\end{array}$ \\
\hline
\end{tabular}




\begin{tabular}{|c|c|c|c|}
\hline $\begin{array}{l}\text { Study \& } \\
\text { Method }\end{array}$ & Participants & Intervention & $\begin{array}{l}\text { Outcome } \\
\text { measures }\end{array}$ \\
\hline $\begin{array}{l}\text { prospective } \\
\text { cohort study }\end{array}$ & $\begin{array}{l}\text { the ICU and } \\
\text { receiving enteral } \\
\text { nutrition. } \\
37 \text { ICUs } \\
\text { participated, most } \\
\text { (75\%) in tertiary } \\
\text { care centres. } 400 \\
\text { patients were } \\
\text { enrolled. The } \\
\text { primary diagnosis } \\
\text { was a medical } \\
\text { disease. } \\
\text { Demographics: mean } \\
\text { age 56.6yrs, } \\
\text { APACHE II mean } \\
\text { 18.2 (range, 14-22), } \\
\text { primary admitting } \\
\text { diagnoses were: } 264 \\
\text { medical, 97 trauma, } \\
39 \text { surgery. }\end{array}$ & & $\begin{array}{l}\text { admission to } \\
\text { start of enteral } \\
\text { nutrition } \\
\text { 3. Administered } \\
\text { versus } \\
\text { prescribed } \\
\text { enteral nutrition } \\
\text { ratio calculated } \\
\text { 4. Gastrointestinal } \\
\text { complications } \\
\text { related to } \\
\text { enteral } \\
\text { nutrition, and } \\
\text { their } \\
\text { management } \\
\text { were } \\
\text { predefined then } \\
\text { these variables } \\
\text { were measured. }\end{array}$ \\
\hline $\begin{array}{l}\text { Montejo et } \\
\text { al. (2002) } \\
\text { Prospective } \\
\text { randomised } \\
\text { multicentre } \\
\text { trial }\end{array}$ & $\begin{array}{l}\text { Setting: Spain } \\
\mathrm{n}=101 \text { critically ill } \\
\text { patients who could } \\
\text { receive early enteral } \\
\text { nutrition for more } \\
\text { than } 5 \text { days in the } \\
\text { ICUs of } 11 \text { Spanish } \\
\text { teaching hospitals. } \\
\text { Inclusion: Patients } \\
\text { who could receive } \\
\text { early enteral } \\
\text { nutrition for }>5 \\
\text { days, }>18 \text { years old, } \\
\text { with no } \\
\text { contraindications to } \\
\text { enteral nutrition. } \\
\text { Exclusion: } \\
\text { anatomical } \\
\text { disruptions of } \\
\text { gastrointestinal tract, } \\
\text { previous } \\
\text { gastrointestinal } \\
\text { surgery, or } \\
\text { contraindication for } \\
\text { enteral nutrition or }\end{array}$ & $\begin{array}{l}\text { Two groups: } \\
\text { 1. Nasogastric } \\
\text { tube fed. } \\
\text { 2. Nasojejunal } \\
\text { tube fed. }\end{array}$ & $\begin{array}{l}\text { 1. Gastrointestinal } \\
\text { complications. } \\
\text { 2. Efficacy of diet } \\
\text { administration. } \\
\text { 3. Primary } \\
\text { outcomes: } \\
\text { mortality, } \\
\text { length of stay, } \\
\text { nosocomial } \\
\text { pneumonia, } \\
\text { MODS } \\
\text { (multiple organ } \\
\text { dysfunction } \\
\text { score) at day } 5 \text {, } \\
\text { MODS at } \\
\text { discharge. }\end{array}$ \\
\hline
\end{tabular}




\begin{tabular}{|c|c|c|c|}
\hline $\begin{array}{l}\text { Study \& } \\
\text { Method }\end{array}$ & Participants & Intervention & $\begin{array}{l}\text { Outcome } \\
\text { measures }\end{array}$ \\
\hline & $\begin{array}{l}\text { gastric endoscopy. } \\
\text { Demographics (no } \\
\text { significant group } \\
\text { differences): } \\
\text { Group } 1 \text { (n = 51, } \\
\text { gastric): } 35 \text { men and } \\
16 \text { women, mean age } \\
59 \pm 18 y r s, \text { APACHE } \\
\text { II score } 19 \pm 7, \\
\text { MODS score } 8 \pm 3 \text {. } \\
\text { Group } 2 \text { (n = 50, } \\
\text { jejunal): } 36 \text { men and } \\
14 \text { women, mean age } \\
57 \pm 17 y r s, \text { APACHE } \\
\text { II score } 18 \pm 6, \\
\text { MODS score } 8 \pm 3 \text {. } \\
\text { Sample size } \\
\text { calculations } \\
\text { conducted by the } \\
\text { authors and were: } \\
152 \text { participants with } \\
80 \% \text { power and } 5 \% \\
\text { significance. }\end{array}$ & & \\
\hline $\begin{array}{l}\text { Neumann \& } \\
\text { DeLegge } \\
\text { (2002) } \\
\text { Prospective } \\
\text { randomised } \\
\text { trial }\end{array}$ & $\begin{array}{l}\text { Setting: USA } \\
\mathrm{n}=60 \text { medical ICU } \\
\text { patients } \\
\text { Included: ICU } \\
\text { patients requiring } \\
\text { enteral nutrition via } \\
\text { gastric or small- } \\
\text { bowel tubes. } \\
\text { Excluded: those } \\
\text { patients with } \\
\text { gastrointestinal } \\
\text { obstruction, ileus, } \\
\text { pancreatitis, } \\
\text { documented } \\
\text { gastroparesis, and an } \\
\text { inability to gain } \\
\text { informed consent. }\end{array}$ & $\begin{array}{l}\text { Two groups: } \\
\text { 1. Naso-gastric } \\
\text { tube fed. } \\
\text { 2. Naso-small } \\
\text { bowel tube } \\
\text { fed. }\end{array}$ & 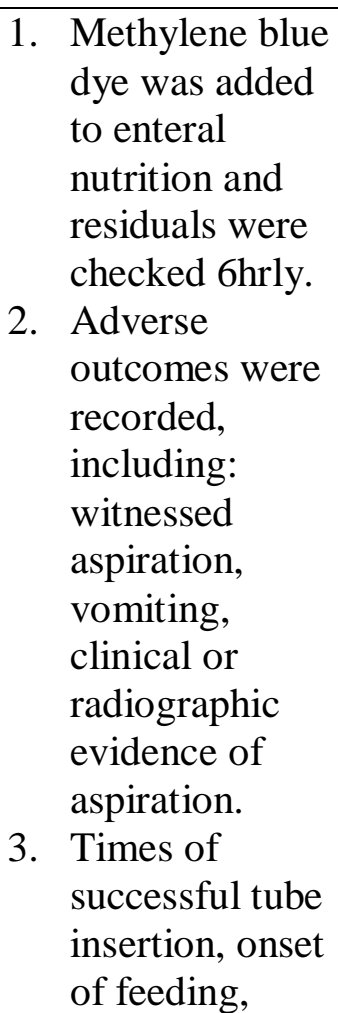 \\
\hline
\end{tabular}




\begin{tabular}{|c|c|c|c|}
\hline $\begin{array}{l}\text { Study \& } \\
\text { Method }\end{array}$ & Participants & Intervention & $\begin{array}{l}\text { Outcome } \\
\text { measures }\end{array}$ \\
\hline & $\begin{array}{l}\text { Demographics: } \\
\text { Group } 1 \text { ( } \mathrm{n}=30 \text {, } \\
\text { gastric): } 15 \text { men and } \\
15 \text { women, mean } \\
\text { patient age was } \\
58.1 \pm 15.4 \text { years, } \\
\text { predominant } \\
\text { admitting diagnoses } \\
\text { included pneumonia, } \\
\text { sepsis, congestive } \\
\text { heart failure, } \\
\text { gastrointestinal } \\
\text { bleeding and chronic } \\
\text { obstructive } \\
\text { pulmonary disease. } \\
\text { Group } 2 \text { (n = } 30, \\
\text { small bowel): } 15 \\
\text { men and } 15 \text { women, } \\
\text { mean patient age } \\
\text { was } 59.6 \pm 15.3 \text { with } \\
\text { similar admitting } \\
\text { diagnoses. } \\
\text { No sample size } \\
\text { calculations } \\
\text { reported. }\end{array}$ & & $\begin{array}{l}\text { achievement of } \\
\text { goal rate, } \\
\text { termination of } \\
\text { feeding were } \\
\text { recorded. }\end{array}$ \\
\hline $\begin{array}{l}\text { Taylor, } \\
\text { Fettes, } \\
\text { Jewkes, \& } \\
\text { Nelson } \\
\text { (1999) } \\
\text { Prospective } \\
\text { randomised } \\
\text { controlled } \\
\text { trial }\end{array}$ & $\begin{array}{l}\text { Setting: UK } \\
\mathrm{n}=82 \text { patients. } \\
\text { Inclusion criteria: } \\
\text { presence of head } \\
\text { injury requiring } \\
\text { mechanical } \\
\text { ventilation from day } \\
1 \text {; best Glasgow } \\
\text { Coma Scale (GCS) } \\
\text { score > } 3 \text { and at least } \\
\text { one reactive pupil at } \\
\text { some time during the } \\
\text { first } 24 \text { hrs; older } \\
\text { than } 10 \text { yrs; unable } \\
\text { to take oral nutrition } \\
\text { for more than } 24 \text { hrs, } \\
\text { possible to } \\
\text { commence enteral } \\
\text { nutrition within } 24\end{array}$ & $\begin{array}{l}\text { Two groups: } \\
\text { 1. Standard } \\
\text { enteral } \\
\text { nutrition } \\
\text { (gradually } \\
\text { increased to } \\
\text { goal rate). } \\
\text { 2. Enhanced } \\
\text { enteral } \\
\text { nutrition } \\
\text { (started at } \\
\text { feeding goal } \\
\text { rate). }\end{array}$ & $\begin{array}{l}\text { 1. Percentage of } \\
\text { estimated } \\
\text { energy and } \\
\text { nitrogen } \\
\text { requirements } \\
\text { met and serum } \\
\text { concentrations } \\
\text { of proteins and } \\
\text { IGF-1. } \\
\text { 2. Neurologic } \\
\text { outcome } \\
\text { (scoring system } \\
\text { described). } \\
\text { 3. Incidences of } \\
\text { infective and } \\
\text { total } \\
\text { complications } \\
\text { during hospital } \\
\text { stay up to six } \\
\text { months. }\end{array}$ \\
\hline
\end{tabular}




\begin{tabular}{|c|c|c|c|}
\hline $\begin{array}{l}\text { Study \& } \\
\text { Method }\end{array}$ & Participants & Intervention & $\begin{array}{l}\text { Outcome } \\
\text { measures }\end{array}$ \\
\hline & $\begin{array}{l}\text { hrs of injury. } \\
\text { Exclusion criteria: } \\
\text { recruitment into a } \\
\text { concurrent drug } \\
\text { study, gunshot head } \\
\text { wound, presence of } \\
\text { organ failure or } \\
\text { potentially fatal } \\
\text { disease before head } \\
\text { injury, moribund } \\
\text { state immediately } \\
\text { after head injury, } \\
\text { difficulty obtaining } \\
\text { follow-up. } \\
\text { Demographics: } \\
\text { Group } 1 \text { (n = } 41, \\
\text { standard, control): } \\
\text { median age } 28 \text { yrs, } \\
\text { ISS } 25, \text { APACHE II } \\
\text { score } 14, \text { best GCS } \\
\text { score } 8 . \\
\text { Group } 2 \text { (n = } 41, \\
\text { enhanced, } \\
\text { intervention): } \\
\text { median age } 34 \text { yrs, } \\
\text { ISS } 26, \text { APACHE II } \\
\text { score } 14 \text {, best GCS } \\
\text { score } 9 . \\
\text { Sample size } \\
\text { calculations } \\
\text { conducted by the } \\
\text { authors and were: } 82 \\
\text { age were similar } \\
\text { between groups but } \\
\text { the intervention } \\
\text { group had a higher } \\
\text { GCS score and lower } \\
\text { APACHE II scores, } \\
\text { higher ISS score and } \\
\text { age, and more } \\
\text { patients with one } \\
\text { fixed pupil at } 24 \text { hrs. } \\
\end{array}$ & & \\
\hline
\end{tabular}




\begin{tabular}{|l|l|l|l|}
\hline $\begin{array}{l}\text { Study \& } \\
\text { Method }\end{array}$ & Participants & \multicolumn{2}{|c|}{ Intervention } \\
\hline & $\begin{array}{l}\text { Outcome } \\
\text { measures }\end{array}$ \\
\hline & $\begin{array}{l}\text { 80\% power and 5\% } \\
\text { significance. }\end{array}$ & \\
\hline
\end{tabular}




\section{Appendix 8. Risk of bias analysis for randomised controlled trials*}

\begin{tabular}{|c|c|c|c|c|}
\hline \multirow[b]{2}{*}{ Possible bias } & \multicolumn{2}{|c|}{ (Pinilla et al., 2001) } & \multicolumn{2}{|c|}{ (McClave et al., 2005) } \\
\hline & Judgement & Description & Judgement & Description \\
\hline $\begin{array}{l}\text { Adequate } \\
\text { sequence } \\
\text { generation? }\end{array}$ & Yes & $\begin{array}{l}\text { Computer- } \\
\text { generated table } \\
\text { of random } \\
\text { numbers was } \\
\text { used with results } \\
\text { provided in } \\
\text { sealed } \\
\text { envelopes. }\end{array}$ & Unclear & $\begin{array}{l}\text { Authors state the } \\
\text { "patients were } \\
\text { randomized to } \\
\text { one of two } \\
\text { groups", however } \\
\text { this process is not } \\
\text { described. }\end{array}$ \\
\hline $\begin{array}{l}\text { Allocation } \\
\text { concealment? }\end{array}$ & Yes & $\begin{array}{l}\text { Computer- } \\
\text { generated table } \\
\text { of random } \\
\text { numbers was } \\
\text { used with results } \\
\text { provided in } \\
\text { sealed } \\
\text { envelopes. }\end{array}$ & Unclear & $\begin{array}{l}\text { Authors state the } \\
\text { "patients were } \\
\text { randomized to } \\
\text { one of two } \\
\text { groups", however } \\
\text { this process is not } \\
\text { described. }\end{array}$ \\
\hline $\begin{array}{l}\text { Blinding? (of } \\
\text { intervention } \\
\text { vs control } \\
\text { group) }\end{array}$ & No & $\begin{array}{l}\text { Not done, may } \\
\text { have been } \\
\text { difficult with } \\
\text { clinicians } \\
\text { managing the } \\
\text { GRVs. }\end{array}$ & No & $\begin{array}{l}\text { Not done, may } \\
\text { have been } \\
\text { difficult with } \\
\text { clinicians } \\
\text { managing the } \\
\text { GRVs. }\end{array}$ \\
\hline $\begin{array}{l}\text { Incomplete } \\
\text { outcome data } \\
\text { addressed? }\end{array}$ & Yes & Data complete. & Yes & Data complete. \\
\hline $\begin{array}{l}\text { Free of } \\
\text { selective } \\
\text { reporting? }\end{array}$ & Yes & $\begin{array}{l}\text { All outcome } \\
\text { measures were } \\
\text { addressed in } \\
\text { reporting. }\end{array}$ & Yes & $\begin{array}{l}\text { All outcome } \\
\text { measures were } \\
\text { addressed in } \\
\text { reporting. }\end{array}$ \\
\hline $\begin{array}{l}\text { Free of other } \\
\text { bias? }\end{array}$ & Yes & & Yes & \\
\hline $\begin{array}{l}\text { GRADE } \\
\text { (Level of } \\
\text { quality) }\end{array}$ & Moderate & & Moderate & \\
\hline
\end{tabular}

*Adapted from Higgins, J., \& Altman, D. (2008). Assessing risk of bias in included studies. In J. Higgins \& S. Green (Eds.), Cochrane Handbook for Systematic Reviews of Interventions Version 5.0.1 (updated September 2008): The Cochrane Collaboration. 


\section{Appendix 9. Risk of bias analysis for descriptive observational study*}

\begin{tabular}{|c|c|c|}
\hline (Metheny et al., 2008) & Evidence & ?criteria met \\
\hline Title and abstract & $\begin{array}{l}\text { Study design and informative } \\
\text { balanced summary provided. }\end{array}$ & Met \\
\hline \multicolumn{3}{|l|}{ Introduction } \\
\hline Background/ rationale & Clear background and rationale. & Met \\
\hline Objectives & Study objectives described. & Met \\
\hline \multicolumn{3}{|l|}{ Methods } \\
\hline Study design & Clearly outlined. & Met \\
\hline Setting & Clearly described. & Met \\
\hline Participants & Inclusion demographics provided. & Met \\
\hline Variables & $\begin{array}{l}\text { Percentage of aspiration } \\
\text { according to changes in GRVs } \\
\text { was described. }\end{array}$ & Met \\
\hline $\begin{array}{l}\text { Data } \\
\text { sources/measurement }\end{array}$ & Measurements were described. & Met \\
\hline Bias & $\begin{array}{l}\text { There was no comment identified } \\
\text { in the methods related to potential } \\
\text { bias. }\end{array}$ & Not met \\
\hline Study size & $\begin{array}{l}\text { There was no discussion of } \\
\text { calculations regarding sample } \\
\text { size. }\end{array}$ & Not met \\
\hline Quantitative variables & $\begin{array}{l}\text { Groupings and analyses of the } \\
\text { variables were described. }\end{array}$ & Met \\
\hline Statistical methods & $\begin{array}{l}\text { Statistical methods and subgroup } \\
\text { analysis was described. }\end{array}$ & Met \\
\hline \multicolumn{3}{|l|}{ Results } \\
\hline Participants & $\begin{array}{l}\text { Numbers of participants, tracheal } \\
\text { secretion assays, and GRVs were } \\
\text { provided. }\end{array}$ & Met \\
\hline Descriptive data & $\begin{array}{l}\text { Characteristics of study } \\
\text { participants were provided. }\end{array}$ & Met \\
\hline Outcome data & $\begin{array}{l}\text { Numbers of outcome events were } \\
\text { provided. }\end{array}$ & Met \\
\hline Main results & $\begin{array}{l}\text { Main results were provided with } \\
\text { category boundaries for } \\
\text { continuous variables. }\end{array}$ & Met \\
\hline Other analyses & $\begin{array}{l}\text { Analysis of subgroups and } \\
\text { sensitivity analyses were } \\
\text { conducted. }\end{array}$ & Met \\
\hline \multicolumn{3}{|l|}{ Discussion } \\
\hline Key results & Key findings were discussed. & Met \\
\hline Limitations & $\begin{array}{l}\text { Identified study limitations were } \\
\text { discussed. }\end{array}$ & Met \\
\hline Interpretation & $\begin{array}{l}\text { The overall interpretation of the } \\
\text { study results in the light of other } \\
\text { research was discussed. }\end{array}$ & Met \\
\hline
\end{tabular}




\begin{tabular}{|l|l|l|}
\hline (Metheny et al., 2008) & Evidence & ?criteria met \\
\hline Generalisability & $\begin{array}{l}\text { There was no discussion of the } \\
\text { generalisability of the study } \\
\text { results. }\end{array}$ & met \\
\hline Other information & Financial disclosures were \\
\hline Funding & Mrovided. & Met \\
\hline $\begin{array}{l}\text { GRADE (Level of } \\
\text { quality)? }\end{array}$ & Low & \\
\hline
\end{tabular}

*Adapted from von Elm, E., Altman, D., Egger, M., Pocock, S., Gotzsche, P., \& Vandenbroucke, J. (2007). The strengthening the reporting of observational studies in epidemiology (STROBE) statement: Guidelines for reporting observational studies. Lancet, 370, 1453-1457. 